\title{
Accelerating the Understanding and Development of Hydrogen Storage Materials: A Review of the Five-Year Efforts of the Three DOE Hydrogen Storage Materials Centers of Excellence
}

\author{
LEONARD E. KLEBANOFF, KEVIN C. OTT, LIN J. SIMPSON, KATHLEEN O'MALLEY, \\ and NED T. STETSON
}

\begin{abstract}
A technical review of the progress achieved in hydrogen storage materials development through the U.S. Department of Energy's (DOE) Fuel Cell Technologies Office and the three Hydrogen Storage Materials Centers of Excellence (CoEs), which ran from 2005 to 2010 is presented. The three CoEs were created to develop reversible metal hydrides, chemical hydrogen storage materials, and high-specific-surface-area (SSA) hydrogen sorbents. For each CoE, the approach taken is specified, key outcomes and accomplishments identified, and recommendations for future work are suggested. The Metal Hydride Center of Excellence addresses work on destabilized hydrides, including the $\mathrm{LiBH} / \mathrm{Mg}_{2} \mathrm{NiH}_{4}$ system, borohydrides, amides, and alanes; and compares the best materials to DOE targets. The Chemical Hydrogen Storage Center of Excellence discusses the classes of materials studied for chemical hydrogen storage, focusing on ammonia borane and examines the progress in developing efficient regeneration schemes. The Hydrogen Sorption Center of Excellence describes the progress in developing high-SSA sorbents and pathways for developing improved materials capable of achieving DOE targets. The phenomenon of spillover is also observed and its importance to ensuring improved measurements is discussed. Through the five-year effort of the Hydrogen Storage Materials Centers of Excellence, significant progress was achieved in developing and understanding hydrogen storage materials.
\end{abstract}

DOI: $10.1007 / \mathrm{s} 40553-014-0011-\mathrm{z}$

(c) The Minerals, Metals \& Materials Society and ASM International 2014

\section{INTRODUCTION}

THE use of hydrogen and fuel cells to power lightduty vehicles offers an effective pathway to reduce greenhouse gas emissions and petroleum usage. ${ }^{[1]}$ In addition to the challenges associated with improving the power density and durability of polymer electrolyte membrane (PEM) fuel cells while reducing their costs, there are difficulties in developing hydrogen storage technologies that offer high specific energy and energy density at low costs for use in onboard vehicles. ${ }^{[2]}$ Working with the U.S. automotive manufacturers through the FreedomCAR and Fuel Partnership (now U.S. DRIVE), the U.S. Department of Energy (DOE) produced in 2003 a comprehensive set of performance metrics for onboard hydrogen storage systems. The metrics included 2015 targets for specific energy and

LEONARD E. KLEBANOFF, Principal Member of the Technical Staff, is with the Hydrogen and Combustion Technology Department, Sandia National Laboratories, Livermore, CA 94551. KEVIN C. OTT, formerly Director of Applied Energy Programs with the Los Alamos National Laboratory, Los Alamos, NM 87545, is now Self-employed Consultant. LIN J. SIMPSON, Senior Scientist, is with the National Renewable Energy Laboratory, Golden, CO 80401. KATHLEEN O'MALLEY, Energy Engineer, is with the SRA International, Inc., Fairfax, VA 22033. NED T. STETSON, Hydrogen Storage Program Manager, is with the Fuel Cell Technologies Office, US Department of Energy, 1000 Independence Avenue SW, Washington, DC 20585.

Contact e-mail: ned.stetson@ee.doe.gov

Manuscript submitted April 26, 2012.

Article published online April 22, 2014 energy density of $3.0 \mathrm{kWh} / \mathrm{kg}(9 \mathrm{wt}$ pct) and $2.7 \mathrm{kWh} / \mathrm{L}$ $\left(81 \mathrm{~g} \mathrm{H}_{2} / \mathrm{L}\right)$, respectively. ${ }^{[3]}$ In 2009 , after re-evaluating the performance metrics with comparisons to available vehicle performance data, the DOE issued a revised set of performance targets that included "Ultimate Full Fleet" targets for specific energy and energy density of $2.5 \mathrm{kWh} / \mathrm{kg}$ (7.5 wt pct) and $2.3 \mathrm{kWh} / \mathrm{L}\left(70 \mathrm{~g} \mathrm{H}_{2} / \mathrm{L}\right)$, respectively. ${ }^{[3]}$ Just considering the energy density target as an example, compressed hydrogen at ambient temperatures has a density of about $40 \mathrm{~g} \mathrm{H}_{2} / \mathrm{L}$; liquid hydrogen at its normal boiling point of $20 \mathrm{~K}\left(-253^{\circ} \mathrm{C}\right)$ has a density of $71 \mathrm{~g} \mathrm{H}_{2} / \mathrm{L}$. Since the energy density targets are for the complete system, neither normal compressed hydrogen nor liquid hydrogen is theoretically able to meet all of the targets. Therefore, it was recognized that advanced hydrogen storage technologies would need to be developed if all the performance metrics were to be achieved.

When hydrogen interacts with other materials or elements, either as the dihydrogen molecule or as monoatomic hydrogen, hydrogen densities greater than that of compressed hydrogen gas or liquid hydrogen can be obtained. For instance, dihydrogen can be adsorbed onto high surface area, porous materials, where even at low pressures of a few bars the hydrogen density of the adsorbed layer can approach the density of liquid hydrogen. When atomic hydrogen bonds to other elements, either through metallic-type bonding as in interstitial metal hydrides, covalent bonding as in complex hydrides and compounds such as ammonia 
borane and water, or ionic bonding as in binary alkali metal hydrides such as sodium hydride, hydrogen densities double that of liquid hydrogen can be obtained. ${ }^{[4]}$ Therefore, materials might provide a pathway to high energy density storage of hydrogen with the potential to meet the DOE performance targets. The materials-based storage technologies can be roughly categorized into three groups: sorbents, reversible metal hydrides, and offboard regenerable chemical hydrogen storage. Prior to the 2003 timeframe, most materialsbased hydrogen storage technology development had focused on reversible interstitial metal hydrides, hydrolysis of chemical hydrogen storage materials, specifically sodium borohydride $\left(\mathrm{NaBH}_{4}\right)$, and investigation of activated carbon, carbon nanotubes, and nanofibers as hydrogen adsorbents. ${ }^{[5]}$

In 2004, in an effort to accelerate the development of materials-based hydrogen storage technologies, the DOE, through the Hydrogen, Fuel Cells and Infrastructure Technologies Program (now the Fuel Cell Technologies Office) of the Office of Energy Efficiency and Renewable Energy, announced the formation of three "Hydrogen Storage Materials Centers of Excellence" to develop reversible metal hydrides, chemical hydrogen storage materials, and high-surface-area hydrogen sorbents. ${ }^{[6]}$ Each of the three centers consisted of a team of individual partner institutions which worked in a concerted, synergistic way to carry out hydrogen storage materials discovery and characterization in one of each of the three categories. Each center included computational analysis, materials preparation, and materials characterization capabilities. The centers continued their efforts for approximately 5 years and were concluded in 2010. Over the 5-year period of operation, the three centers dramatically increased the knowledge base on performance of materials with potential for hydrogen storage. As can be seen in Figure 1(a), prior to 2005, while a large number of intermetallic alloys had been well characterized for hydrogen storage, especially the $\mathrm{AB}-, \mathrm{AB}_{2-}$, and $\mathrm{AB}_{5}$-type alloys which form interstitial hydrides, relatively few other materials had been thoroughly investigated for hydrogen storage applications. Through the efforts of the three Centers of Excellence many more materials have been prepared and characterized as potential hydrogen storage materials, as shown in Figure 1(b). This progress was accomplished through the synergistic and collaborative nature of the Centers of Excellence where theoretical activities were closely coupled with a variety of synthesis and characterization capabilities. While the focus was to develop materials for hydrogen storage in light-duty vehicles, some of the materials developed may be applicable to other transportation, and portable or stationary power applications as well. Furthermore, many may be useful in today's major high technology applications including carbon capture $/ \mathrm{CO}_{2}$ sequestration, energy storage, batteries, semiconductor electronics, composites, drilling fluids, inks, drug delivery, transparent conductors, photovoltaics, purification, biomass catalysts, fuel cell catalysts, and energy generation. The following three sections of this review provide a summary of the work performed through each center and their recommendations for continued work in their specific materials category.

\section{HYDROGEN STORAGE RESEARCH IN THE DOE METAL HYDRIDE CENTER OF EXCELLENCE (MHCoE)}

Prior to the establishment of the MHCoE, there had been already a great deal of research directed toward metal hydrides, both interstitial and complex anionic materials. The interstitial metal hydrides had already received extensive research. ${ }^{[-9]}$ These interstitial materials satisfied virtually all of the requirements for automotive use (e.g., volumetric density, kinetic performance, and purity of hydrogen released among others). However, their gravimetric hydrogen capacity is typically 1 to 3 pct, which was viewed as too low by the DOE for fuel cell automotive applications with a range of at least 300 miles. Less extensively examined were the complex anionic materials, although the existing studies pointed to the potential of these materials. The catalytic promotion of reversibility had been demonstrated in $\mathrm{NaAlH}_{4} \cdot{ }^{[10]}$ Nitrogen-based materials were found that could reversibly bind hydrogen with improved capacity $^{[11]}$ and it had been shown that the thermodynamic properties of complex anionic materials could be modified through additives. ${ }^{[12,13]}$ Furthermore, it was known that $\mathrm{AlH}_{3}$ had excellent hydrogen storage and release properties, ${ }^{[14]}$ but it was not possible to recharge the spent material (i.e., hydrogenate $\mathrm{Al}$ ) at reasonable conditions. Interest had been steadily moving toward higher gravimetric capacity materials, in anticipation of automotive and other mobile applications. ${ }^{[15]}$ However, in many cases there were only a handful of examples for each material class, and the ability to theoretically account for the hydrogen desorption/absorption in these materials was limited. Thus, the purpose of the $\mathrm{MHCoE}$ was to perform exhaustive applied R\&D in these and other topical areas of complex metal hydrides, working toward a material that could satisfy all of the DOE hydrogen storage targets for light-duty vehicles.

The $\mathrm{MHCoE}$ brought together 21 partners from industry, academia, and the national laboratories to collaborate, provide technical leadership, and contribute to the MHCoE R\&D program. Sandia National Laboratories served as the "lead partner" for the MHCoE. The MHCoE enjoyed significant collaborations beyond these institutional partners listed in Table I. The MHCoE engaged with 17 external partners within the US and 10 international partners via its various collaborations as well as with the Chemical Hydrogen Storage and Hydrogen Sorption Centers of Excellence.

The materials work was divided into four project areas each focused on a particular approach. Originally there was also an Engineering project area, but that was retired when the DOE established the Hydrogen Storage Engineering Center of Excellence in 2009. The purpose of the project groups was to organize the $\mathrm{MHCoE}$ technical work along appropriate and flexible technical lines and to foster collaboration. These projects included the following: 


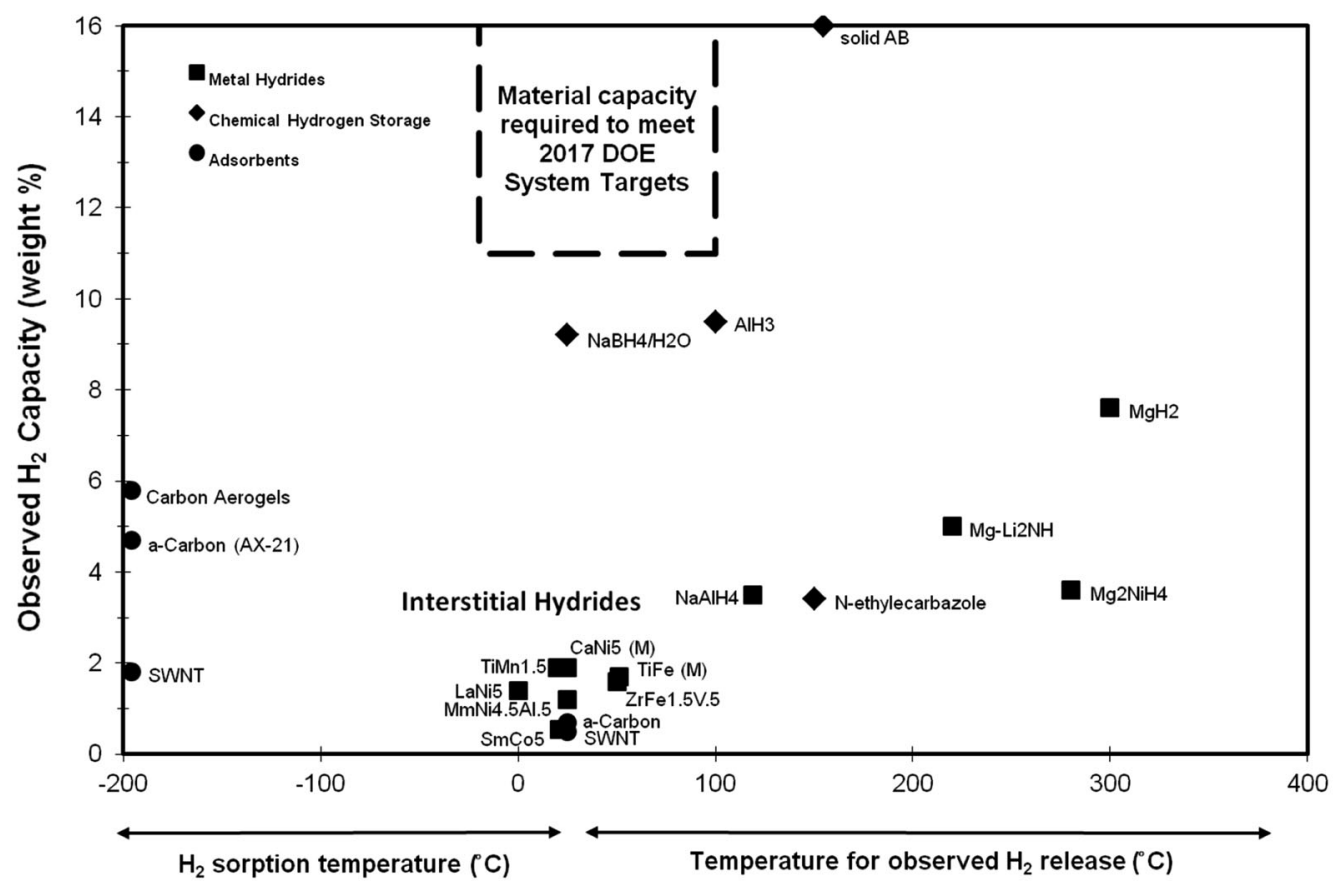

(a)

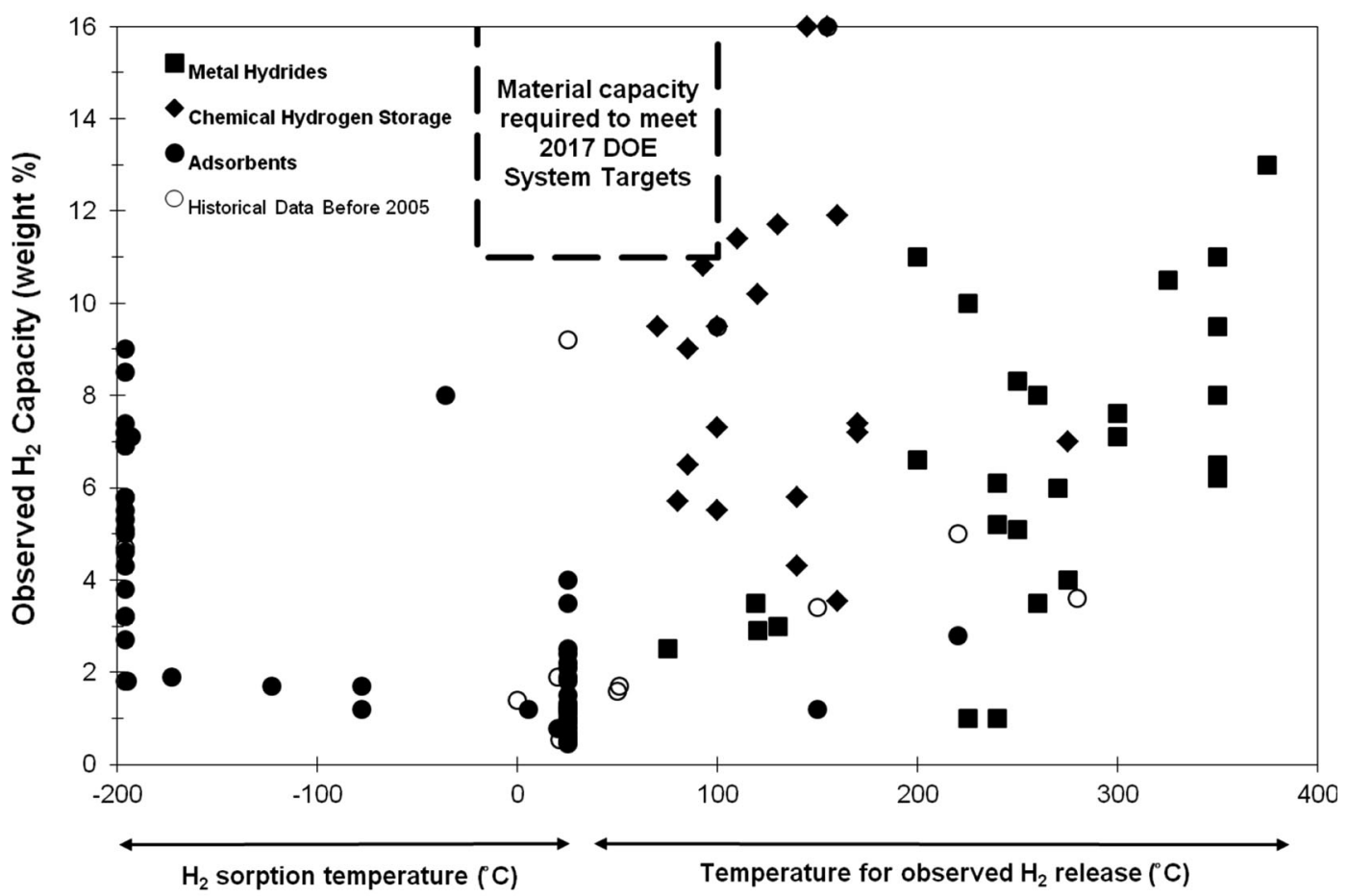

(b)

Fig. 1-(a) State of hydrogen storage materials characterization prior to 2005. (b) State of hydrogen storage materials characterization at the conclusion of the three Centers of Excellence.

(1) Destabilized hydrides, where the objective was to develop strategies for reducing hydrogen storage thermal requirements and improve kinetics by destabilizing metal hydride systems. This project also aimed to enhance kinetics by evaluating nanoengineering.
(2) Complex anionic materials, where the objective was to predict and synthesize highly promising new anionic hydride materials, with a particular focus on borohydride materials.

(3) Amide/imide storage materials, where the objective was to assess the viability of amides and imides 
Table I. Metal Hydride Center of Excellence List of Partners

\begin{tabular}{lll}
\hline Industrial Partners & \multicolumn{1}{c}{ Academic Partners } & \multicolumn{1}{c}{ National Laboratories } \\
\hline General Electric & California Institute of Technology & Brookhaven National Laboratory \\
HRL Laboratories, LLC & Carnegie Mellon University & Jet Propulsion Laboratory \\
Intematix & Georgia Institute of Technology & National Institute of Standards \& Technology \\
United Technologies Research Center & Ohio State University & Oak Ridge National Laboratory \\
& Stanford University & Sandia National Laboratories \\
& University of Hawaii at Manoa & Savannah River National Laboratory \\
& University of Illinois Urbana-Champaign & \\
& University of Nevada, Reno & \\
& University of New Brunswick & \\
& University of Pittsburgh & \\
& University of Utah & \\
\hline
\end{tabular}

(materials containing $-\mathrm{NH}_{2}$ and $-\mathrm{NH}$ moieties, respectively) for onboard hydrogen storage.

(4) Alane, $\mathrm{AlH}_{3}$, where the objective was to understand the sorption and regeneration properties of alane $\left(\mathrm{AlH}_{3}\right)$ for hydrogen storage. $\mathrm{AlH}_{3}$ is a nearly ideal hydrogen releasing material, but to regenerate $\mathrm{AlH}_{3}$ directly from the end product $\mathrm{Al}$ with gaseous $\mathrm{H}_{2}$ requires impractical high pressures.

In addition to these formal projects, the $\mathrm{MHCoE}$ established a Theory Group. The MHCoE Theory Group made use of first-principles methods to predict new materials and their thermodynamic properties, provide new directions for experimentalists, and assist in the interpretation of experimental results. In many ways, the MHCoE Theory Group set a new standard for how collaboration among theorists can be achieved, and how that theoretical activity can guide experimental work.

A full account of the MHCoE work can be found in the Final Report for the MHCoE. ${ }^{[16,17]}$ The following are selected highlights from the $\mathrm{MHCoE}$ program, with an emphasis on the most promising materials that came out of the MHCoE.

\section{OUTCOMES AND ACCOMPLISHMENTS}

Significant progress was made in the MHCoE over its 5-year duration. Major accomplishments in the four different project areas are described below. The MHCoE R\&D effort can be numerically summarized as follows. Ninety-four new material systems were explored, leading to 221 publications describing the MHCoE R\&D activity. Approximately one-third of the publications were collaborative in nature, involving at least two different institutional partners in the MHCoE. Nine patents were submitted in the course of the $\mathrm{MHCoE}$ work. More details are now given for a selected number of these new results.

\section{A. Destabilization}

Many light element compounds are known that have high hydrogen capacities, as reviewed by Orimo and colleagues. ${ }^{[18]}$ However, most of these materials are thermodynamically too stable, and they release and store hydrogen much too slowly for practical use.

One of the approaches to improving the thermodynamic properties of metal hydride materials is called "destabilization.",[13,19-21] In destabilization, another material is added that modifies the final chemical state upon hydrogen release. The concept is that by varying the final state there is a potential to tune the reaction thermodynamics and, therefore, reduce the enthalpic barrier to hydrogen release. During the 5-year tenure of the MHCoE, approximately 20 new "destabilized" hydrogen storage systems were experimentally developed and tested including $\mathrm{LiBH}_{4} / \mathrm{MgF}_{2}, \quad \mathrm{LiBH}_{4} / \mathrm{MgCl}_{2}$, $\mathrm{LiBH}_{4} / \mathrm{MgI}_{2}, \mathrm{LiBH}_{4} / \mathrm{MgS}, \mathrm{LiBH}_{4} / \mathrm{MgSe}, \mathrm{LiBH}_{4} / \mathrm{Mg}_{2} \mathrm{Si}$, $\mathrm{LiBH}_{4} / \mathrm{Mg}_{2} \mathrm{Cu}, \mathrm{LiBH}_{4} / \mathrm{Mg}_{2} \mathrm{NiH}_{4}, \mathrm{LiH} / \mathrm{B}_{4} \mathrm{C}, \mathrm{LiBH}_{4} / \mathrm{Si}$, $\mathrm{CaSiN}_{2}, \mathrm{MgSiN}_{2}, \mathrm{LiBC}, \mathrm{Mg}(\mathrm{BC})_{2}, \mathrm{LiH} / \mathrm{TiO}_{2}, \mathrm{LiH} / \mathrm{SiO}_{2}$, and $\mathrm{LiBH}_{4} / \mathrm{SiO}_{2}{ }^{[14]}$ Although light element hydrides have high hydrogen contents, thus far no single compound has been identified that has the thermodynamic properties required to meet all of the DOE targets.

The initial destabilized systems investigated by Vajo et al. ${ }^{[19]}$ were $\mathrm{LiH} / \mathrm{Si}$ and $\mathrm{MgH}_{2} / \mathrm{Si}$. Both systems have 5 wt pct hydrogen capacity. While the release temperature for $\mathrm{LiH} / \mathrm{Si}$ was too high for practical applications, thermodynamic modeling (CALPHAD) indicated that the decomposition of $\mathrm{MgH}_{2}$ in the presence of Si to form $\mathrm{Mg}_{2} \mathrm{Si}$ would reduce the reaction enthalpy from $-75.3 \mathrm{~kJ} / \mathrm{mol} \mathrm{H}_{2}$ to only $-36.4 \mathrm{~kJ} / \mathrm{mol}$ and, therefore, might be of interest. However, in practice the system was found to have very slow kinetics and to be challenging to reverse the reaction and rehydrogenate $\mathrm{Mg}_{2} \mathrm{Si}$. Efforts were, therefore, turned to destabilized systems with higher potential capacities and more promise to meet the challenging storage performance targets.

The $\mathrm{LiBH}_{4} / \mathrm{Mg}_{2} \mathrm{NiH}_{4}$ system was studied by Vajo et al. ${ }^{[22]}$ at HRL because of its remarkable features including: high capacity, reversibility, reaction through a direct low-temperature kinetic pathway, formation of a unique ternary boride phase, and low reaction enthalpy coupled with low entropy. This interesting system reveals in many ways the full power of the destabilization approach, and points the way to possible future courses of study.

Dehydrogenation of a mixture of $4 \mathrm{LiBH}_{4}+5$ $\mathrm{Mg}_{2} \mathrm{NiH}_{4}$ is shown in Figure 2. 


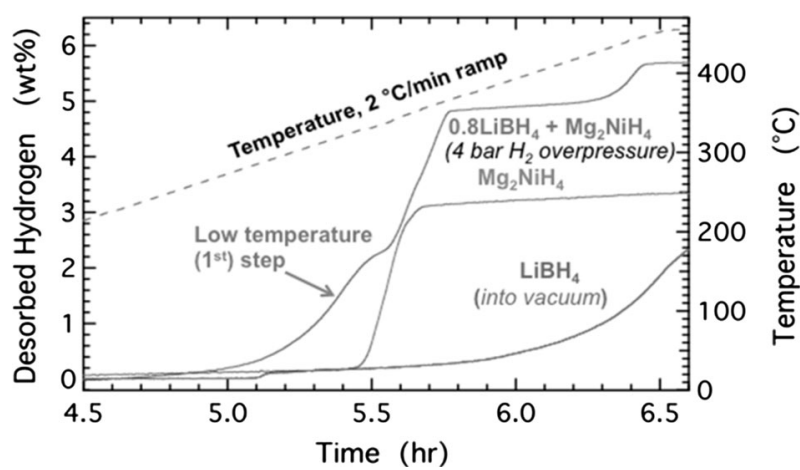

Fig. 2-Dehydrogenation of $4 \mathrm{LiBH}_{4}+5 \mathrm{Mg}_{2} \mathrm{NiH}_{4}, \mathrm{Mg}_{2} \mathrm{NiH}_{4}$, and $\mathrm{LiBH}_{4}$. Dehydrogenation was conducted using a $2 \mathrm{~K} / \mathrm{min}$ temperature ramp in 4 bar of $\mathrm{H}_{2}$ for $4 \mathrm{LiBH}_{4}+5 \mathrm{Mg}_{2} \mathrm{NiH}_{4}$ and $\mathrm{Mg}_{2} \mathrm{NiH}_{4}$, and (initial) vacuum for $\mathrm{LiBH}_{4}$. The small desorption step for $\mathrm{LiBH}_{4}$ (at $5.1 \mathrm{~h})$ occurs at the melting point, $\sim 558 \mathrm{~K}\left(\sim 285^{\circ} \mathrm{C}\right)$. Thus, the $1^{\text {st }}$ step for the $4 \mathrm{LiBH}_{4}+5 \mathrm{Mg}_{2} \mathrm{NiH}_{4}$ mixture begins below the melting point for $\mathrm{LiBH}_{4} \cdot{ }^{[20]}$

The reaction occurs in 3 steps. The first step is consistent with the reaction given by

$$
\begin{aligned}
4 \mathrm{LiBH}_{4}+5 \mathrm{Mg}_{2} \mathrm{NiH}_{4} \leftrightarrow & 2 \mathrm{MgNi}_{2.5} \mathrm{~B}_{2}+4 \mathrm{LiH} \\
& +8 \mathrm{MgH}_{2}+8 \mathrm{H}_{2}
\end{aligned}
$$

This reaction step releases $2.6 \mathrm{wt}$ pct hydrogen. As shown in Figure 2, dehydrogenation occurs at temperatures lower than the dehydrogenation temperature for either pure $\mathrm{LiBH}_{4}$ or pure $\mathrm{Mg}_{2} \mathrm{NiH}_{4}$. This is an important feature, as it indicates that a new hydrogen release pathway has been opened up by mixing the $\mathrm{LiBH}_{4}$ and $\mathrm{Mg}_{2} \mathrm{NiH}_{4}$ materials. This pathway likely involves direct reaction between $\mathrm{LiBH}_{4}$ and $\mathrm{Mg}_{2} \mathrm{NiH}_{4}$, rather than $\mathrm{H}_{2}$ release from either of the individual components. The reaction begins at temperatures as low as $523 \mathrm{~K}\left(250^{\circ} \mathrm{C}\right)$, which is low for borohydride-based systems. The low reaction temperature may be due to the catalytic nature of $\mathrm{Ni}$ in the $\left[\mathrm{NiH}_{4}\right]^{2-}$ anion. Thus far, this system appears to be the only reversible destabilized system that reacts through a (new) direct reaction pathway. In contrast, the well-studied $\mathrm{LiBH}_{4}$ $\mathrm{MgH}_{2}$ system ${ }^{[13,21]}$ reacts sequentially with initial dehydrogenation of $\mathrm{MgH}_{2}$ followed by reaction of $\mathrm{Mg}$ with $\mathrm{LiBH}_{4}$. It seems likely that to achieve the full benefit of the mixed hydride system destabilization strategy, reaction through new pathways is necessary, making this system an important demonstration that such methods are possible.

The good kinetics of the $\mathrm{LiBH}_{4} / \mathrm{Mg}_{2} \mathrm{NiH}_{4}$ reaction allows its equilibrium to be characterized over the temperature range $543 \mathrm{~K}$ to $633 \mathrm{~K}\left(270{ }^{\circ} \mathrm{C}\right.$ to $\left.360{ }^{\circ} \mathrm{C}\right)$. The pressure varies logarithmically with the inverse temperature characterized by a change in enthalpy $(\Delta \mathrm{H})$ of $15 \mathrm{~kJ} / \mathrm{mol}^{-\mathrm{H}_{2}}$ and a change in entropy $(\Delta S)$ of $62 \mathrm{~J} / \mathrm{K}$ mol- $\mathrm{H}_{2} \cdot{ }^{[22]}$ This change in enthalpy is very low for a reversible system. A low enthalpy is advantageous for practical systems in which heat must be supplied to release hydrogen and dissipated during rehydrogenation. However, systems with low enthalpies $(<-20 \mathrm{~kJ} /$ mol- $\mathrm{H}_{2}$ ) typically cannot be rehydrogenated at practical pressures because the equilibrium temperatures, given by $T_{\text {eq }}=\Delta H / \Delta S$, are too low. Remarkably, for this system $\Delta S$ is also very low, which raises the equilibrium temperature and enables reversibility. Vajo et al. ${ }^{[22]}$ speculated that the low $\Delta S$ originates from the relatively high entropy of two complex hydride anion species, $\left[\mathrm{BH}_{4}\right]^{-}$and $\left[\mathrm{NiH}_{4}\right]^{2-}$, in the hydrogenated phase.

Overall, the capacity for the direct low-temperature step shown above is too low for practical use for hydrogen storage onboard vehicles. However, $\mathrm{Mg}_{2} \mathrm{NiH}_{4}$ is a transition metal-based complex hydride of which there are numerous (literally hundreds of formulations) known examples. Therefore, the remarkable behavior of this system holds promise that other $\mathrm{LiBH}_{4} /$ transition metal-based complex hydride systems could be found with higher hydrogen capacities.

\section{B. Nanoconfinement}

Quite often the rates of hydrogen absorption and release from light metal hydrides are undesirably low. It may be that the slow hydrogen exchange rates can be attributed to slow rates of diffusion which, in turn, originate from the covalent and ionic bonding characteristic of light elements. Based on this hypothesis, the first project group sought to improve the hydrogen exchange rates by restricting the hydride particle size to the nanometer scale. Diffusion times vary as the square of the diffusion length; thus, decreasing particle size by a factor of 10 would decrease diffusion times by a factor of 100. Restricting the particle size of hydride materials is difficult considering that metal hydride materials often agglomerate as hydrogen is released and stored. To address this issue, a novel approach was employed where hydride materials were incorporated into the pores of nanoporous scaffolds to confine the hydride particles to nanoscale dimensions and to maintain these dimensions during cycling. The strategy is described by de Jongh and Adelhelm ${ }^{[23]}$ who has employed a similar approach.

Work by Vajo and co-workers ${ }^{[24,25]}$ in the MHCoE shows that nanoconfinement can lead to dramatic $(\sim 50 \times)$ increases in hydrogen release rates. However, a synthetic difficulty is finding a way to introduce the complex metal hydride into the nanoscaffold. A significant breakthrough ${ }^{[25]}$ in nanoconfinement came from the organometallic synthesis methods developed by Jensen and co-workers at the University of Hawaii (UH). The original syntheses ${ }^{[21]}$ of nanoconfined $\mathrm{LiBH}_{4}$ required infusing the carbon aerogel with liquid (i.e., melted) $\mathrm{LiBH}_{4}$. However, this method is not very versatile and also can damage nanoframeworks since elevated temperatures are used. The UH group developed a low-temperature homogeneous organometallic approach to incorporate $\mathrm{Mg}$ based hydrides into carbon aerogels that has resulted in high loadings without degradation of nanoporous scaffold. The strategy is shown in Figure 3. ${ }^{[20]}$

Figure 3 shows how precursor $\mathrm{MgBu}_{2}$ can be infused in the aerogel scaffold using heptane as a solvent. Then the $\mathrm{MgBu}_{2}$ can be thermally decomposed (also driving 


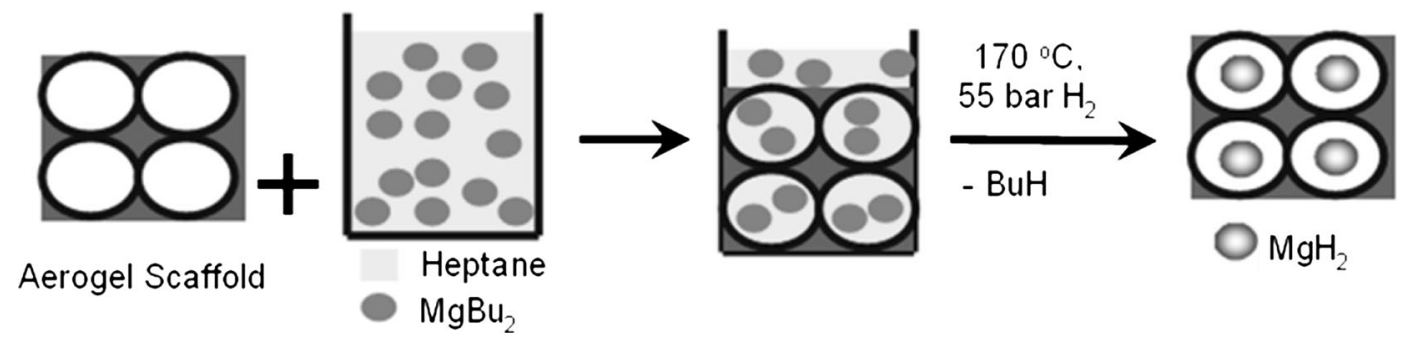

Fig. 3 - Organometallic approach to incorporation of metal hydrides into C aerogels. ${ }^{[17,22]}$

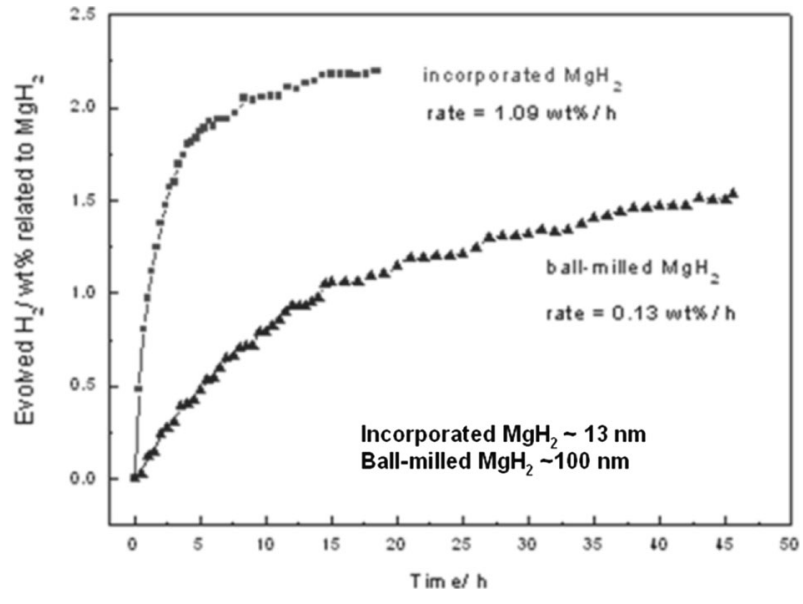

Fig. 4 - Comparison of $\mathrm{H}_{2}$ evolution from bulk-like ball-milled $\mathrm{MgH}_{2}$ with $\mathrm{MgH}_{2}$ confined in $13 \mathrm{~nm}$ pores in carbon aerogel. ${ }^{[22]}$

off heptane), yielding nanoconfined $\mathrm{Mg}$ that can then be hydrogenated to give scaffold-incorporated $\mathrm{MgH}_{2}$.

Studies of this approach ${ }^{[25]}$ have shown that high (9 to 16 wt pct) $\mathrm{MgH}_{2}$ loadings can be achieved in the carbon aerogel without host degradation. Figure 4 shows that the rate of dehydrogenation from $\mathrm{MgH}_{2}$ incorporated in $13 \mathrm{~nm}$ pores in $\mathrm{C}$-aerogel at $525 \mathrm{~K}\left(252{ }^{\circ} \mathrm{C}\right)$ is $\sim 17$ times faster than the initial rate found for bulk ball-milled $\mathrm{MgH}_{2}$. The rate remains the same over 4 cycles of dehydrogenation-rehydrogenation, indicating the $\mathrm{Mg}$ is well confined in the pores even when thermally cycled. ${ }^{[25]}$

Equilibrium studies of the plateau pressure of hydrogen at $523 \mathrm{~K}\left(250{ }^{\circ} \mathrm{C}\right)$ from $\mathrm{MgH}_{2}$ confined to $13 \mathrm{~nm}$ pores agree well with database plateau pressure for bulk $\mathrm{MgH}_{2}$ to within 10 pct accuracy. If there were a change in the thermodynamics, there would be a corresponding change in the equilibrium hydrogen pressure at a given temperature, which was not observed experimentally. Presumably if the $\mathrm{MgH}_{2}$ particles were made significantly smaller than 13-nm diameter there would be a significant change in the thermodynamics of $\mathrm{H}_{2}$ release. The effects of the nanoscaffold on the material's gravimetric and volumetric hydrogen storage density have been discussed by Vajo. ${ }^{[20,24]}$

\section{Borohydrides}

The second project group, complex anionic materials, focused on the synthesis and characterization of highweight-capacity metal hydrides that contain well-defined chemical moieties, in particular the borohydrides containing $\mathrm{BH}_{4}{ }^{-}$anions. A review of the major international effort to develop borohydride hydrogen storage materials has been published by Stavila et al., ${ }^{[20]}$ and within the $\mathrm{MHCoE}$, over 50 borohydride materials were developed and studied by many of the MHCoE PI's. A great deal of screening and characterization work was conducted at Sandia ${ }^{[26]}$ on $\mathrm{Ca}\left(\mathrm{BH}_{4}\right)_{2}$ and also $\mathrm{Mg}\left(\mathrm{BH}_{4}\right)_{2}$ by Majzoub, Rönnebro, and co-workers. ${ }^{[27]}$ The group II alkaline earth metal borohydrides were of primary interest over alkali metal borohydrides due to their high potential capacities for hydrogen storage.

Calcium borohydride has a theoretical hydrogen capacity of $11.6 \mathrm{wt}$ pct, making it of interest to potentially meet the DOE onboard storage performance targets; however, prior to the work of Rönnebro, Majzoub, and co-workers at Sandia, there was little known regarding its fundamental properties as a potential hydrogen storage material. $\mathrm{Ca}\left(\mathrm{BH}_{4}\right)_{2}-(\mathrm{THF})_{2}$ was commercially available and could be desolvated by heating under vacuum. Theoretical calculations by Majzoub indicated that $\mathrm{Ca}\left(\mathrm{BH}_{4}\right)_{2}$ could be obtained directly through a solid-state reaction of $\mathrm{CaB}_{6}$ with $\mathrm{CaH}_{2}$ under hydrogen pressure. The researchers demonstrated that a 1:2 ratio mixture of $\mathrm{CaB}_{2}$ with $\mathrm{CaH}_{2}$ reacted under 700 bar $\mathrm{H}_{2}$ at $673 \mathrm{~K}$ to $713 \mathrm{~K}\left(400{ }^{\circ} \mathrm{C}\right.$ to $440{ }^{\circ} \mathrm{C}$ ) directly produced $\mathrm{Ca}\left(\mathrm{BH}_{4}\right)_{2}$ in 60 pct yield with respect to starting materials and with $9.6 \mathrm{wt}$ pet theoretical reversible hydrogen capacity. ${ }^{[28]}$ Cycle studies showed loss of reversible capacity on subsequent cycles, with only 3.5 to $5 \mathrm{wt}$ pct reversible after several cycles, depending on conditions and additives used. ${ }^{[27]}$ Several polymorphs for $\mathrm{Ca}\left(\mathrm{BH}_{4}\right)_{2}$ with differing stability ranges were identified. Majzoub and Rönnebro ${ }^{[29]}$ used a combined method of searching the inorganic crystal structure database (ICSD) coupled with use of the prototype electrostatic ground state $(\mathrm{PEGS})^{[30]}$ method to identify potential low-energy ground-state structures. Further work to refine the structures with in situ synchrotron data in collaboration with Filinchuk et $a l .^{[31]}$ identified three polymorphs: a low-temperature $\alpha$-phase $(F 2 d d)$ that undergoes a second-order $\alpha \rightarrow \alpha^{\prime}$ $(I-42 d)$ transition upon heating to $\sim 495 \mathrm{~K}\left(222^{\circ} \mathrm{C}\right)$. The $\alpha$ - and $\alpha^{\prime}$-phases were found to transform into a denser, stable $\beta$-phase $(P-4)$. The $\beta$-phase fully decomposes between $655 \mathrm{~K}$ and $660 \mathrm{~K}\left(382{ }^{\circ} \mathrm{C}\right.$ and $\left.387^{\circ} \mathrm{C}\right)$. While work on $\mathrm{Ca}\left(\mathrm{BH}_{4}\right)_{2}$ stimulated much international interest and research, due to high desorption temperatures, poor reversibility and thermodynamics, further work on $\mathrm{Ca}\left(\mathrm{BH}_{4}\right)_{2}$ within the $\mathrm{MHCoE}$ was discontinued. 


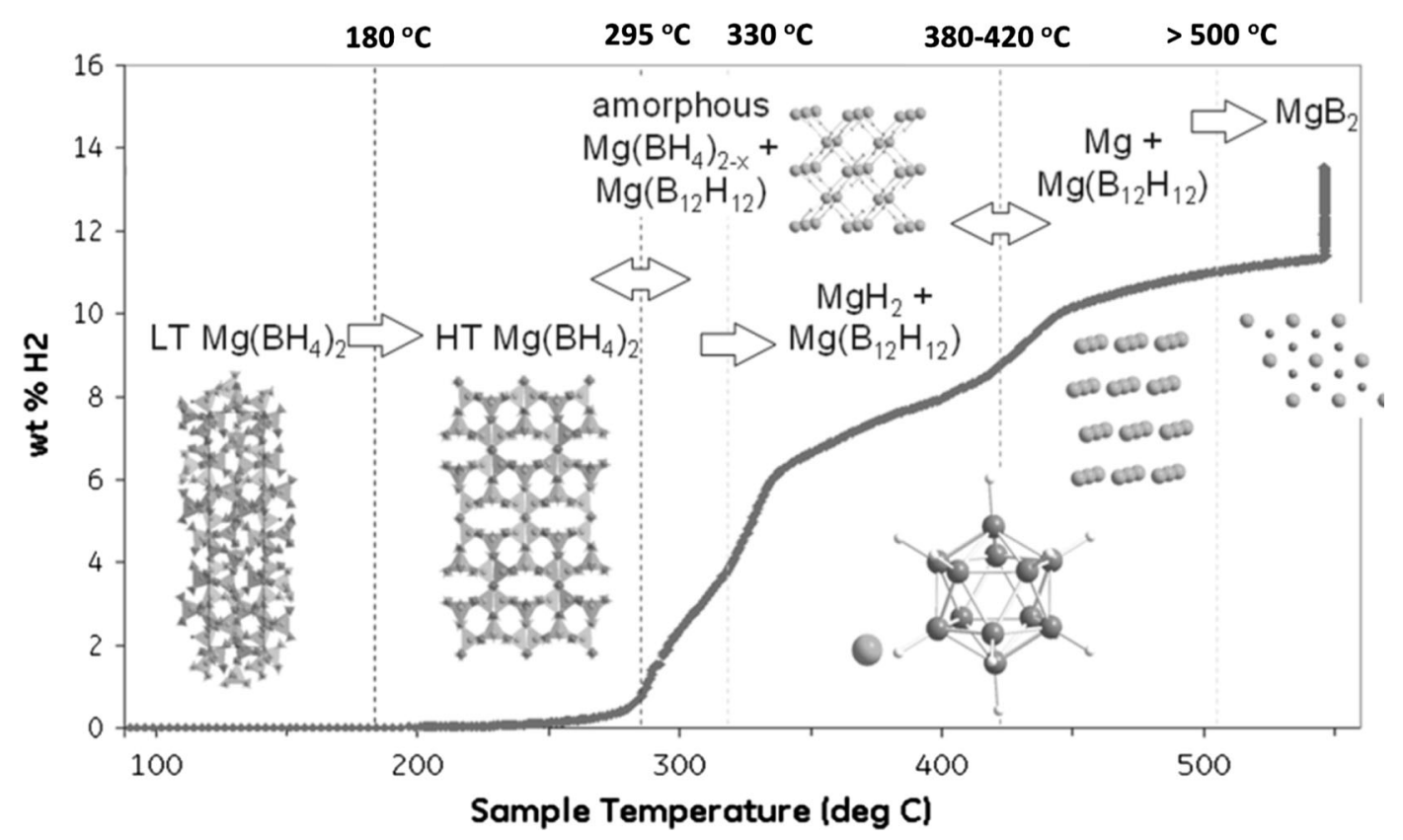

Fig. 5- Overall reaction sequence for the release of hydrogen from $\mathrm{Mg}\left(\mathrm{BH}_{4}\right)_{2} \cdot{ }^{[17,20,25]}$

As with many borohydrides, $\mathrm{Mg}\left(\mathrm{BH}_{4}\right)_{2}$ was attractive because of the exceptionally high theoretical hydrogen weight percent, 14.9 pct, for this material. $\mathrm{Mg}\left(\mathrm{BH}_{4}\right)_{2}$ was first synthesized by Konopolev, ${ }^{[32]}$ who reported on the synthetic procedures and first-order hydrogen desorption properties. Konopolev observed $\mathrm{H}_{2}$ desorption from $\mathrm{Mg}\left(\mathrm{BH}_{4}\right)_{2}$ above $593 \mathrm{~K}\left(320^{\circ} \mathrm{C}\right)$, with $\Delta H$ $\sim 53 \mathrm{~kJ} / \mathrm{mol} \mathrm{H}_{2}$ for hydrogen desorption. At that time, almost nothing was known about the reaction pathway, and nothing was known about the possible reversibility of the system.

Zhao and co-workers initiated MHCoE work on $\mathrm{Mg}\left(\mathrm{BH}_{4}\right)_{2}$. A great deal of effort was devoted to understanding the crystal structures of the material as it was heated, eventually releasing hydrogen. Using a unique in situ X-ray diffraction (XRD) method that also allowed full characterization of emitted volatiles, Soloveichik and colleagues ${ }^{[33]}$ at GE were able to directly correlate crystal structure with temperature and hydrogen release.

The overall reaction sequence for hydrogen release from $\mathrm{Mg}\left(\mathrm{BH}_{4}\right)_{2}$ is shown in Figure 5. ${ }^{\text {[20] }}$

The overall reaction sequence can be written as

$$
\begin{gathered}
6 \mathrm{Mg}\left(\mathrm{BH}_{4}\right)_{2} \rightarrow 5 \mathrm{MgH}_{2}+\mathrm{Mg}\left(\mathrm{B}_{12} \mathrm{H}_{12}\right)+13 \mathrm{H}_{2} \uparrow \\
5 \mathrm{MgH}_{2}+\mathrm{Mg}\left(\mathrm{B}_{12} \mathrm{H}_{12}\right) \rightarrow 5 \mathrm{Mg}+5 \mathrm{H}_{2} \uparrow+\mathrm{Mg}\left(\mathrm{B}_{12} \mathrm{H}_{12}\right)
\end{gathered}
$$

$$
5 \mathrm{Mg}+\mathrm{Mg}\left(\mathrm{B}_{12} \mathrm{H}_{12}\right) \rightarrow 6 \mathrm{MgB}_{2}+6 \mathrm{H}_{2} \uparrow
$$

Thus, hydrogen is first released from $\mathrm{Mg}\left(\mathrm{BH}_{4}\right)_{2}$ to form $\mathrm{MgH}_{2}$ and $\mathrm{Mg}\left(\mathrm{B}_{12} \mathrm{H}_{12}\right) . \mathrm{MgH}_{2}$ then releases $\mathrm{H}_{2}$, followed by eventual release at high temperature from the highly stable $\mathrm{MgB}_{12} \mathrm{H}_{12}$ material. A full $12 \mathrm{wt}$ pct of hydrogen is released from the material, and the low $\Delta H$ of desorption indicates that facile hydrogenation of $\mathrm{MgB}_{2}$ should be possible. Unfortunately, due to presumed kinetic limitations, the reaction was not reversible under the conditions used for these initial GE studies. However, reversibility was subsequently demonstrated at higher temperatures and pressures by Severa et al. ${ }^{[34]}$ No toxic gaseous species (such as diborane, $\mathrm{B}_{2} \mathrm{H}_{6}$ ) or other impurities were found in the desorbed gas in this study. ${ }^{[33]}$ An intermediate $\mathrm{MgB}_{12} \mathrm{H}_{12}$ was observed which turned out to have widespread implications for hydrogen storage from borohydride materials. These studies demonstrated an attractive $\Delta H$ for hydrogen desorption of $\sim 40 \mathrm{~kJ} / \mathrm{mol} \mathrm{H}_{2}$, indicating a moderate chance for reversibility under reasonable conditions if no kinetic limitations existed.

This $\sim 12 \mathrm{wt}$ pct reversibility for $\mathrm{Mg}\left(\mathrm{BH}_{4}\right)_{2}$ makes it a record-breaking material for reversible hydrogen storage. Although the process conditions of pressure and temperature for both dehydrogenation and hydrogenation are higher than desired, $\mathrm{Mg}\left(\mathrm{BH}_{4}\right)_{2}$ has the highest reversible capacity for any metal hydride material discovered thus far. If the kinetic limitations could be overcome, then the thermodynamics of the system would allow facile hydrogen release and reversibility. As a result of this promise, further investigation of $\mathrm{Mg}\left(\mathrm{BH}_{4}\right)_{2}$ was recommended since this material has high promise, but more material R\&D is still needed.

It should be noted that the appearance of these relatively unknown $\mathrm{MB}_{12} \mathrm{H}_{12}$ salts led to a great deal of MHCoE work. Stavila et al. ${ }^{[35]}$ at Sandia developed an efficient synthesis method to directly make $\mathrm{MB}_{12} \mathrm{H}_{12}$ materials in an unsolvated state, allowing the properties of pure $\mathrm{CaB}_{12} \mathrm{H}_{12}, \mathrm{Li}_{2} \mathrm{~B}_{12} \mathrm{H}_{12}$, and $\mathrm{NaB}_{12} \mathrm{H}_{12}$ to be examined for the first time. ${ }^{[35]}$ Interestingly, it proved difficult to synthesize $\mathrm{MgB}_{12} \mathrm{H}_{12}$. These $\mathrm{B}_{12} \mathrm{H}_{12}$ salts were also investigated extensively theoretically by Ozolins and co-workers. ${ }^{[36]}$ 


\section{Amides}

The third project group was inspired by the 2002 Nature article by Chen et al. ${ }^{[37]}$ and investigated nitrogen-containing materials for hydrogen storage. Chen observed that $\mathrm{LiMgN}$ took up a significant amount of hydrogen, and the resulting material (proposed to be $\mathrm{LiNH}_{2}+2 \mathrm{LiH}$ ) could also desorb $\mathrm{H}_{2}$, giving a reversible hydrogen storage system operating below $\sim 523 \mathrm{~K}\left(\sim 250^{\circ} \mathrm{C}\right)$. This report spurred a great deal of international interest in $\mathrm{N}$-based hydrogen storage materials, as reviewed recently. ${ }^{[20]}$ During the course of the MHCoE program, 15 different amiderelated systems were investigated, including mixtures of amides and borohydrides, amides and alanates, and LiMgN itself. ${ }^{[16,17]}$ Two prominent N-based systems $\left(2 \mathrm{LiNH}_{2}+\mathrm{MgH}_{2}\right)$ were explored by Luo and co-work$\operatorname{ers}^{[37,38]}$ at Sandia, and $\mathrm{LiMgN}$ investigated by Fang and co-workers at Utah. Additional information on the $\mathrm{LiMgN}$ system follows.

$\mathrm{LiMgN}$ can be formed as the product of the reaction between $\mathrm{LiNH}_{2}$ and $\mathrm{MgH}_{2}$ when the molar ratio of $\mathrm{LiNH}_{2}$ to $\mathrm{MgH}_{2}$ is $1: 1$ as shown by the following reaction:

$$
\mathrm{MgH}_{2}+\mathrm{LiNH}_{2} \rightarrow \mathrm{LiMgN}+2 \mathrm{H}_{2}
$$

This system was first investigated theoretically ${ }^{[39]}$ by the MHCoE Theory Group PIs Sholl, Johnson, and their colleagues. Theoretically, this reaction was predicted to have a very attractive hydrogen desorption enthalpy of $\Delta H=32 \mathrm{~kJ} / \mathrm{mol} \mathrm{H}_{2}$ and a hydrogen capacity of $8.2 \mathrm{wt}$ pct. The high predicted weight percent of hydrogen is due to the full dehydrogenation to $\mathrm{LiMgN}$, bypassing the undesired imide intermediate. Since Reaction 5 represents the complete dehydrogenation of the system, LiMgN would be an important candidate material for hydrogen storage if the dehydrogenation took place at low temperature and if it was reversible.

To demonstrate the feasibility of Reaction 5 experimentally, Lu et al. ${ }^{[40]}$ at University of Utah prepared a mixture of $\mathrm{MgH}_{2}$ and $\mathrm{LiNH}_{2}$ with a molar ratio of 1:1 by ball milling for 24 hours. Figure 6 shows the TGA profile of the as-milled $\mathrm{MgH}_{2} / \mathrm{LiNH}_{2}$ mixture as the sample is heated. The reaction starts at about $393 \mathrm{~K}$ $\left(120^{\circ} \mathrm{C}\right)$ and the weight loss accelerates at about $473 \mathrm{~K}$ $\left(200^{\circ} \mathrm{C}\right)$. The total weight loss was $8.1 \mathrm{wt}$ pet of the initial weight after the sample was held at $493 \mathrm{~K}$ $\left(220{ }^{\circ} \mathrm{C}\right)$ for 20 minutes. Assuming all the weight losses were due to the release of hydrogen, the dehydrogenation process can be considered complete, confirming the theoretically predicted Reaction 5. Differential thermal analyses (DTA) of the hydrogen release were carried out. The results ${ }^{[40]}$ indicated that the dehydrogenation is characterized by a $\Delta H$ of $33.5 \mathrm{~kJ} / \mathrm{mol} \mathrm{H}_{2}$, which is very close to the theoretically predicted reaction enthalpy of $32 \mathrm{~kJ} / \mathrm{mol} \mathrm{H}_{2}$ found in the MHCoE work of Alapati et $a l .{ }^{[39]} \mathrm{XRD}$ studies of the reaction showed the presence of $\mathrm{LiMgN}$ in the fully dehydrogenated state, confirming the reaction above.

Of course, the material must be reversible to be useful for automotive hydrogen storage. Further studies

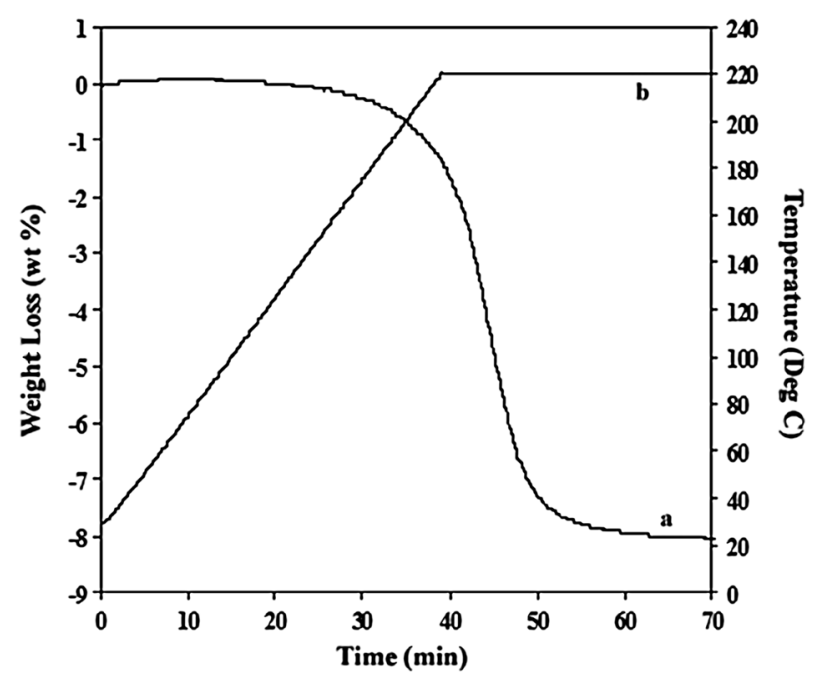

Fig. 6-Thermogravimetric analysis (TGA) data for desorption from ball-milled $\left(\mathrm{LiNH}_{2}+\mathrm{MgH}_{2}\right) \cdot{ }^{[17,40]}$

showed that $\mathrm{LiMgN}$ could be rehydrogenated at 138 bar $\mathrm{H}_{2}$ and $513 \mathrm{~K}\left(240{ }^{\circ} \mathrm{C}\right)$, and that 2 to $4 \mathrm{~mol}$ pct Ti significantly catalyzed the rehydrogenation. ${ }^{[40]}$ However, the reaction was observed to be more complex than the single-step process shown in Reaction 5 and subsequent theory by Akbarzadeh and co-workers ${ }^{[41]}$ predicted a multistep nature to the hydrogenation and dehydrogenation reactions governed by thermodynamic factors.

The following multistep reaction mechanism is put forth in Figure 7 to explain the hydrogen storage properties of $\mathrm{LiMgN}$ :

Extensive FTIR and XRD measurements support the assignment that upon hydrogenation, $\mathrm{LiMgN}$ converts to $\mathrm{LiH}+1 / 2 \mathrm{Mg}\left(\mathrm{NH}_{2}\right)_{2}+1 / 2 \mathrm{MgH}_{2}$ via the intermediate imide $\mathrm{Li}_{2} \mathrm{Mg}(\mathrm{NH})_{2}$. The assignment of the imide in this reaction as an intermediate is speculative, as its detection in the cycling has not been confirmed, although the overall data suggest a multi-step behavior as predicted by Akbarzadeh et al. ${ }^{[41]}$ The nature of the reaction pathway for the $\mathrm{LiMgN}$ system needs further investigation. Nonetheless, it is a material showing reversibility, with $\sim 8$ wt pct capacity and dehydrogenation and hydrogenation temperatures in the range $433 \mathrm{~K}$ to $493 \mathrm{~K}\left(160^{\circ} \mathrm{C}\right.$ to $\left.220^{\circ} \mathrm{C}\right)$. The long-term cycling behavior needs to be examined.

Chandra and co-workers at the University of NevadaReno investigated the long-term cycling and effects of impurities on cycling for various material systems. In the case of lithium amide/lithium hydride system $\left(\mathrm{LiNH}_{2}+\right.$ $\mathrm{LiH}$ ), Chandra et al. discovered that the hydrogen capacity losses during cycling could be mitigated through the addition of $\mathrm{N}_{2}$ to the hydrogen used to rehydrogenate the material. Nitrogen loss from the system through the formation of ammonia in the desorption products has been observed with most amide/imide systems. For the $\mathrm{LiNH}_{2}+\mathrm{LiH}$ system, it was proposed that liquid $\mathrm{Li}$ formed at low absorbed hydrogen contents with which $\mathrm{N}_{2}$ could react to form 


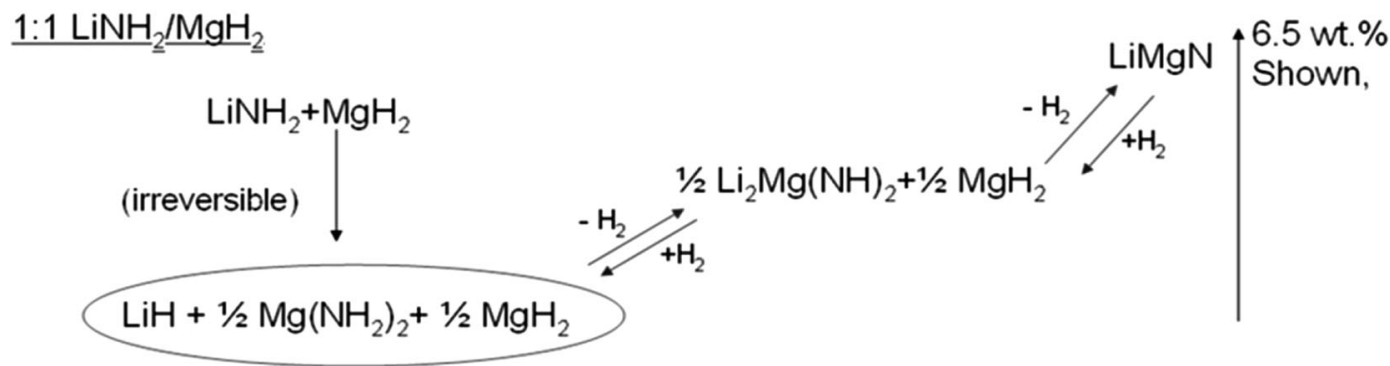

Fig. 7—Proposed mechanism for hydrogen absorption/desorption involving 1:1 $\mathrm{LiNH}_{2} / \mathrm{MgH}_{2}{ }^{[17]}$

$\mathrm{Li}_{3} \mathrm{~N}$ and prevent further formation and accumulation of $\mathrm{LiH}^{[42]}$

\section{E. Alane}

Virtually all of the materials investigated in the $\mathrm{MHCoE}$ were considered for their potential as onboard reversible materials in which the spent material can be rehydrogenated without being removed from the vehicle. However, two materials out of the 94 investigated in the MHCoE were considered for their "off-board" regeneration potential. These materials were $\mathrm{AlH}_{3}$ and $\mathrm{LiAlH}_{4}$. A comprehensive review of the history and recent progress associated with $\mathrm{AlH}_{3}$ and $\mathrm{LiAlH}_{4}$ has been written by Graetz et al. ${ }^{[43]}$

\section{1. $\mathrm{AlH}_{3}$}

In many ways, aluminum hydride $\left(\mathrm{AlH}_{3}\right)$, often referred to as "alane," represents a nearly ideal hydrogen storage material from a desorption point of view. $\mathrm{AlH}_{3}$ has a gravimetric capacity of $10 \mathrm{wt}$ pct and volumetric capacity of $149 \mathrm{~g} \mathrm{H}_{2} / \mathrm{L}$, along with a hydrogen desorption temperature of $\sim 333 \mathrm{~K}$ to $448 \mathrm{~K}$ $\left(\sim 60{ }^{\circ} \mathrm{C}\right.$ to $175^{\circ} \mathrm{C}$ ) (depending on particle size and the addition of catalysts). Due to aluminum hydride's low temperature of decomposition and its ability to store 10 pct hydrogen by weight, this material has been the subject of study for decades, as reviewed by Sandrock et $a l .{ }^{[44]}$ and more recently by Graetz et al. ${ }^{[43,45]}$ The difficulty with $\mathrm{AlH}_{3}$ lies in its regeneration from the dehydrogenated state, namely $\mathrm{Al}$ metal; the pressure to regenerate $\mathrm{AlH}_{3}$ directly from aluminum and gaseous hydrogen is simply too high to be practical on a large scale. After the initial research phase ${ }^{[43,45]}$ characterizing the structure and hydrogen release properties of $\mathrm{AlH}_{3}$, attention turned quickly to the problem of regeneration. It was already known that $\mathrm{AlH}_{3}$ could be generated by reacting $\mathrm{LiAlH}_{4}$ with $\mathrm{AlCl}_{3}$ using organic solvents. This method produces stable salt byproducts that are costly to recycle and, therefore, not useful for many applications.

In the $\mathrm{MHCoE}$, two primary methods were discovered for the offboard regeneration of $\mathrm{AlH}_{3}$ from $\mathrm{Al}$ metal. The first method is regeneration of $\mathrm{AlH}_{3}$ using a two-step organometallic process developed by Graetz and colleagues at Brookhaven National Laboratory (BNL). The second method is the regeneration of $\mathrm{AlH}_{3}$ via electrochemical means developed by Zidan and co-workers at Savannah River National Laboratory (SRNL).
In the BNL work, the general approach was to use organometallic chemistry to try to form $\mathrm{AlH}_{3}$ in the presence of a stabilizing agent. Whereas forming $\mathrm{AlH}_{3}$ directly from $\mathrm{Al}$ and $\mathrm{H}_{2}$ in the gas phase is nearly impossible due to the instability of $\mathrm{AlH}_{3}$; through adduct formation, $\mathrm{AlH}_{3}$ could be more easily formed and stabilized, with the need to subsequently remove the stabilizing agent to obtain the final material.

The results ${ }^{[43,45]}$ can be summarized in Figure 8.

As shown in Figure 8, direct formation of the stabilized $\mathrm{AlH}_{3}$ moiety has been achieved using dimethylethylamine (DMEA) and also trimethylamine (TMA) as the stabilizing agents. Both DMEA and TMA bind too strongly to $\mathrm{AlH}_{3}$ to allow facile removal of the stabilizing amine. However, both $\mathrm{TMA}-\mathrm{AlH}_{3}$ and DMEA-AlH $\mathrm{H}_{3}$ can be transaminated using triethylamine (TEA) to TEA-AlH $\mathrm{A}_{3}$, which could then be easily thermally dissociated to produce pure $\mathrm{AlH}_{3}$ without inadvertent release of $\mathrm{H}_{2}$.

A major concern with such an "off-board" regeneration method is the energy required to execute these chemical steps. In 2011, an independent analysis of an $\mathrm{AlH}_{3}$ storage system was conducted by Hua and Ahluwalia $^{[46]}$ of Argonne National Laboratory. Argonne's analysis assumed 70-wt pct aluminum hydride slurry, and used TMA as the stabilizing agent. The Argonne analysis indicated a well-to-tank (WTT) efficiency of 40 pct assuming 75 pct yields in the transamination step and $75 \mathrm{pct}$ in TEA decomposition and recovery step, along with losses in producing hydrogen (73 pct efficiency) and compressing and recycling hydrogen. This WTT value could be higher if the yields in the various synthetic steps increased, and full use was made of waste heat during the processing. The WTT DOE target is 60 pct.

Zidan and colleagues ${ }^{[47]}$ at SRNL investigated the second possibility of regenerating $\mathrm{AlH}_{3}$ electrochemically. The idea is to utilize electrolytic potential to increase hydrogen activity and, therefore, drive chemical reactions to regenerate $\mathrm{AlH}_{3}$. However, the use of electrochemistry has to take into account that $\mathrm{Al}$ and $\mathrm{AlH}_{3}$ oxidize in aqueous environments, thereby prohibiting the use of all protic solvents as electrolytes. For this reason, SRNL developed a novel route using a non-aqueous solvent system. A polar aprotic solvent such as tetrahydrofuran (THF) is used in the electrolytic cells which are operated at ambient pressure and temperature.

Details of the electrochemical regeneration route can be found in the publication by Zidan et al. ${ }^{[47]}$ However, 


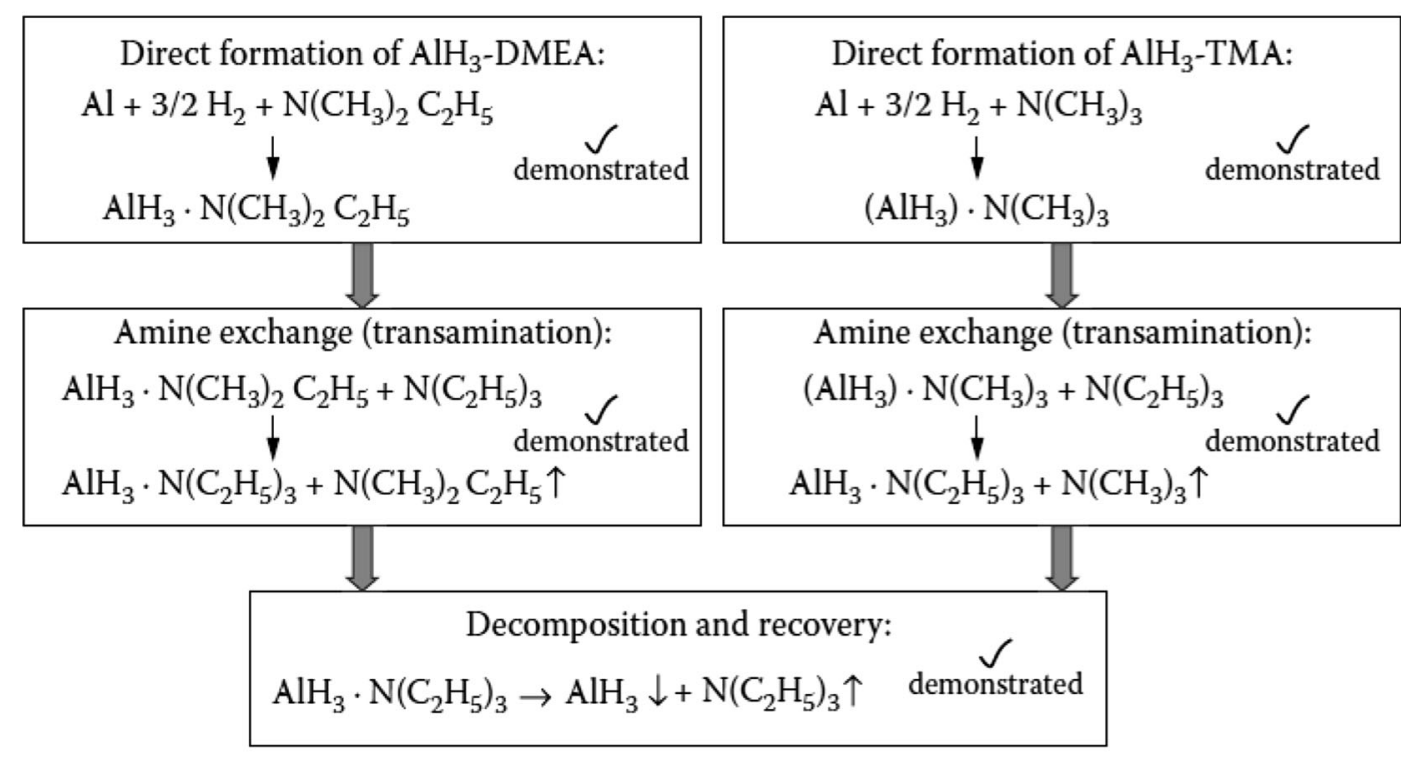

Overall reaction: $\mathrm{Al}+3 / 2 \mathrm{H}_{2} \rightarrow \mathrm{AlH}_{3}$

Fig. 8- Regeneration of $\mathrm{AlH}_{3}$ via demonstrated chemical routes. Although not indicated, catalytic levels of Ti are present in the original Al being processed. ${ }^{[43]}$

the general idea is as follows: starting with spent $\mathrm{Al}$ (formed from the desorption of $\mathrm{H}_{2}$ from $\mathrm{AlH}_{3}$ ), the $\mathrm{Al}$ is removed from the vehicle, and processing begins. The $\mathrm{Al}$ is reacted with $\mathrm{NaH}$ and $\mathrm{H}_{2}$ to form $\mathrm{NaAlH}_{4}$. This $\mathrm{NaAlH}_{4}$ is dissolved in THF and placed in the cell. Alternatively, Al from the vehicle can enter the electrochemical environment as the $\mathrm{Al}$ anode. When the cell is polarized, Al metal can be converted to $\mathrm{Al}^{3+}$, which reacts with dissolved $\mathrm{AlH}_{4}{ }^{-}$ions to produce $\mathrm{AlH}_{3}$ complexed with THF. ${ }^{[47]}$

Once the $\mathrm{AlH}_{3}$-THF adduct is formed as a white solid, the THF must be removed from the $\mathrm{AlH}_{3}$. This proved to be problematic, as the temperatures required to remove the THF also led to some dehydrogenation of $\mathrm{AlH}_{3}$, leading to a mixture of both $\mathrm{Al}$ and $\mathrm{AlH}_{3}$ in the final product. Results improved dramatically when another proprietary adduct besides THF was introduced, which led to facile removal of the adduct, forming pure $\mathrm{AlH}_{3}$ in gram quantities.

\section{2. $\mathrm{LiAlH}_{4}$}

Lithium aluminum hydride $\left(\mathrm{LiAlH}_{4}\right)$ is a promising compound for hydrogen storage, with a high gravimetric and volumetric hydrogen density and a low decomposition temperature. Its hydrogen release is described by the following two-step reactions:

$$
\begin{aligned}
& 3 \mathrm{LiAlH}_{4} \rightarrow \mathrm{Li}_{3} \mathrm{AlH}_{6}+2 \mathrm{Al}+3 \mathrm{H}_{2} \quad 5.3 \text { wt pet } \mathrm{H} \\
& \Delta H=-10 \mathrm{~kJ} / \mathrm{mol} \quad \text { Step } 1 \\
& \mathrm{Li}_{3} \mathrm{AlH}_{6} \rightarrow 3 \mathrm{LiH}+\mathrm{Al}+1.5 \mathrm{H}_{2} \quad 2.6 \text { wt pet } \mathrm{H} \\
& \Delta H=+25 \mathrm{~kJ} / \mathrm{mol} \quad \text { Step } 2
\end{aligned}
$$

Similar to $\mathrm{AlH}_{3}, \mathrm{LiAlH}_{4}$ does not form by direct hydrogenation at reasonable hydrogen pressures. Therefore, there is considerable interest in developing new routes to regenerate the material from the dehydrogenated products $\mathrm{LiH}$ and $\mathrm{Al}$ at low temperature to yield crystalline $\mathrm{LiAlH}_{4}$.

McGrady from University of New Brunswick and Jensen from $\mathrm{UH}$ initiated a collaboration that led to a remarkably mild process to generate $\mathrm{LiAlH}_{4}$ from the dehydrogenation products $\mathrm{LiH}$ and $\mathrm{Al}^{[43,48]}$

$$
\mathrm{LiH}+\mathrm{Al}[\mathrm{Ti}] \rightarrow \mathrm{LiAlH}_{4}[\mathrm{Ti}] \text { Conditions : } 298 \mathrm{~K}\left(25^{\circ} \mathrm{C}\right) \text {, }
$$$$
24 \text { hours in } \mathrm{Me}_{2} \mathrm{O} / \mathrm{H}_{2}(100 \text { bar })
$$

This process is remarkable for its mild conditions and convenience. The dehydrogenated products, $\mathrm{LiH}+$ $\mathrm{Al}+\mathrm{Ti}$ catalyst, are dissolved in $\mathrm{Me}_{2} \mathrm{O}$ at a hydrogen pressure of 100 bar. At this pressure, $\mathrm{Me}_{2} \mathrm{O}$ is a liquid, and the $\mathrm{LiH}+\mathrm{Al}$ [Ti] material dissolves. After 24 hours at room temperature, the hydrogen pressure is released. With venting of $\mathrm{H}_{2}, \mathrm{Me}_{2} \mathrm{O}$ also vents, and one is left with a quantitative conversion to catalyzed $\mathrm{LiAlH}_{4}$. Studies $^{[48]}$ of the hydrogen release properties of the $\mathrm{LiAlH}_{4}$ (Ti catalyzed) thus formed shows that $7 \mathrm{wt}$ pet of hydrogen is released from $353 \mathrm{~K}$ to $453 \mathrm{~K}\left(80{ }^{\circ} \mathrm{C}\right.$ to $180{ }^{\circ} \mathrm{C}$ ), with excellent kinetics, and only $\sim 100 \mathrm{ppm}$ of $\mathrm{Ti}$ is required for the catalysis. The material has been cycled up to 5 times with this process, but there is some cycle-induced degradation of that material that is being investigated further. ${ }^{[4]}$ A study by Argonne has suggested that as the relative amount of DME required for the process is minimized, the WTT efficiency of the process can approach the 60 pct DOE target. ${ }^{[49]}$ 


\section{Theory group}

The pursuit of hydrogen storage materials benefitted greatly from the MHCoE Theory Group, and there existed very close collaborations between the MHCoE theorists and experimentalists. Prior to the $\mathrm{MHCoE}$, the state of metal hydride modeling and theory (circa 2005) can be summarized as

(1) Density functional theory (DFT) had been used to compute the thermodynamics of only a few individual metal hydride compounds. ${ }^{[50]}$ There had been little attempt to predict phase diagrams/van't Hoff plots for metal hydrides.

(2) Theory could not predict reaction complexities, for example metastable species and multi-step reactions, that can occur in solid-state $\mathrm{H}_{2}$ desorption/ absorption reactions.

(3) Theory could not predict the crystal structures of complex metal hydrides.

(4) Virtually no theoretical work had been done on amorphous metal hydrides, or kinetics.

Today, the state of metal hydride theory and modeling today has advanced in many ways:

(1) DFT can now be routinely used to predict the $\Delta H$ and $\Delta G$ of complex metal hydrides.

(2) Reactions can now be predicted over wide ranges of pressure, temperature, and composition, thereby focusing experimental efforts on promising compounds. Linear search methods have been implemented allowing the scanning of literally millions of different reaction conditions (composition, temperature, and pressure) ${ }^{[39]}$ with predictions for promising materials finding confirmation in experiments. Their multistep character can now be predicted and understood as well. ${ }^{[41]}$

(3) Theory can now predict the existence of important and surprising reaction intermediates that are being confirmed by experiment (e.g., $\left[\mathrm{B}_{12} \mathrm{H}_{12}\right]^{2-}$ intermediates). ${ }^{[51]}$

(4) The prototype electrostatic ground-state (PEGS) method, developed by Majzoub and Ozolins, ${ }^{[30]}$ can predict ground-state crystal structures beyond the use of the ICSD database, thereby increasing accuracy and enabling thermodynamic predictions for new structural phases of materials.

(5) A much deeper understanding exists of the thermodynamics of the selected reactions, due to the MHCoE work of Johnson and co-workers. ${ }^{[16,17]}$

(6) Theory is addressing the problem of understanding metal hydride interactions with nanoconfined structures ${ }^{[52]}$ in order to better understand nanoconfined materials.

This list above represents a considerable advancement in the theoretical prediction of materials, phases, intermediates, and mechanisms of hydrogen storage reactions. The progress is attributable not only to the MHCoE Theory Group, but to hydrogen storage theorists worldwide. This review of the MHCoE theory efforts is too short given the considerable theoretical advancements that were made. The reader is referred to the recent review by Stavila et al. ${ }^{[20]}$ as well as to the MHCoE Final Report to the DOE ${ }^{[16,17]}$ for more details of the MHCoE theoretical results.

\section{MATERIALS DOWNSELECTION}

One of the primary tasks of the MHCoE was to make sober assessments of the materials that were discovered, and to assess if further work was warranted on them, given the technical goals of the program. This process was termed "materials downselect." If a material was "downselected" it was considered worthy of further study, and work on it continued. If a material was not "downselected," due to lack of promise, work on it discontinued. Although all of the DOE requirements indicated previously are required for a hydrogen-fueled light-duty automobile, within the MHCoE program particular attention was paid to five technical targets because they are challenging and have a large influence on the successful engineered implementation of the technology. These included system gravimetric density, material reversibility, thermodynamic requirements, material stability and volatilization, and materials kinetics.

Over the course of the $\mathrm{MHCoE}$ work, 94 materials systems were investigated in the 4 materials Projects (A-D). Of these 94, research work on 84 materials was discontinued and not recommended for further investigation due to some shortcoming of the material. $\mathrm{Mg}\left(\mathrm{BH}_{4}\right)_{2}, \mathrm{AlH}_{3}, \mathrm{LiAlH}_{4}, 2 \mathrm{LiNH}_{2}+\mathrm{MgH}_{2}$, and LiM$\mathrm{gN}$ were recommended for further study. Some materials were investigated in the final days of the $\mathrm{MHCoE}$, and needed further study before a downselect decision could be made. These other materials include $\operatorname{Mg}\left(\mathrm{BH}_{4}\right)_{2}\left(\mathrm{NH}_{3}\right)_{2}, \quad\left(\mathrm{NH}_{4}\right)_{2} \mathrm{~B}_{10} \mathrm{H}_{10}, \quad \mathrm{AlB}_{4} \mathrm{H}_{11}, \quad$ and $\mathrm{Al}\left(\mathrm{BH}_{4}\right)_{3} / \mathrm{NH}_{3}$.

\section{COMPARISON OF MATERIALS TO DOE TARGETS}

This section compares the best onboard reversible materials the $\mathrm{MHCoE}$ produced against the targets set forth by the DOE. These targets are for the entire storage system that would be placed inside a light-duty vehicle, including not only the metal hydride material but also the tank holding the metal hydride, the heat exchange hardware inside the tank to allow thermal management of the system, all associated plumbing, regulators, pressure relief devices, and other pieces of hardware. However, in our materials work, most of our information arrives in the form of materials properties, for example the material gravimetric capacity, material volumetric capacity, etc. In order to compare to the DOE 2010 targets, it is most convenient to translate the system "targets" into materials "goals."

To perform this translation, some assumptions must be made about the engineering gravimetric and volumetric penalties that would exist if a metal hydride were actually deployed in a real system. It is assumed that the hardware 


\begin{tabular}{|l|c|}
\hline $\begin{array}{l}\text { Storage } \\
\text { System } \\
\text { Parameter }\end{array}$ & $\begin{array}{c}2010 \text { DOE } \\
\text { Target } \\
\text { (New) }\end{array}$ \\
\hline $\begin{array}{l}\text { System Grav.: } \\
\mathrm{kgH}_{2} / \mathrm{kg} \text {-system }\end{array}$ & $4.5 \%$ \\
\hline $\begin{array}{l}\text { System Vol.: } \\
\mathrm{gH}_{2} / \mathrm{L} \text { system }\end{array}$ & 28 \\
\hline $\begin{array}{l}\text { System Fill Time } \\
\left(5 \mathrm{~kg} \mathrm{H}_{2}\right):\end{array}$ \\
mins
\end{tabular}

(a)

\begin{tabular}{|c|c|c|}
\hline \multirow{6}{*}{$\begin{array}{l}\text { Convert to } \\
\text { inferred } \\
\text { materials } \\
\text { properties } \\
\text { for making } \\
\text { Spider } \\
\text { Charts }\end{array}$} & $\begin{array}{l}\text { Storage Material } \\
\text { Parameter }\end{array}$ & "Goal" \\
\hline & $\begin{array}{l}\text { Material Grav.: } \\
\mathrm{kgH}_{2} / \mathrm{kg} \text {-material }\end{array}$ & $9.0 \%$ * \\
\hline & $\begin{array}{l}\text { System Vol.: } \mathrm{gH}_{2} / \mathrm{L} \\
\text { material }\end{array}$ & $56^{\star \star}$ \\
\hline & $\begin{array}{l}\text { 1/(Fill Time }) \\
\operatorname{Min}^{-1}\end{array}$ & 0.238 \\
\hline & $\begin{array}{l}\text { Operational } \\
\text { Cycle Life: } \\
\text { cycles }\end{array}$ & 1000 \\
\hline & $\begin{array}{l}\text { 1/(Fuel Impurities) } \\
\mathrm{ppm}^{-1}\end{array}$ & 0.01 \\
\hline
\end{tabular}

(b)

Fig. 9-Conversion of DOE Hydrogen Storage System Parameters and Targets $(a)$ to Hydrogen Storage Material Parameters, and "Goals" (b), assuming 50 pct system and gravimetric and volumetric penalties.

imposes a 50 pet volumetric penalty and a 50 pct gravimetric penalty on the materials properties. It is possible that these penalties could be somewhat less in a wellengineered and designed storage system, which would then place fewer demands on the materials' gravimetric and volumetric density goals. Another caveat is that the gravimetric and volumetric penalties may vary somewhat from material to material. Using the 50 pct penalty assumptions, Figure 9(b) shows a number of the storage material "goals" that are in support of the analogous DOE targets shown in Figure 9(a).

Table II gives a listing of the best "onboard reversible" materials that were examined in the $\mathrm{MHCoE}$, and compares them to the materials "goals" and also to materials known before the $\mathrm{MHCoE}$ program, namely $\mathrm{NaAlH}_{4}$ and a proprietary interstitial metal hydride $\mathrm{AB}_{2} \mathrm{H}_{3}$ sold by Ovonic Hydrogen Systems. ${ }^{[53]}$ It can be seen from Table II that significant gains were made in developing high gravimetric capacity materials. However, the kinetics of these materials for hydrogen release at the $358 \mathrm{~K}\left(85^{\circ} \mathrm{C}\right)$ temperature of the waste heat of a PEM fuel cell was sorely lacking.

\section{RECOMMENDATIONS}

Summarized here are recommendations from the $\mathrm{MHCoE}$ on high-priority future R\&D directions for metal hydride hydrogen storage materials. No attempt is made to rank these recommendations in order of priority.
(1) Improve
our understanding of destabilized
materials

The work performed in the MHCoE and elsewhere in the international hydrogen storage community has established that metal hydride systems can be destabilized by addition of a second compound to provide lower thermodynamic thresholds for releasing hydrogen. It is clear from the studies that much more fundamental work is needed on the mechanism of the destabilization and how the kinetics can be improved. The work by Vajo et al. ${ }^{[22]}$ on the $\mathrm{LiBH}_{4} / \mathrm{Mg}_{2} \mathrm{NiH}_{4}$ material showed that entirely new reaction pathways can emerge in these multicomponent metal hydride systems. The detailed mechanistic route by which destabilization is achieved and why the kinetics are inhibited needs to be examined in greater detail for existing promising destabilized systems and those yet to be discovered.

\section{(2) Nanoscaffolds/Nanoporous Materials}

Research in the MHCoE demonstrated that several advantages may accrue when incorporating a metal hydride into a nanoporous material. For example, the kinetics of hydrogen release can be enhanced greatly. The initial assumption of why the kinetics might be improved are based on the general idea that diffusion times follow the relationship $t \sim L^{2} / D$, where $t$ is the diffusion time, $D$ is the diffusion coefficient, and $L$ is the required diffusion distance. If nanoporous materials reduce the required diffusion distances, the diffusion time should be reduced and the reaction rate should increase. This is only a very general concept, and in fact the real atomistic mechanism for why the kinetics of the studied systems is improved remains unknown. Fundamental studies need to be performed in order to 


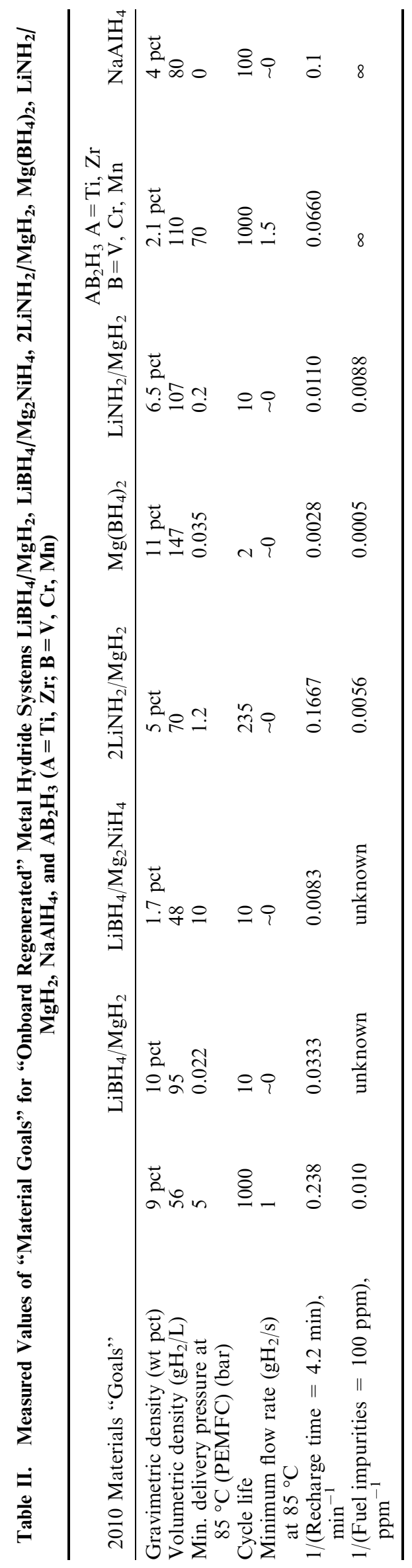

understand the nature and origin of fast diffusing species presumed to exist in these nanoconfined systems.

In addition, in order for these nanoconfined materials to serve as practical hydrogen storage materials, the gravimetric and volumetric penalties associated with the nanoscaffold need to be significantly reduced. Nanomaterials with $\sim 5$ to $10 \mathrm{~nm}$ pore dimensions, with $>3 \mathrm{~cm}^{3} / \mathrm{g}$ pore volume, need to be developed to reduce the gravimetric penalty associated with using nanoconfinement. ${ }^{[20,24]}$

\section{(3) Kinetics of Solid-State Reactions}

Almost all of the complex anionic materials that were developed in the MHCoE were severely kinetically limited, particularly at the $358 \mathrm{~K}\left(85^{\circ} \mathrm{C}\right)$ waste heat temperature of a PEM fuel cell. The theoretical understanding of the kinetics of solid-state reactions in the hydrogen storage arena is very limited. Clearly, the ability to address quantitatively the kinetics of these hydrogen desorption and absorption reactions requires detailed understanding of the mechanistic pathways, the intermediates involved, and the activation barriers that the reactions must overcome. Therefore, detailed theoretical methods need to be developed to predict and account for the kinetics of model solid-phase hydrogen storage reactions. These theoretical studies should be conducted in concert with experiments needed to validate the theory.

\section{(4) Catalysis of Solid-State Reactions}

In the MHCoE, there have been a number of examples where additives were observed to play dramatic roles in catalyzing hydrogen storage reactions. In general, very little theoretical understanding exists on how these additives work. As a result, there is no guiding understanding to develop a strategy for choosing additives to catalyze a particular hydrogen storage reaction. Given the importance of kinetics in these systems, it is very important to improve the understanding of how additives aid the kinetics of both hydrogen desorption and absorption reactions. Therefore, detailed theoretical approaches need to be developed that will elucidate how specific catalytic agents are improving the kinetics of well-documented experimental hydrogen storage systems. This will require concerted theoretical and experimental work.

\section{(5) Borohydrides}

The borohydrides offer the potential for 12 to 14 wt pct materials and their properties can vary widely. It is important to gain a fundamental understanding of the factors that control borohydride properties, such as reversibility, diborane release, ammonia release, and temperature for $\mathrm{H}_{2}$ release. With this understanding, a material that satisfies all DOE requirements might be found.

In the future, much more work should be devoted to the borohydride materials. Although over 50 borohydride systems were investigated in the MHCoE, many more systems remain to be discovered. Combined theoretical and experimental studies of borohydride stability, and their tendency to release diborane need further work. Furthermore, investigation of the role of 
$\left[\mathrm{B}_{12} \mathrm{H}_{12}\right]^{2-}$ species, and how these enter into the reaction pathways for borohydride hydrogen desorption and absorption reactions are also important.

\section{(6) Offboard Materials $\mathrm{AlH}_{3}$ and $\mathrm{LiAlH}_{4}$}

For $\mathrm{AlH}_{3}$, further work on the organometallic approach should emphasize increasing the yield of the different chemical steps, and the purity of the products obtained. In general, the yields for forming DMEA$\mathrm{AlH}_{3}$ using a pressurized reactor were good. Difficulties occurred using a vacuum distillation transamination step, where trace amounts of metallic aluminum were observed. It is known that trace amounts of aluminum promotes the decomposition of $\mathrm{AlH}_{3}$. This fact restricts the window for cleanly separating $\mathrm{AlH}_{3}$ from TEA$\mathrm{AlH}_{3}$. Hence after repeated attempts to recover pure $\mathrm{AlH}_{3}$ from TEA-AlH $\mathrm{H}_{3}$, the final product always consisted of both $\mathrm{AlH}_{3}$ and aluminum. This problem needs to be resolved experimentally. As for $\mathrm{LiAlH}_{4}$, work needs to be conducted to investigate why the material loses hydrogen capacity with cycling and in particular what is happening to the Ti catalyst during the repeated hydrogenation/rehydrogenation cycles.

\section{HYDROGEN STORAGE RESEARCH IN THE DOE CHEMICAL HYDROGEN STORAGE CENTER OF EXCELLENCE (CHSCOE)}

Chemical hydrogen storage is defined as the release of hydrogen from covalent chemical compounds, and as in any materials-based approach, includes the recycling of the dehydrogenated "spent" fuel back to the original material to complete the storage cycle. The sections below will cover the approaches and strategies for release of hydrogen from covalent compounds as well as their regeneration from their respective "spent" fuels.

There are three major approaches to releasing hydrogen from covalent compounds that are shown in Figure 10: (1) Hydrolysis including steam reforming; (2) Thermolysis, where heating of the compound leads to release of hydrogen; and (3) Catalytic release, where a catalyst is used to increase the rate of hydrogen release from a covalent compound. The CHSCoE has explored all three of these approaches.

Hydrolysis, and particularly catalytic hydrolysis, was explored as a way to release hydrogen from covalent chemical compounds such as polyhedral boranes and sodium borohydride. Here, water is used to hydrolyze

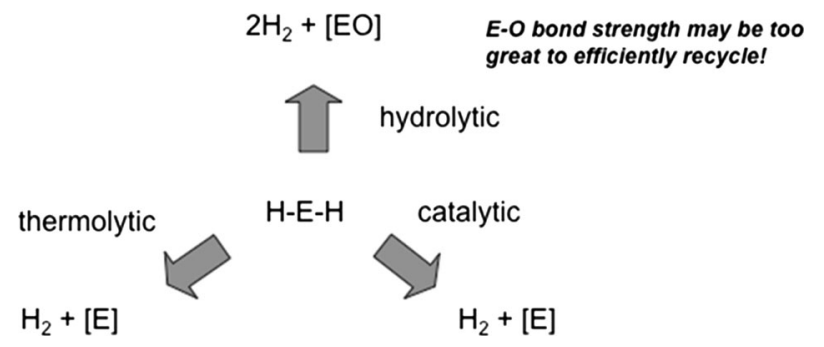

Fig. 10-The major technical approaches to releasing hydrogen from chemical hydrogen storage compounds. [element] $-\mathrm{H}$ bonds, forming [element] $-\mathrm{O}$ bonds and hydrogen. One of the drawbacks of hydrolysis is that it leads to the formation of very stable [element] $-\mathrm{O}$ bonds which, as will be discussed below, leads to thermodynamic costs associated with recycling of very stable compounds to high energy compounds-fuel. One of the positive attributes of hydrolysis is that water contributes hydrogen to the total hydrogen released, but the water must be carried onboard the vehicle, and represents a potentially more complex engineering problem to resolve.

Thermolysis of compounds that release hydrogen endothermically tends to require a high temperature $\left(>423 \mathrm{~K}\left[150{ }^{\circ} \mathrm{C}\right]\right)$ to sustain hydrogen release. They are less desirable as the heat to sustain the reaction must come from burning some of the hydrogen released, diminishing the amount of hydrogen available. There are numerous materials that release hydrogen endothermically including simple hydrocarbons, alane, and the compounds described in the section on the $\mathrm{MHCoE}$ activities. Materials that release hydrogen exothermically should not in principle require an auxiliary source of energy to drive reaction; however, the existence of materials that release hydrogen exothermically owe their limited stability to a relatively small activation barrier to reaction that must be overcome to initiate the reaction. In exothermic release materials, once the reaction is initiated, the heat of reaction drives further release. A significant challenge for this type of material is that the reaction can runaway if there are no means to control the rate of thermolysis. Thus, an engineered system that utilizes an exothermic release material such as ammonia borane (to be described in more detail below) must utilize a method that can initiate reaction and enable subsequent control of the rate of reaction, as well as the rejection of the heat of reaction.

Chemical catalysis is the means by which rates of reaction may be increased at a given temperature or the temperature of reaction may be reduced. Many approaches involving a wide variety of storage materials have attempted to improve temperature or rates of release by finding an appropriate catalyst for the release reaction. For exothermic reactions, if the reaction can be initiated at a lower temperature in the presence of a catalyst and in an appropriate reactor, such as in a flow reactor, then the residence time in the catalytic zone may help to control the rate of release, and thus the temperature of release. This is, therefore, a means of controlling an exothermic reaction. Catalysts have been discovered that promote the rapid dehydrogenation of ammonia borane at room temperature, and in the process liberating heat. This then provides an example of a method to initiate and control the release of hydrogen from a material that releases hydrogen exothermically.

When the CHSCoE was in its formative stages in the 2004 to 2005 timeframe, little was known about the potential for storing hydrogen in covalent chemical bonds. Some research had been undertaken on "activated" hydrocarbons by Cooper at Air Products. ${ }^{[54]}$ The release of hydrogen from ammonia borane $(\mathrm{AB})$ was known largely through the use of $\mathrm{AB}$ as a precursor to boron nitride, a high-temperature ceramic material resulting from the release of all of the hydrogen from $\mathrm{AB}$ at high temperature. 
Table III. Chemical Hydrogen Storage Center of Excellence List of Partners

\begin{tabular}{lll}
\hline Industrial Partners & \multicolumn{1}{c}{ Academic Partners } & National Laboratories \\
\hline $\begin{array}{l}\text { Rohm and Haas } \\
\text { (now Dow Chemical Co.) }\end{array}$ & University of Alabama & Los Alamos National University \\
U.S. Borax & Northern Arizona University & Pacific Northwest National Laboratory \\
Millenium Cell & University of California, Davis & \\
Intematix & University of California, Los Angeles & \\
& University of Missouri & \\
& Pennsylvania State University & \\
& University of Pennsylvania & \\
\hline
\end{tabular}

The potential of $\mathrm{AB}$ as a hydrogen storage material was subsequently recognized by $T$-Raissi ${ }^{[55]}$ at the University of Central Florida who provided much of the early literature on $\mathrm{AB}$ as a storage material, demonstrating that up to nearly $20 \mathrm{wt}$ pct of hydrogen could be released. Another line of research on chemical hydrogen storage was focused on the generation of hydrogen upon hydrolysis of sodium borohydride (SBH). A substantial fraction of the U.S. literature was contributed by researchers at Millennium Cell, which, at the time, was developing an onboard hydrogen storage system demonstration with Daimler-Chrysler. ${ }^{[56,57]}$

In 2005, the interest in exploring AB and other related materials was driven by the high potential hydrogen capacity, the exothermicity of hydrogen release that could lead to high rates of hydrogen evolution, and the possibility of reducing the temperature of release into the range of what was recognized to be needed for vehicular applications. Major barriers to success were identified, which included the regeneration of spent fuel. Because of the exothermicity of releasing two moles of hydrogen from ammonia borane (ca. $58.6 \mathrm{~kJ} / \mathrm{mol}$ [14 $\mathrm{kcal} / \mathrm{mol}])$, the release is irreversible at reasonable and practical pressures of hydrogen. The spent fuel must, therefore, be regenerated in some way other than simple rehydrogenation; it was recognized that this would likely have to be done chemically and thus offboard the vehicle. A second challenge resulting from offboarding the spent fuel and refueling the vehicle with $\mathrm{AB}$ then became one of materials handling-how to efficiently, reproducibly, reliably, and safely onboard/ offboard a solid material. Thus, a further challenge for the CHSCoE was the search for liquid fuels and spent fuels that could provide an alternative to the difficulties in on- and off-boarding of solid materials.

The CHSCoE began its work in the spring of 2005 and was composed of thirteen partners from industry, academia, and the national laboratories with expertise in boron chemistry and catalysis, the mining and processing of boron compounds, theory and modeling, or process engineering as shown in Table III.

The CHSCoE's approach was to focus on light element compounds ( $\mathrm{B}, \mathrm{C}$, and $\mathrm{N}$ ) containing hydrogen, with a particular focus on those that might have the possibility of releasing hydrogen exothermically to be able to attain fast kinetics of hydrogen release. This approach also required the $\mathrm{CHSCoE}$ to address the development of simple, energetically inexpensive offboard regeneration schemes.

As the CHSCoE conducted its research, it became evident that the class of $\mathrm{B}-\mathrm{N}-\mathrm{H}$ compounds is promising owing to their electronic structure and bonding that made them particularly susceptible to losing hydrogen. Much of the research conducted by the CHSCoE focused on ammonia borane, $\mathrm{NH}_{3} \mathrm{BH}_{3}$, its derivatives, and other closely associated compounds. Other materials classes were also examined, but did not have the promise of the $\mathrm{B}-\mathrm{N}-\mathrm{H}$ or $\mathrm{B}-\mathrm{C}-\mathrm{N}-\mathrm{H}$ containing compounds. Because of the CHSCoE's principle focus on ammonia borane, the regeneration of spent fuel resulting from dehydrogenation of ammonia borane was necessary to demonstrate feasibility of closing the fuel cycle. At the start of the Center in 2005, very little was known or demonstrated within the storage community regarding the chemical regeneration of the $\mathrm{BNH}_{x}$ spent fuel back to ammonia borane. At the time, the hydrogen storage community's opinion was that the undeveloped notion of spent fuel regeneration represented a daunting and significant technical barrier to the acceptance of the concept of offboard regenerable storage materials.

The CHSCoE was organized to meet the technical challenges briefly outlined above, and as the R\&D proceeded and materials and process downselects occurred, the organization of R\&D effort within the Center evolved as well. At the height of the Center's activities, teams were exploring thermolytic release of hydrogen from solid materials, discovery of liquid $\mathrm{BNH}$ and $\mathrm{CBNH}$ compounds, catalytic release of hydrogen from liquid and solvent-based systems, chemical regeneration of spent fuels, preliminary engineering studies and cost estimates, particularly in regards to spent fuel regeneration, and were searching for less exothermic, potentially onboard regenerable compounds related to ammonia borane. During the tenure of the Center, its partners discovered or explored 12 major classes of compounds comprising over 130 materials or materials combinations. Many of the materials classes examined were chosen because of their potentially high hydrogen storage capacity coupled with their typically high rates of hydrogen evolution related to their exothermic release of hydrogen, a unique property of this class of materials. Material gravimetric capacities up to 16 pct were demonstrated, and many other candidate materials demonstrated capacities in excess of $9 \mathrm{wt}$ pct; these materials capacities are consistent with what will be 


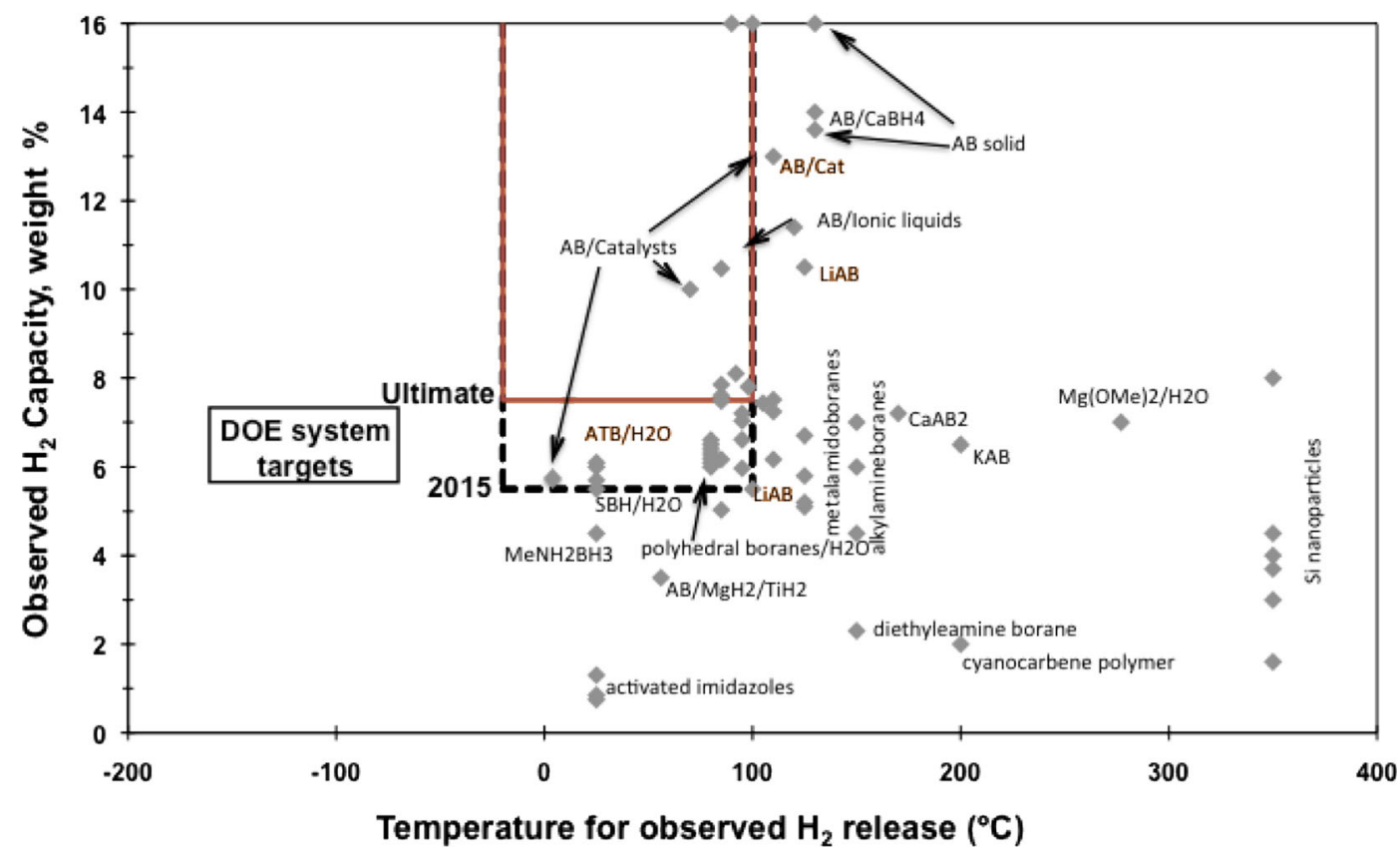

Fig. 11-State of chemical hydrogen storage in 2010 after completion of the CHSCoE activities. The plot indicates the general types of families of hydrogen storage materials the CHSCoE contributed and the temperature span over which the various materials release the indicated quantity of hydrogen.

needed to meet the stringent DOE system capacity requirements for an engineered storage system. The plot shown in Figure 11 illustrates the progress made during the tenure of the Center; this plot, made after the R\&D was completed, does not contain data from all of the materials explored because it would be too crowded, but rather shows representative data from several of the various families of chemical hydrogen storage materials explored by the Center. This plot of the materials weight fraction of hydrogen $v s$ temperature for a variety of chemical hydrogen storage materials indicates that many fit within the DOE system targets "box." This "box" represents the gravimetric capacity of a system (materials plus system hardware), and so the material alone has to have a weight fraction much $>5 \mathrm{wt}$ pct hydrogen to be of practical interest for a system, and thus only those materials that are substantially above $5 \mathrm{wt}$ pct are to be of interest in a practical sense.

In Figure 11, data for hydrogen release from some materials are shown at multiple temperatures to indicate the temperature range over which the release of hydrogen is possible. For example, catalyzed release of hydrogen from $\mathrm{AB}$ is shown as three distinct points (diamonds) ranging in temperature from $298 \mathrm{~K}$ to $383 \mathrm{~K}\left(25^{\circ} \mathrm{C}\right.$ to $\left.110^{\circ} \mathrm{C}\right)$. Above $343 \mathrm{~K}\left(70{ }^{\circ} \mathrm{C}\right)$, AB has the capacity and the rates of release to potentially meet DOE system targets. At $298 \mathrm{~K}\left(25^{\circ} \mathrm{C}\right)$, catalyzed release of hydrogen from $\mathrm{AB}$ can be fast with the appropriate catalyst, and may be of interest for "cold start" applications even though the capacity is unlikely to meet DOE system targets. Similarly, mixtures of AB in ionic liquids (IL) also demonstrate a broad temperature range for fast hydrogen release in the temperature regime of practical application for vehicular applications. From this plot, it can be seen that a number of materials fall close to the gravimetric and temperature ranges considered necessary for vehicular applications. Others, such as silicon nanoparticles ${ }^{[58-61]}$ release hydrogen at too high a temperature, and do not release hydrogen with adequate gravimetric capacity. When the CHSCoE concluded its research, chemical regeneration of spent fuel from ammonia borane had been demonstrated in the laboratory with two major variants with over ten regeneration schemes having been partially or completely demonstrated, thereby showing potential to overcome regeneration as a barrier to the technological implementation of chemical hydrogen storage; however, more R\&D is need to reduce cost and increase efficiencies.

The rest of this section provides some of the technical details of the findings of the CHSCoE, and a discussion of the most promising materials found to date.

\section{CLASSES OF MATERIALS EXAMINED BY THE CHSCOE RESULTS AND ACCOMPLISHMENTS}

The major findings and accomplishments for the materials classes investigated by the $\mathrm{CHSCoE}$ are described below.

\section{A. Exothermic Hydrocarbons as Chemical Hydrogen Storage Materials}

CHSCoE researcher Thorn and colleagues examined certain "activated" hydrocarbons as potential hydrogen storage materials, such as substituted dihydrobenzimi- 
dazoles. ${ }^{[62]}$ It was found that certain derivatives exhibited exothermic and rapid hydrogen release when reacted with protic acids in the presence of a catalyst. However, these materials were limited to $<2$ wt pct hydrogen, and so the CHSCoE moved on to other more promising compounds. The CHSCoE also made a cursory examination of $\mathrm{C}-\mathrm{N}$ based carbene compounds; however these, as are most hydrocarbons, are limited to releasing $1 \mathrm{H}$ per $\mathrm{CH}_{2}$ unit or approximately $7 \mathrm{wt}$ pct hydrogen. It was felt that these compounds had little hope of achieving the DOE system targets.

\section{B. Hydrolysis of Boron Hydrogen Compound}

As mentioned briefly above, one of the chemical hydrogen storage systems that pre-dated the $\mathrm{CHSCoE}$ was the hydrolysis of sodium borohydride, $\mathrm{NaBH}_{4}$ (SBH). ${ }^{[57]}$ Aqueous solutions of SBH can provide 4 to $7 \mathrm{wt}$ pct hydrogen, with half the hydrogen coming from water, and the product being sodium metaborate. Additional research and analysis carried out by CHS$\mathrm{CoE}$ researchers Linehan and colleagues ${ }^{[63]}$ indicated that regeneration of the borate back to borohydride was energetically inefficient and costly. Also, hydrolysis of $\mathrm{SBH}$ at concentrations sufficient to meet DOE's gravimetric target resulted in the crystallization of borate from solution; this was deemed to be unacceptable from an engineered systems perspective. Precipitation could be avoided by diluting the fuel with more water, but then the gravimetric hydrogen content fell below what is felt to be feasible for a storage system as described by the DOE technical targets. With these less than promising difficulties of SBH hydrolysis and regeneration, the DOE determined to forego additional research on hydrolysis of SBH. ${ }^{[64]}$

The Hawthorne and Sneddon groups of the CHSCoE explored the hydrolysis of neutral boron hydrides such as the polyhedral borane anions ${ }^{[65]}$ and ammonia triborane $\mathrm{e}^{[66,67]}$ as shown in the following equations:

$$
\begin{aligned}
\mathrm{NaB}_{11} \mathrm{H}_{14}+34 \mathrm{H}_{2} \mathrm{O} \stackrel{\text { catalyst }}{\longrightarrow} & \mathrm{NaB}(\mathrm{OH})_{4}+10 \mathrm{~B}(\mathrm{OH})_{3} \\
& +24 \mathrm{H}_{2} 6.3 \text { wt pct }
\end{aligned}
$$

$$
\begin{aligned}
\mathrm{NH}_{3} \mathrm{~B}_{3} \mathrm{H}_{7}+6 \mathrm{H}_{2} \mathrm{O} \rightarrow & \mathrm{NH}_{4}^{+}+3 \mathrm{BO}_{2}^{-}+2 \mathrm{H}^{+} \\
& +8 \mathrm{H}_{2} 9.7 \text { wt pct }
\end{aligned}
$$

While these hydrolysis reactions have a slightly higher gravimetric capacity than SBH they suffer in the same way as the product borates are insoluble and are energetically expensive to recycle to the borane fuels. The CHSCoE discontinued research on hydrolysisbased approaches early on, and moved on to more promising materials and processes.

\section{Thermolytic Hydrogen Release from Ammonia Borane $(A B)$}

After the CHSCoE's R\&D was completed, a review of the chemistry of thermal dehydrogenation of $\mathrm{NH}_{x} \mathrm{BH}_{x}$ compounds was published by Bowden, and Autrey of the CHSCoE. ${ }^{[68]}$ Ammonia borane ${ }^{[69]}$ is a white crystalline solid that liberates hydrogen exothermically in part because the strong $\mathrm{B}-\mathrm{N}$ bond in $\mathrm{NH}_{3} \mathrm{BH}_{3}$ polarizes the hydrogen atoms attached to the $\mathrm{B}$ and $\mathrm{N}$ atoms. The $\mathrm{B}-$ $\mathrm{H}$ bonds carry a slight negative charge, and the $\mathrm{N}-\mathrm{H}$ bonds carry a slight positive charge, and so the molecule is poised to eliminate $\mathrm{H}_{2}$. Indeed, $A B$ in the solid state releases hydrogen exothermically in a stepwise fashion as shown in Eqs. [11] to [13] and Figure 12. Hydrogen begins to be released slowly above $358 \mathrm{~K}\left(85^{\circ} \mathrm{C}\right)$, and is quite rapid by $403 \mathrm{~K}\left(130^{\circ} \mathrm{C}\right)$ in the absence of promoters or catalysts. At elevated temperatures, the well-known ceramic boron nitride is the product.

$n \mathrm{NH}_{3} \mathrm{BH}_{3} \rightarrow\left(\mathrm{NH}_{2} \mathrm{BH}_{2}\right)_{n}+n \mathrm{H}_{2} \quad\left(<373 \mathrm{~K}\left[<100^{\circ} \mathrm{C}\right]\right)$

$$
\left(\mathrm{NH}_{2} \mathrm{BH}_{2}\right)_{n} \rightarrow(\mathrm{NHBH})_{n}+n \mathrm{H}_{2} \quad\left(>373 \mathrm{~K}\left[>100^{\circ} \mathrm{C}\right]\right)
$$

$$
(\mathrm{NHBH})_{n} \rightarrow n \mathrm{BN}+n \mathrm{H}_{2} \quad\left(>773 \mathrm{~K}\left[>500^{\circ} \mathrm{C}\right]\right)
$$

The molecular details of this stepwise process depend largely on the conditions and the presence of additives and the type of catalyst used. ${ }^{11} \mathrm{~B}$ nuclear magnetic resonance is a useful tool for characterizing the intermediate and final products along the hydrogen release pathway(s) and was used extensively by the CHSCoE. Linear, cyclic, branched, and cross-linked $\mathrm{H}_{\mathrm{n}} \mathrm{BN}$ compounds and polymers are found depending upon reaction conditions as shown in Figure 13.

One particular intermediate, borazine, $\mathrm{B}_{3} \mathrm{~N}_{3} \mathrm{H}_{6}$, is volatile and reactive, and under certain conditions small amounts of the by-products ammonia and diborane are released. These gaseous impurities represent a challenge to not only avoid losing boron or nitrogen from the

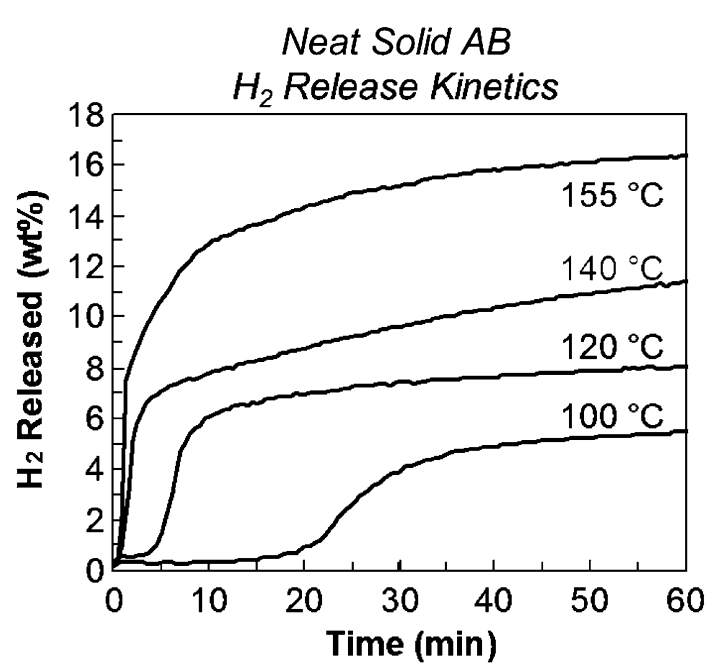

Fig. 12-Hydrogen release profile of pure ammonia borane at various temperatures. $6 \mathrm{wt}$ pet hydrogen corresponds to approximately one equivalent of hydrogen per mole $\mathrm{AB}$. 


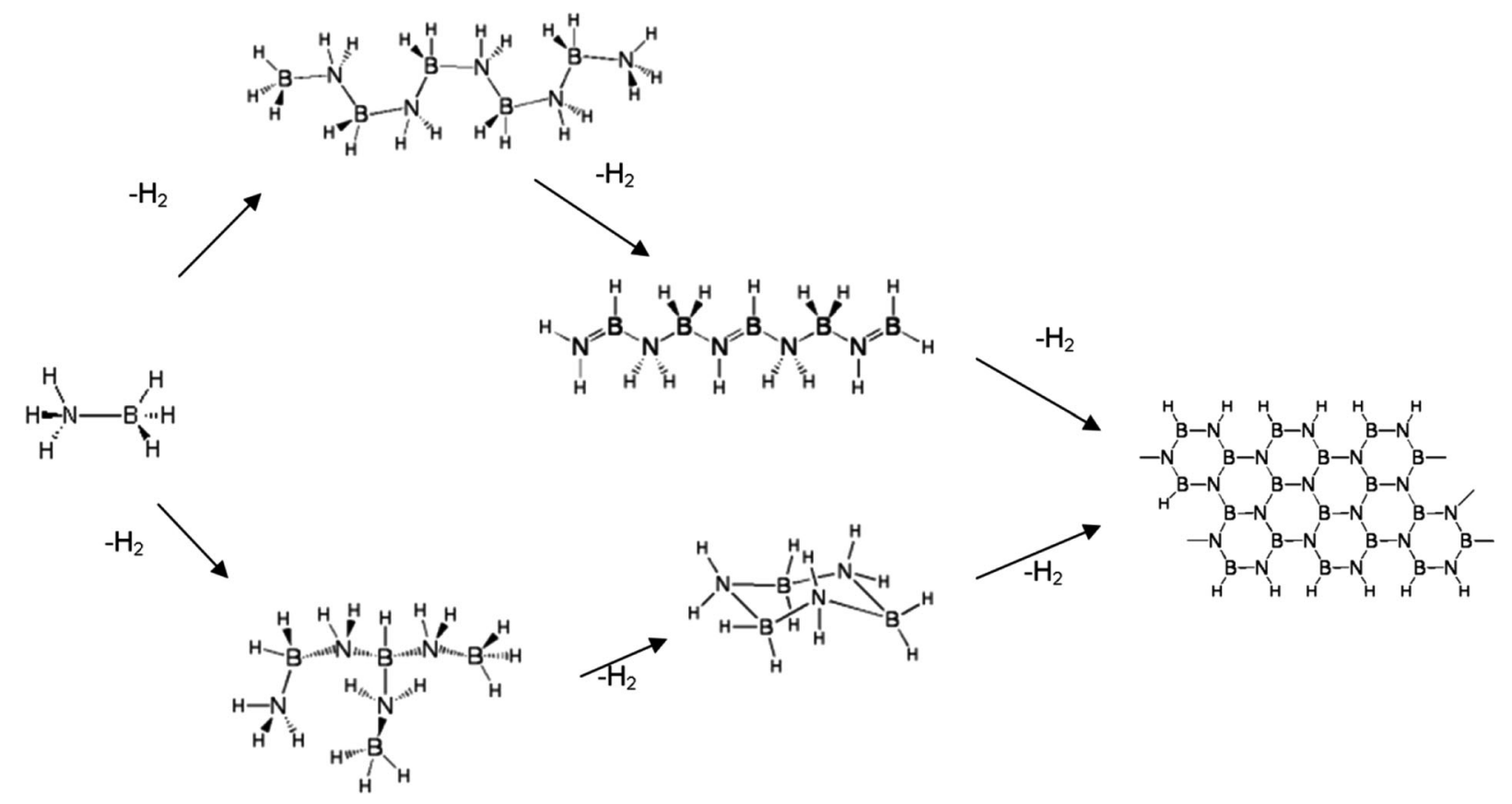

Fig. 13 - Schematic representation of AB dehydrogenation to give linear, branched, and cyclic products with various hydrogen contents.

system, but also in poisoning downstream fuel cell membranes and electrocatalysts.

The release of hydrogen from pure solid AB exhibits complex kinetics that may be defined as a nucleation and growth process, described by an Avrami kinetics model. Such processes are characterized by an "incubation" or nucleation period, followed by a rapid net reaction phase or growth phase. Thus, there is a considerable delay in observable hydrogen release upon heating of pure solid AB until critical concentrations of reactive intermediates are achieved.

Another facet of the release of hydrogen from pure solid AB is the material foams. During the early stages of hydrogen release, the material undergoes a phase change to a somewhat fluid phase that is formed by the hydrogen released, undergoing a significant expansion in volume. Upon additional hydrogen release, the material resolidifies. The large change in volume is unacceptable in a fuel system where there is little volume to accept such expansion in volume of the spent fuel. CHSCoE research led by Autrey and colleagues led to the finding that there are a number of additives that mitigated the foaming of AB. One of those additives was methylcellulose; upon addition of as little as $15 \mathrm{wt}$ pet methylcellulose the foaming was completely reduced. This comes with the compromise of a small fraction of the hydrogen capacity; however, it was also found that additives that mitigated the foaming also shortened or eliminated the "incubation" period. So the net impact of the additive was not only to reduce foaming, but to improve the overall kinetics of reaction by eliminating the incubation period.

In addition to the $\mathrm{CHSCoE}$ work on pure solid AB, partners worked on various approaches to improving the kinetics and temperature of release. Infiltrating AB from solution into the pores of mesoporous or nano- scale materials such as carbons, silicon oxides, or nanoscale boron nitrides was performed by Autrey, Karkamkar, and Kauzlarich ${ }^{[70-73]}$ and led to reduced temperatures of hydrogen release with improved kinetics and a reduction in the concentration of volatile intermediates or by-products. However, the mass of the mesoporous "scaffold" reduced the overall gravimetric capacity of the material to the point where the materials could no longer meet the gravimetric system targets for hydrogen capacity, and so this work was set aside in favor of more promising approaches and materials.

Other additives to $\mathrm{AB}$ also led to interesting results, some of which will be described in more detail below. Sneddon found that the addition of $\mathrm{LiNH}_{2}$ or $\mathrm{LiH}$, both strong bases, increased the rate and extent of hydrogen release from $\mathrm{AB}$. However, these additives promote the formation of $\mathrm{LiBH}_{4}$, a relatively unreactive compound that limits further hydrogen release at low temperature.

\section{Catalytic Release of Hydrogen from Ammonia Borane}

Thermal dehydrogenation of $\mathrm{AB}$ occurs at rates that can exceed the DOE targets only above $373 \mathrm{~K}\left(100{ }^{\circ} \mathrm{C}\right)$. A CHSCoE goal was to develop storage materials that could release hydrogen rapidly at lower temperatures appropriate to fuel cell operation (ca. $353 \mathrm{~K}\left[80^{\circ} \mathrm{C}\right]$ ). This of course suggested catalytic approaches that offer the opportunity to increase the rate and decrease the temperature of onset of hydrogen release. R\&D performed by the CHSCoE (Baker, Sneddon, Heinekey, Goldberg, Burrell, and their colleagues ${ }^{[74-87]}$ ) and by researchers outside of the Center resulted in the description of many different catalytic processes and catalysts for the dehydrogenation of ammonia borane (Figure 14). 


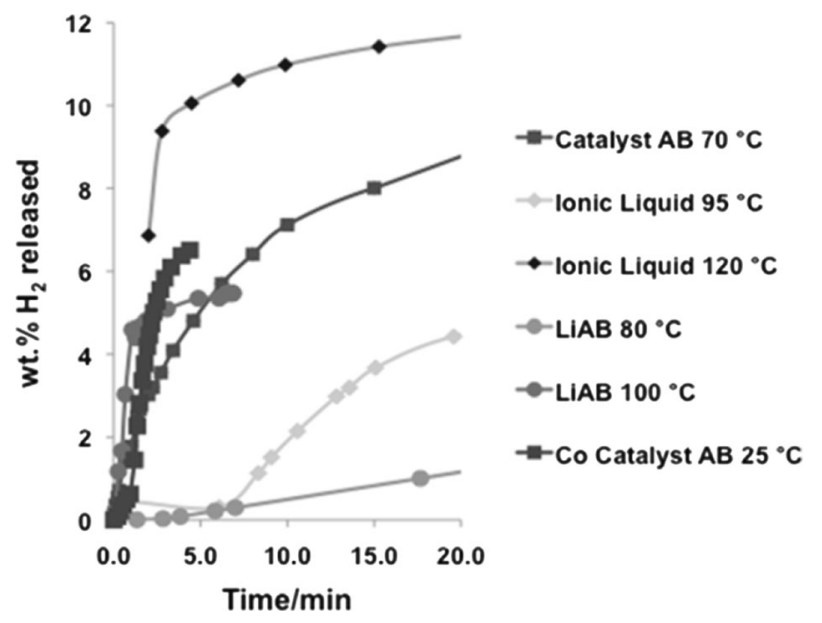

Fig. 14 Comparison of the hydrogen release profile of ammonia borane using two classes of representative catalysts vs $\mathrm{Li}-\mathrm{AB}$ and uncatalyzed $\mathrm{AB}$ dissolved in an ionic liquid.

In order to perform the catalytic dehydrogenation of ammonia borane, it is necessary to make intimate contact of ammonia borane with the catalyst. This is most readily accomplished using a "homogeneous catalysis" approach, where the catalyst and the substrate ammonia borane are both dissolved in a liquid. Another method is the "heterogeneous catalysis" approach, where the substrate as a liquid is contacted with a solid catalyst. Each approach has their advantages and disadvantages depending on the nature of the desired reaction to be carried out. However, both require that the substrate, ammonia borane in this case, be in a liquid state. A number of approaches to developing liquid storage materials were examined ranging from solutions of ammonia borane in water and in conventional organic solvents to more concentrated solutions of ammonia borane in IL (low melting organic salts) as demonstrated by Sneddon and his colleagues, ${ }^{\left[88^{-92}\right]}$ to various organic amine derivatives of ammonia borane that had melting points at or below room temperature in a few cases. The CHSCoE's research began by exploring the homogeneous catalyst approach owing to its experimental simplicity, and with the hope that this could guide future heterogeneous catalyst selection. Using the homogeneous catalysis approach, the $\mathrm{CHSCoE}$ gained valuable information on the catalytic and mechanistic details involved in the catalytic release of hydrogen from BNH compounds.

Strong Lewis and Bronsted acids were examined by Baker as catalysts for hydrogen release of aqueous solutions of $\mathrm{AB} .^{[74]}$ The formation of acyclic aminoborane oligomers by chain transfer is followed by facile dehydrocyclization at $>333 \mathrm{~K}\left(>60^{\circ} \mathrm{C}\right)$ to yield borazine and additional hydrogen. From this work, a proposed mechanism for initiation of hydrogen release via dehydropolymerization of ammonia borane for this acid catalyzed hydrogen release was supported by an examination of the reaction thermodynamics using DFT and experimental evidence.

The research groups of Baker, Heinekey, and Goldberg demonstrated a variety of other catalyst systems that promote dehydrooligomerization of ammonia borane in conventional organic solvents. The reaction products, temperatures of release, and extent of conversion are a function of the catalyst used. For example, Nheterocyclic carbene-nickel complexes form active catalysts that result in approximately $2.5 \mathrm{~mol}$ of hydrogen evolved per mole of $\mathrm{AB}$ at $333 \mathrm{~K}\left(60{ }^{\circ} \mathrm{C}\right)$, with the $\mathrm{BNH}$ product being what is referred to as polyborazylene or cross-linked borazylene, a product soluble under reaction conditions.

A variety of other homogeneous and heterogeneous catalysts also promote the release of $>2$ equivalents of hydrogen per mole of $\mathrm{AB}$ at good rates at temperatures above $343 \mathrm{~K}\left(70{ }^{\circ} \mathrm{C}\right)$. The so-called "Pincer" ligand complexes of Ir and less expensive Co were shown by Heinekey and Goldberg to form active catalysts that promote the release of hydrogen by way of an apparently different pathway. These pincer ligand catalysts catalyze the very rapid release (minutes) of only one mole of hydrogen $/ \mathrm{AB}$ at room temperature in organic solvents, generating the $\mathrm{BNH}$ product described as the "cyclic pentamer" $\left[\mathrm{BH}_{2} \mathrm{NH}_{2}\right]_{5} \cdot{ }^{\left[{ }^{[0]}\right.}$ The cyclic pentamer is unreactive to further release of hydrogen under all reasonable conditions explored. This low-temperature pincer ligand catalyst system is of great interest not only because of its apparent mechanistic differences with most other catalysts, but also because it may represent a potential "cold start" catalyst, one that can quickly generate hydrogen and heat to help initiate highertemperature catalysts to generate more hydrogen and heat to facilitate the startup of a cold fuel cell system.

There are different pathways to products and the marked difference in their kinetics demonstrated among these two classes of catalysts; those that result in the rapid evolution of 1 equivalent of hydrogen and "pentamer" vs those catalysts that promote the loss of 2 equivalents of hydrogen and yield "polyborazylene." They have been studied using a combination of spectroscopic techniques, isotope labeling, trapping studies, and theory and modeling. These studies have led to the proposed general mechanistic scheme of catalytic dehydrogenation of ammonia borane via transition metalmediated catalysts as proposed by the team of Baker, Linehan, and Dixon ${ }^{[93]}$ and shown in Figure 15. The metal catalyzed hydrogen release from ammonia borane is proposed to proceed by one of two paths depending on the nature of the catalyst. After coordination to the transition metal, the hydrogen releases from the $\mathrm{B}-\mathrm{N}$ species and either the hydrogen leaves and the $\mathrm{BN}$ fragment remains coordinated to the metal or the $\mathrm{B}-\mathrm{N}$ moiety leaves and the hydrogen remains coordinated to the metal. If the $\mathrm{BN}$ fragment remains on the metal it generally undergoes further $\mathrm{BN}$ insertion reaction leading to the loss of a single hydrogen molecule per AB. When the $\mathrm{B}-\mathrm{N}$ moiety leaves the metal center it can undergo further dehydrogenation reactions leading to $>2$ equivalents of hydrogen released.

There are several practical considerations and challenges to using a homogeneous metal catalyst in a hydrogen storage system for vehicular applications where regeneration of the spent fuel is a requirement. If a homogeneous catalyst is used, separation of the 


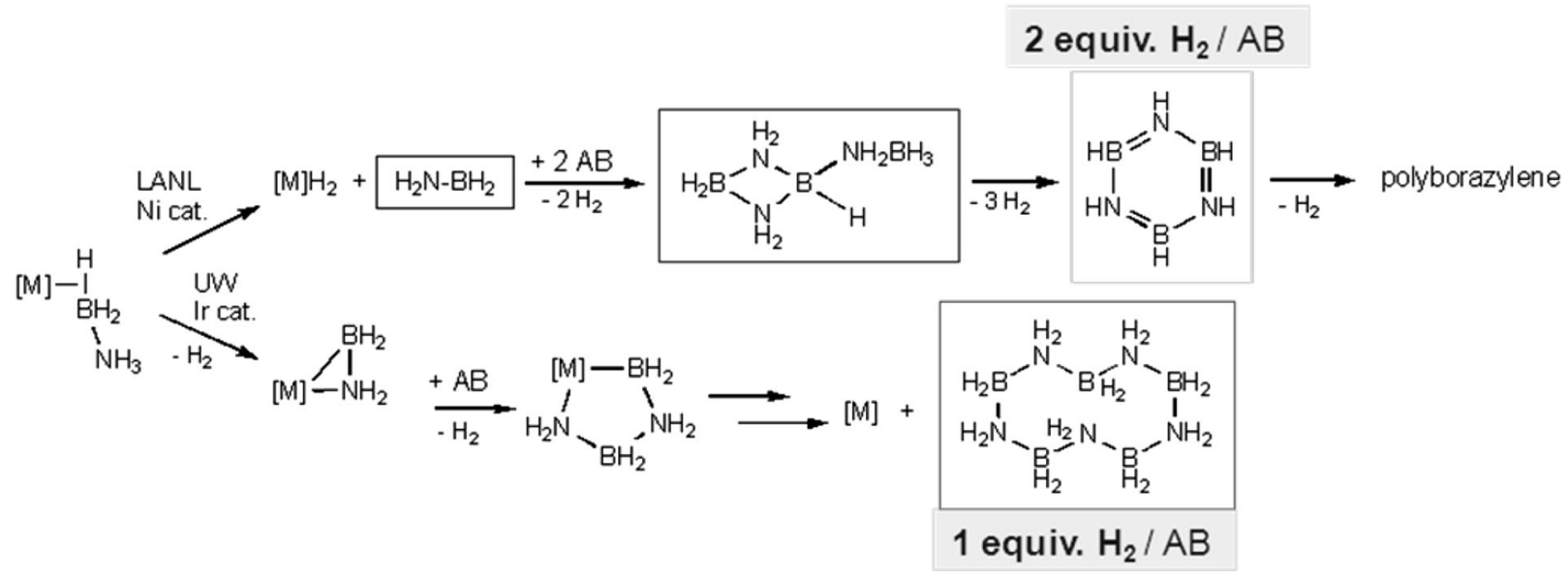

Fig. 15 - Outline of the proposed mechanistic differences between classes of catalyst that result in one equivalent of hydrogen released, vs catalysts that release 2 or more equivalents of hydrogen.

catalyst from the spent fuel mixture prior to regeneration must be accomplished. Also, if the homogeneous catalyst is mixed with ammonia borane to provide a fuel, then it may be a challenge to meet the $323 \mathrm{~K}$ $\left(50{ }^{\circ} \mathrm{C}\right)$ shelf life target, as developing a catalyst that has essentially no dehydrogenation activity at $323 \mathrm{~K}\left(50{ }^{\circ} \mathrm{C}\right)$ and high activity at $353 \mathrm{~K}\left(80^{\circ} \mathrm{C}\right)$ is a significant challenge. Developing an engineered system where ammonia borane in solution is mixed with a homogeneous catalyst may mitigate this concern, but this may be a highly complex system that does not resolve the problem of separation of the catalyst from the spent fuel.

Heterogeneous catalysts avoid the shelf life and catalyst separation challenges faced by homogeneous catalyst systems. Heterogeneous catalysts are generally employed in a tubular reactor that holds the solid catalyst in a "fixed bed." The substrate, in this case a hydrogen storage material dissolved into a solution with a solvent or as a neat liquid material, is flowed through the bed of the solid catalyst, and the dehydrogenation catalysis begins upon mixing. This configuration mitigates the possibility of catalytic reactions release of hydrogen occurring until the fuel is contacted with the heterogeneous catalyst. The spent fuel flows out of the fixed bed reactor, and thus the separation of heterogeneous catalysts from the spent fuel is accomplished. There are several difficulties with the heterogeneous catalysis approach as well. The most pressing problems are difficulties that arise in engineering the reactor system to handle the large and rapid release of hydrogen gas and the concomitant amount of heat during the exothermic dehydrogenation of ammonia borane. Rejecting and controlling the heat transfer from the reactor are crucial to maintaining control over the reaction as it proceeds. There are also the typical problems associated with any heterogeneous catalyst - maintenance of activity over the lifetime of the catalyst and regeneration of catalysts that may become potentially poisoned with products or by-products, or otherwise deactivated. While these are potentially serious problems, the $\mathrm{CHSCoE}$ determined that a heterogeneous catalyst system had a higher probability of success in a vehicular application, and so the CHSCoE narrowed its focus to the development of heterogeneous catalysts and continued to focus on developing additional liquid phase ammonia borane compositions that are required to implement a heterogeneous catalyst reactor system potentially amenable to an onboard vehicular hydrogen storage system.

Subsequently, CHSCoE researchers-Burrell and Semelsberger and their colleagues found that heterogeneous catalysts such as platinum and other transition metals supported on alumina were effective for the dehydrogenation of ammonia borane. Dehydrogenation of $\mathrm{AB}$ dissolved in conventional organic solvent catalyzed by $\mathrm{Pt} / \mathrm{Al}_{2} \mathrm{O}_{3}$ catalysts was found to be rapid at temperatures of $393 \mathrm{~K}\left(120{ }^{\circ} \mathrm{C}\right)$, with decreasing rates down to $323 \mathrm{~K}\left(50{ }^{\circ} \mathrm{C}\right)$. Non-precious metal heterogeneous catalysts containing metals such as $\mathrm{Fe}, \mathrm{Ni}, \mathrm{Co}$, or $\mathrm{Cu}$ among others were also identified. Subsequent screening of these heterogeneous non-precious metal catalysts demonstrated that it was possible to generate high rates (up to twice the DOE target rate) of hydrogen release with a high yield of $>9$ wt pct $\mathrm{H}_{2}$ at temperatures as low as $343 \mathrm{~K}\left(70^{\circ} \mathrm{C}\right)$. However, the spent fuel solutions generated insoluble solid products under these conditions that would foul the catalyst, making cyclability and catalyst lifetime problematic. While this type of catalyst fouling could be reversed, the inability to generate solvent/ammonia borane solutions of high enough concentration to meet the gravimetric target led the CHSCoE to discontinue the use of conventional organic solvents except for catalyst screening purposes. Better liquid formulations using either better solvents or novel liquid compositions are still required to maintain high concentrations of ammonia borane and the corresponding spent fuels in solution throughout the reaction cycle.

\section{E. Ionic Liquid/AB Mixtures}

ILs are ionic, organic salts that have melting points at around ambient temperature. ILs have found utility as 
useful solvents for a variety of chemical reaction types. Since the cation and the anion of the salt have chemical properties that can be "tuned" through a diversity of combinations of cation and anion, the physical properties of IL can be chosen to match the desired property most suitable for the application of interest.

Sneddon's group first explored the utility of IL as a solvent and as an activator of $\mathrm{AB}$ toward dehydrogenation reactions. ${ }^{[90]}$ Subsequently, ILs were found to promote the rate and extent of $\mathrm{H}_{2}$ release from $\mathrm{AB}$. Rates become very fast above $373 \mathrm{~K}\left(100{ }^{\circ} \mathrm{C}\right)$. For example, mixtures of $\mathrm{AB}$ with 1-butyl-3-methylimidazolium chloride (bmimCl) (50:50-wt pct) at $358 \mathrm{~K}$ $\left(85^{\circ} \mathrm{C}\right)$ exhibited no induction period and released 1.0 $\mathrm{H}_{2}$ equivalent in 67 minutes and $2.2 \mathrm{H}_{2}$ equivalent in 330 minutes at $358 \mathrm{~K}\left(85^{\circ} \mathrm{C}\right)$ as shown in Figure 15. At the same temperature, pure solid $\mathrm{AB}$ released $0.81 \mathrm{H}_{2}$ equivalent after 360 minutes, and so the presence of the ionic liquid substantially increases the rate of hydrogen evolution. Significant rate enhancements for the ionic liquid mixtures were obtained with only moderate increases in temperature, with, for example, a 50:50wt pet $\mathrm{AB} / \mathrm{bmimCl}$ mixture releasing $1.0 \mathrm{H}_{2}$ equivalent in 5 minutes and $2.2 \mathrm{H}_{2}$ equivalents in only 20 minutes at $383 \mathrm{~K}\left(110^{\circ} \mathrm{C}\right)$. Increasing the $\mathrm{AB} / \mathrm{bmimCl}$ ratio to 80:20 still gave enhanced $\mathrm{H}_{2}$ release rates compared to the solid state, and produced a system that achieved 11.4 wt pct $\mathrm{H}_{2}$ release.

The hydrogen produced from the $\mathrm{AB} / \mathrm{IL}$ mixtures contained only trace levels of borazine and no detectable diborane as determined by IR spectroscopy. Further analysis indicated that the IL interacts with borazine, impeding its release from the IL such that subsequent cross-linking reactions can occur, mitigating the loss of volatile borazine which is a known fuel cell catalyst poison.

While these $\mathrm{AB} / \mathrm{IL}$ solutions are promising for practical application, balancing the need to obtain acceptable rates above $323 \mathrm{~K}\left(50{ }^{\circ} \mathrm{C}\right)$ with the need to have negligible rates below $323 \mathrm{~K}\left(50^{\circ} \mathrm{C}\right)$ is a challenge in this and all hydrogen release systems as discussed previously. An additional challenge remains in keeping the reaction products, the spent fuel, soluble in the IL especially when more than 1 equivalent of hydrogen is released from solutions of high initial $A B$ concentrations. An analysis has shown that in order to meet DOE gravimetric capacity targets that a minimum of 2 equivalents of hydrogen must be released from concentrated solutions of $50 \mathrm{wt}$ pct $\mathrm{AB}$ in any solvent. $50 \mathrm{wt}$ pet solutions of $\mathrm{AB}$ in IL are about the maximum concentration where the $\mathrm{AB}$ remains in solution, and, depending on the ionic liquid employed, the spent fuel products begin precipitating out, or the mixtures become highly viscous. However, the CHSCoE only examined a few ILs out of the hundreds that are available, and did not explore ternary compositions (2 ILs or additives). More research is needed to find the optimal combination to maintain the fuel and spent fuel in the liquid state while still maintaining high concentrations and high rates of hydrogen release (Figure 16).

In addition to IL, Baker and Davis and their colleagues within the CHSCoE attempted to find liquid

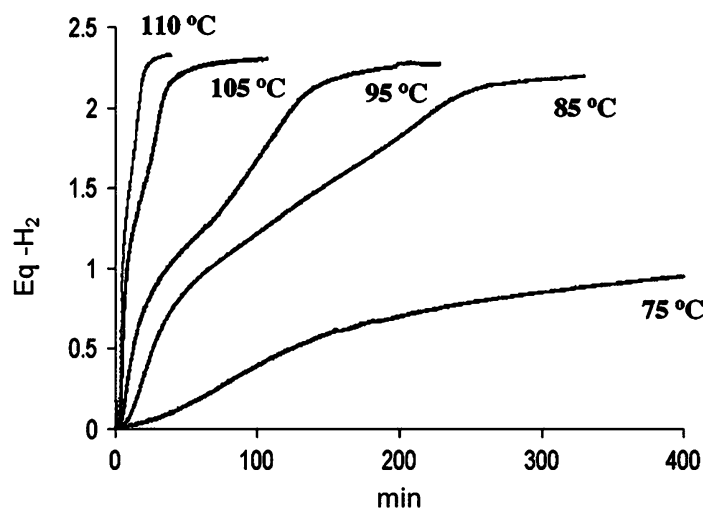

Fig. 16-Hydrogen release profiles of $\mathrm{AB}$ in the ionic liquid bmimCl.

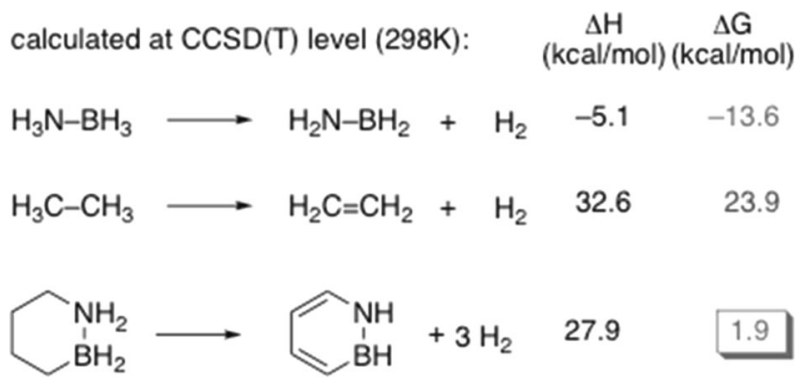

Fig. 17-Computed thermodynamics of ammonia borane, ethane, and the parent 1,2-azaborine indicating its near-thermoneutral release of hydrogen.

compositions consisting of $\mathrm{AB}$ dissolved in liquid alkylamine boranes $\left(\mathrm{RNH}_{2} \mathrm{BH}_{3}\right.$, where $\mathrm{R}$ is an alkyl or aryl substituent). Some promising preliminary results were found suggesting this to be a promising approach, but the CHSCoE did not have time at the end of the project to fully explore this possibly rich area from which to discover liquid compositions. More work is needed on this and related approaches to preparing liquid fuels having high gravimetric hydrogen contents with rapid rates of release at appropriate temperatures to generate the corresponding liquid spent fuels to enable simplified off- and on-boarding of material.

Another area of liquid fuel development that shows substantial early promise and where research continues on is in the area of the exploration of cyclo-CBN materials as first described by CHSCoE researcher Liu and co-workers. ${ }^{[94,95]}$ The premise here is that in these carbon-boron-nitrogen heterocycles (see the bottom of Figure 17 for an example of a $\mathrm{CBN}$ ), the exothermic release of hydrogen from the $\mathrm{BN}$ segment of a molecule can be coupled to and offset the endothermic release of hydrogen from the $\mathrm{CC}$ segment of the same molecule. If the kinetics of release can be made to be similar for the two channels, then the thermodynamics of hydrogen release may be coupled, resulting in principle in a nearthermoneutral release material. This approach is illustrated in Figure 17. 


\section{F. The Search for Less Exothermic Release Materials}

Two approaches were investigated in which $\mathrm{AB}$ was combined with metallic hydrides or metal amides. In one approach, physical mixtures of $\mathrm{AB}$ with metal hydrides, amides, or borohydrides were prepared to develop new composite systems. The other approach used more reactive hydrides that reacted with $\mathrm{AB}$ to form new amidoborane $\left(\mathrm{NH}_{2} \mathrm{BH}_{3}{ }^{-}\right)$complexes. One of the goals of this line of research was to search for materials that released hydrogen at near thermoneutrality. Such materials would then be likely to be directly regenerable onboard with hydrogen pressure. Thus, the potential benefit of discovering an onboard reversible storage material justified the risk of this approach.

As mentioned briefly above, part of the CHSCoE's efforts was at exploring fast and efficient methods to initiate dehydrogenation of ammonia borane, reactions involving the use of the strongly basic lithium amide, $\mathrm{LiNH}_{2}$, to initiate anionic dehydropolymerization of ammonia borane. Sneddon and his group demonstrated that $\mathrm{LiNH}_{2}$ addition to $\mathrm{AB}$ yielded $>2$ equivalents of hydrogen per mole of ammonia borane $/ \mathrm{LiNH}_{2}$ at reasonable rates and at lower temperatures than pure AB. At about this same time, publication of the synthesis and characterization of Na- and $\mathrm{Li}-\mathrm{NH}_{2} \mathrm{BH}_{3}$ was reported. ${ }^{[96]}$ Hydrogen release from $\mathrm{LiNH}_{2} \mathrm{BH}_{3}$ had faster reaction kinetics compared to $\mathrm{AB}$ as can be seen in Figure 18. LiAB releases more than 11 wt pet $\mathrm{H}_{2}$ at $403 \mathrm{~K}\left(130{ }^{\circ} \mathrm{C}\right)$ in approximately 7.5 seconds, a rate of $15 \mathrm{~g} \mathrm{H}_{2} / \mathrm{kg} / \mathrm{s}$ corresponding to the reaction:

$$
\mathrm{LiNH}_{2} \mathrm{BH}_{3} \rightarrow \mathrm{LiNBH}+2 \mathrm{H}_{2} \quad 11.9 \text { wt pet } \mathrm{H}_{2}
$$

This line of research led CHSCoE researchers Autrey and Burrell to recognize that mixtures containing ammonia borane and strongly basic or hydridic reagents such as lithium amide were resulting in compound formation via deprotonation of ammonia borane, subsequently leading to $\mathrm{M}-\mathrm{NH}_{2} \mathrm{BH}_{3}$ compounds. Subsequent to these key observations, Center researchers prepared a number of these metal amidoborane (MAB) compounds by multiple

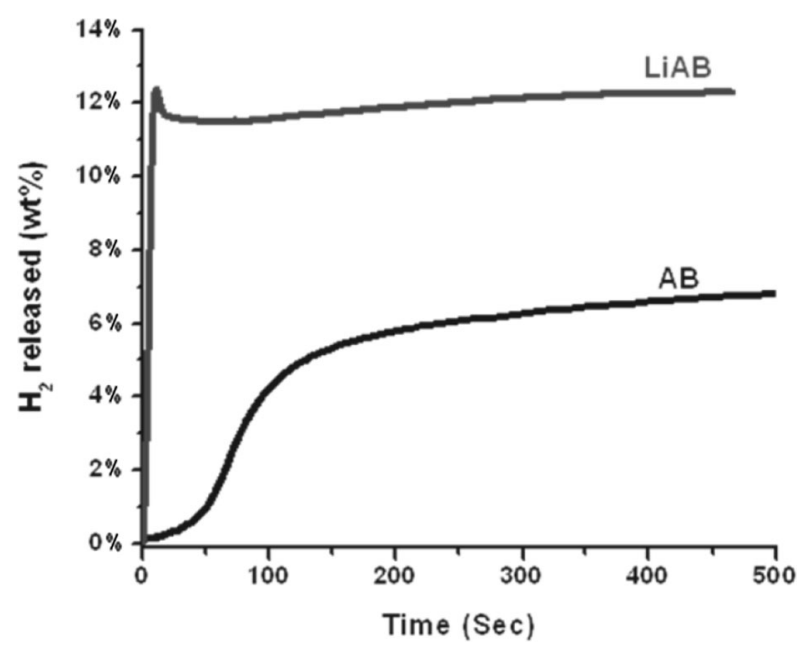

Fig. 18-Hydrogen release from $\mathrm{LiNH}_{2} \mathrm{BH}_{3}$ (LiAB) at $403 \mathrm{~K}$ $\left(130{ }^{\circ} \mathrm{C}\right)$ compared to pure ammonia borane $(\mathrm{AB})$. routes and were well characterized, spectroscopically, structurally, and for their rates and thermodynamics of their hydrogen release reactions. Burrell and his colleagues made a unique contribution to this area by demonstrating that classical solution organometallic chemistry synthetic techniques utilizing reactions between metal-alkyls, hydrides, amides, or other bases strong enough to deprotonate ammonia borane could be used to prepare and isolate a variety of pure metal amidoboranes that could then be studied in detail. ${ }^{[97-99]}$

All of the monometallic MAB's studied to date released hydrogen too exothermically to allow for subsequent direct rehydrogenation of the spent fuel with hydrogen gas. No safe path forward was identified for direct chemical regeneration of the spent fuel $\mathrm{MNBH}_{x}$ so work in monometallic MAB's was discontinued. However, the results from both solid-state and solution approaches demonstrate that the properties can possibly be tuned using a multimetallic approach so the search should continue with adjustments to the strategy to drive toward the goal of achieving a more readily regenerated spent fuel form.

In parallel to the metal amidoborane efforts, a significant research effort within the $\mathrm{CHSCoE}$ was devoted to exploring compounds and mixtures derived from the reaction of $\mathrm{AB}$ and metal borohydrides (MBH) and/or metal hydrides (MH) using solid-state synthesis techniques with the goal of developing new hydrogen storage compounds. Ronnebro and colleagues demonstrated that a wide diversity of reactions of $\mathrm{AB}$ with metal hydrides or borohydrides was obtained by ball milling $\left(\mathrm{MH}=\mathrm{MgH}_{2}, \mathrm{CaH}_{2}, \mathrm{TiH}_{2}\right.$, and/or $\mathrm{ZrH}_{2}$ ), borohydrides $\left(\mathrm{BH}=\mathrm{LiBH}_{4}, \quad \mathrm{NaBH}_{4}, \quad \mathrm{KBH}_{4}\right.$, $\mathrm{Ca}\left(\mathrm{BH}_{4}\right)_{2}$, or $\left.\mathrm{Mg}\left(\mathrm{BH}_{4}\right)_{2}\right)$, or lithium amide $-\mathrm{LiNH}_{2}$.

$$
\mathrm{AB}+\mathrm{Ca}\left(\mathrm{BH}_{4}\right)_{2} \rightarrow \mathrm{H}_{2}+\text { undetermined solid products }
$$

$\mathrm{AB}+\mathrm{Mg}\left(\mathrm{BH}_{4}\right)_{2} \rightarrow \mathrm{H}_{2}+$ undetermined solid products

In the instance of the reaction of $\mathrm{AB}$ with alkaline earth borohydrides, hydrogen evolution (Eqs. [15] and [16]) ensued indicating that compound formation was occurring. TG/DSC/MS analysis during thermolysis of these mixtures indicated that hydrogen release occurred less exothermically relative to pure $\mathrm{AB}$, had lower gasphase impurity levels, and these mixtures did not foam during hydrogen release. This is in contrast to mixtures of $\mathrm{AB}$ and alkali metal borohydrides where there did not appear to be any beneficial additive effects on the enthalpy of hydrogen release. The impurity levels of borazine and ammonia resulting from the alkali metal borohydride $/ \mathrm{AB}$ mixtures were lower than but not as low as in the $\mathrm{Ca}$ - or $\mathrm{Mg}$-borohydride/ $\mathrm{AB}$ mixtures.

Combinations of $\mathrm{AB}$ with $\mathrm{TiH}_{2}$ (0.1 equivalent) resulted in a mixture that upon thermolysis demonstrated a remarkable drop in impurity levels of borazine and ammonia, $<1$ pct compared to neat AB. No foaming of the material is observed during hydrogen release, nor was 


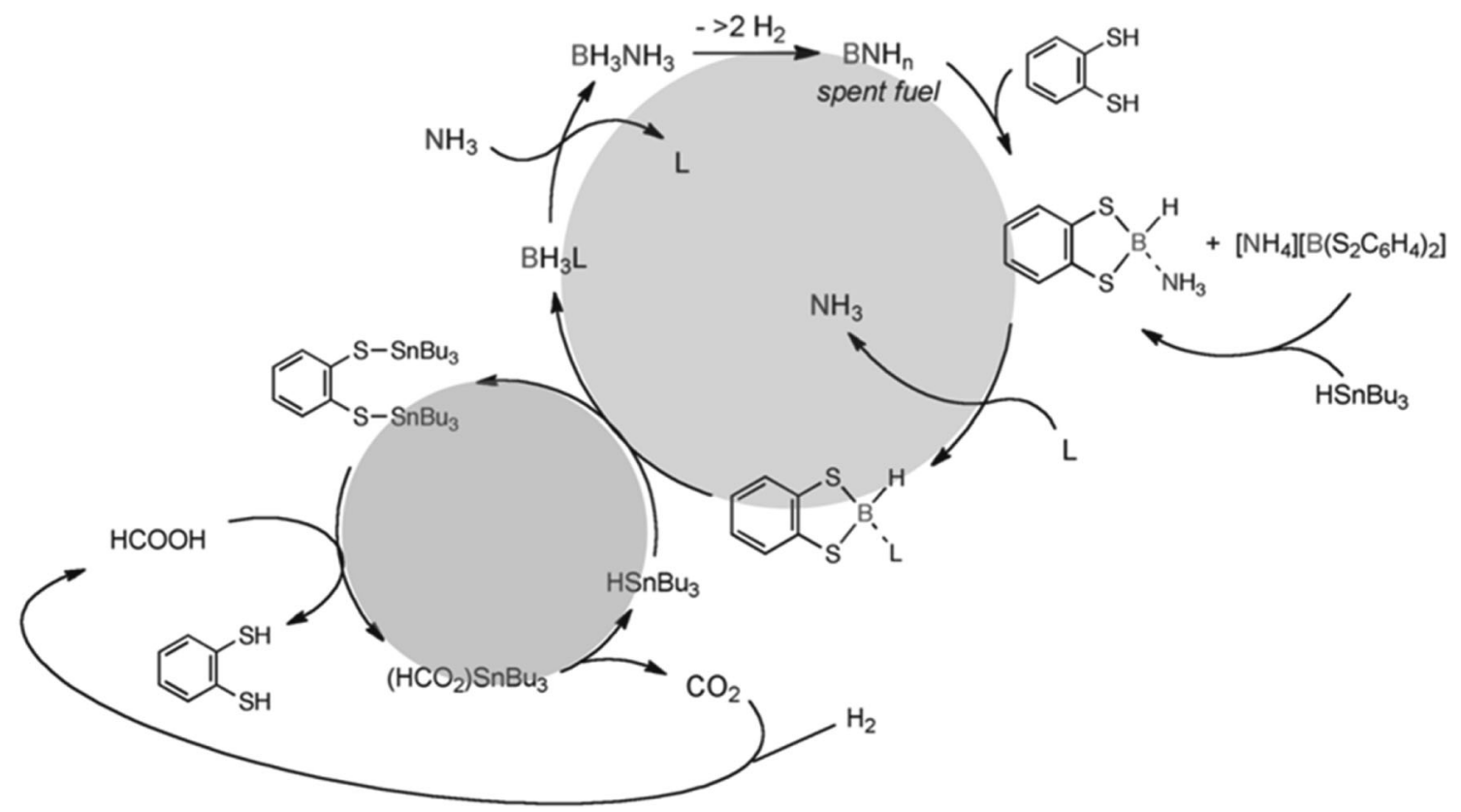

Fig. 19-Regeneration scheme using a dithiol digesting agent and a tin hydride reductant.

there significant difference in the onset of hydrogen release as compared to pure $\mathrm{AB}$. Addition of $\mathrm{MgH}_{2}$ to this mixture resulting in $\mathrm{AB} / \mathrm{MgH}_{2} / \mathrm{TiH}_{2}$ releases hydrogen at a temperature of about $85^{\circ} \mathrm{C}, 30$ deg lower than pure $\mathrm{AB}$; while maintaining the reduced levels of gaseous impurities observed in the $\mathrm{AB} / \mathrm{TiH}_{2}$ mixtures. Hydrogen release from $\mathrm{AB} / \mathrm{MgH}_{2} / \mathrm{TiH}_{2}$ is less exothermic than hydrogen release from pure $\mathrm{AB} \cdot{ }^{[100]}$

\section{REGENERATION OF SPENT FUEL}

The CHSCoE recognized early in its lifetime that if the spent fuel from a storage material could not be regenerated at low cost, then there was no path forward for additional research. It is important to note that no chemical regeneration scheme can be simpler or less costly than the straightforward rehydrogenation with hydrogen gas at moderate pressure. The compounds that the CHSCoE focused on were highly exothermic release materials, and had properties of capacity and rate (among others) that have led most to feel that the positive attributes of chemical hydrogen storage may be on par, or outweigh the more complex and costly offboard chemical reprocessing described below.

Discussion of chemical hydrogen storage regeneration schemes must start with a quantitative description of the free energy of hydrogen release from the storage material. The dehydrogenation of $\mathrm{AB}$ (2.5 equivalents of $\mathrm{H}_{2}$ released, generating polyborazylene) is exothermic by ca. $-59.9 \mathrm{~kJ} / \mathrm{mol}(-14.3 \mathrm{kcal} / \mathrm{mol})$. While this is certainly less exothermic than hydrolysis of $\mathrm{AB}[\Delta H=\mathrm{ca}$. $-950.2 \mathrm{~kJ} / \mathrm{mol}(-227 \mathrm{kcal} / \mathrm{mol})]$ or sodium borohydride, for example these reactions are quite exergonic due to the increase in entropy contributed by the evolved $\mathrm{H}_{2}$ gas. The reverse, endergonic reactions require a tremendous hydrogen pressure, on the order of 100,000 atmospheres, to rehydrogenate the spent fuel. This pressure is of course too great to be feasible on an industrial scale. Instead, the CHSCoE researchers considered several regeneration schemes that involve stepwise reactions of spent fuel with proton $\left(\mathrm{H}^{+}\right)$and hydride $\left(\mathrm{H}^{-}\right)$sources. Addition of $\mathrm{H}^{+}$ and $\mathrm{H}^{-}$has the same net result as direct $\mathrm{H}_{2}$ addition, but the stepwise addition of protons and hydride is mechanistically and thermodynamically feasible as described in this review. Schemes of this sort are the best way to efficiently overcome the intrinsic energy barrier in chemical hydrogen storage regeneration by separating the large thermodynamic and entropic barriers into achievable steps. Because of this processing strategy, the spent fuels from chemical hydrogen storage materials generated to date by the Center must be regenerated offboard in a chemical processing facility.

The CHSCoE invested a substantial amount of effort in providing numerous proof-of-principle demonstrations of reasonable spent fuel resynthesis/regeneration chemistries. One of the most important aspects that we learned through doing multiple cost and energy efficiency analyses was that the most energetically efficient process may not be the least costly, as the most energetically efficient processes are likely to be equilibrium limited and invoke substantial capital and operating expense related to the many complex separations that must be accomplished along the regeneration chemistry pathway. There are many compromises that must be struck in any such complex chemical-reprocessing schemes.

Theory and modeling as contributed by the Dixon group and Camaioni ${ }^{[101]}$ were essential to the CHSCoE spent fuel regeneration efforts. There are thousands of potential combinations of reagents available to perform various reduction sequences, thousands of potential ligands to help drive various equilibrium processes, etc. Theory allowed us 

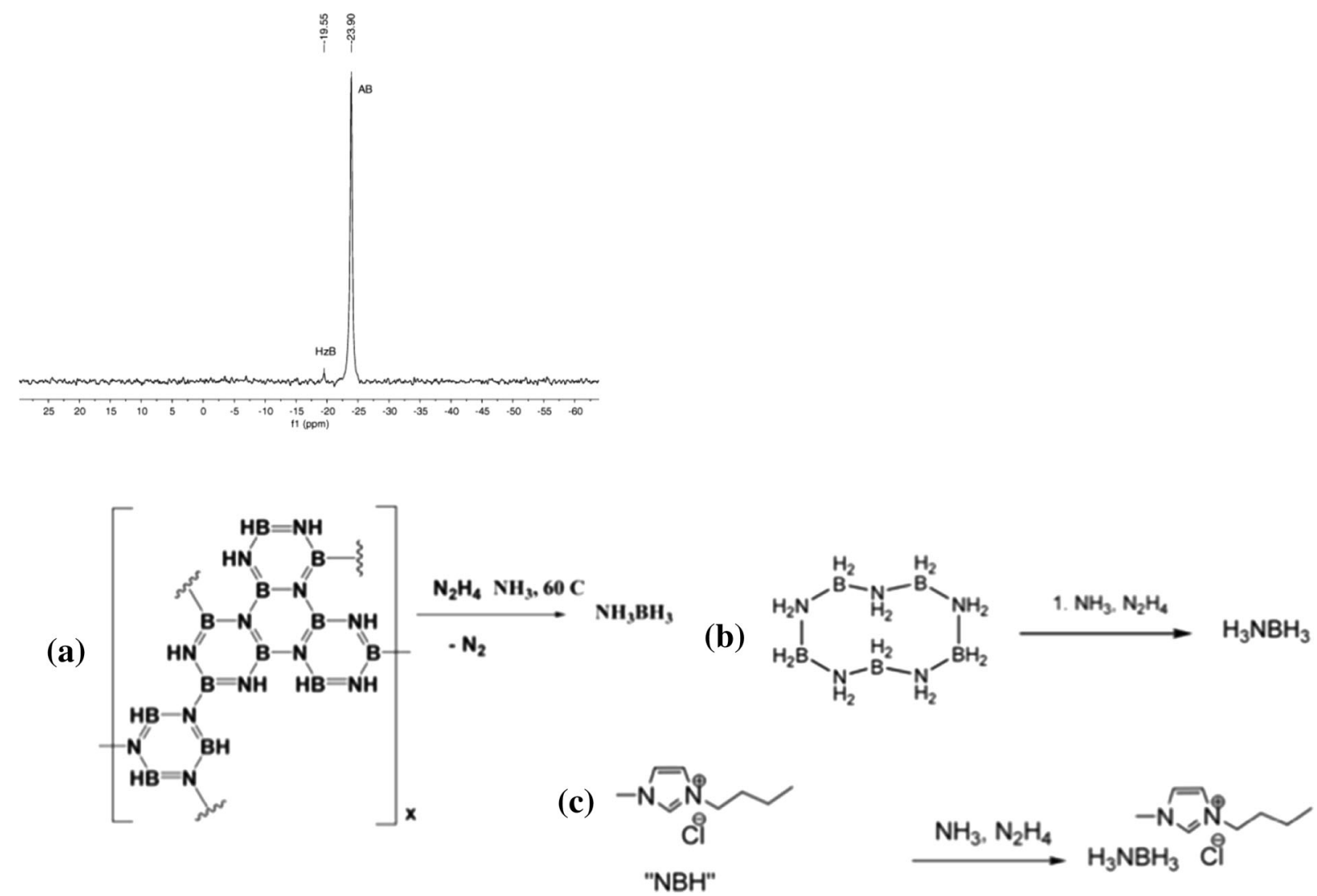

Fig. 20-Hydrazine/ammonia regeneration of polyborazylene. An 11B NMR spectrum of the crude reaction mixture is shown in the top panel indicating the crude reaction mixture contained 8 pct hydrazine borane and 92 pct ammonia borane. Below, the successful conversion of various spent fuel forms ranging from polyborazylene $(a)$, the cyclic pentamer $(b)$, to polyborazylene in an ionic liquid solvent $(c)$ are shown.

to select an experimentally tenable number of these possibilities, and attempt them in the laboratory. From among the dozens of regeneration schemes that were attempted out of thousands of the potential regeneration schemes, two are discussed here that were felt to be the most promising. Both of these processes were operated at small scale in a once-through mode in the laboratory to demonstrate that a spent fuel from ammonia borane could be chemically efficiently recycled back to ammonia borane at high yield at every step.

One of our earliest successes was the very complex scheme shown in Figure 19.

This scheme ${ }^{[102,103]}$ demonstrated by the CHSCoE team of Davis, Stephens, and Gordon involved the dissolution of $\mathrm{BNH}_{x}$ spent fuel with dithiocatechol (addition of $\mathrm{H}^{+}$) followed by reduction of the intermediate with a tin hydride (addition of $\mathrm{H}^{-}$). This required the use of an auxiliary ligand $L$ to help speed the reaction and drive the reaction to completion. This ligand had to be replaced with ammonia to complete the regeneration. The tin hydride was regenerated ${ }^{[104]}$ using a formic acid loop that completed the tin cycle. This scheme, while very complicated in appearance, was demonstrated on a 50 milligram scale in the lab. Even at this small scale, the unoptimized yield was 65 pct. A cost analysis performed by the team of Linehan, Lipiecki, Chin, and Klawiter and their colleagues at Rohm and Haas (now Dow Chemical Co.) indicated that the total regeneration cost was on the order of $\$ 7$ to $\$ 8 / \mathrm{kg} \mathrm{H}$ equivalent. This cost analysis indicated that much of the cost was associated with moving very high molecular weight materials through the plant. To mitigate that, efforts began to look for lower molecular weight reductants and digesting agents.

The next family of regeneration processes first envisaged by $\mathrm{CHSCoE}$ researcher Sutton was based upon hydrazine which was used as both the source of $\mathrm{H}^{+}$in the spent fuel dissolution stage, and then as the reducing agent. ${ }^{[105]}$ The reaction is run in liquid ammonia at $333 \mathrm{~K}\left(60{ }^{\circ} \mathrm{C}\right)$ in one vessel, and separation is achieved by venting the liquid ammonia from the product $\mathrm{AB}$. Using a carefully measured quantity of hydrazine to ensure that little or no by-product hydrazineborane is formed results in near-quantitative yield of $\mathrm{BH}_{3}$-containing species when run in a small-scale laboratory reactor. If any hydrazine borane is formed, or if spent fuel remains, these are readily recycled back to the liquid ammonia reactor, and effectively quantitative yields of ammonia borane might be obtained in a continuous, industrial scale process. In addition to regeneration of polyborazylene-like spent fuels, the relatively intractable "pentamer" is readily converted back into AB, and certain ionic liquid solvents are found to not interfere with the regeneration (Figure 20).

From a purely chemical regeneration perspective, hydrazine regeneration appears to be very attractive 


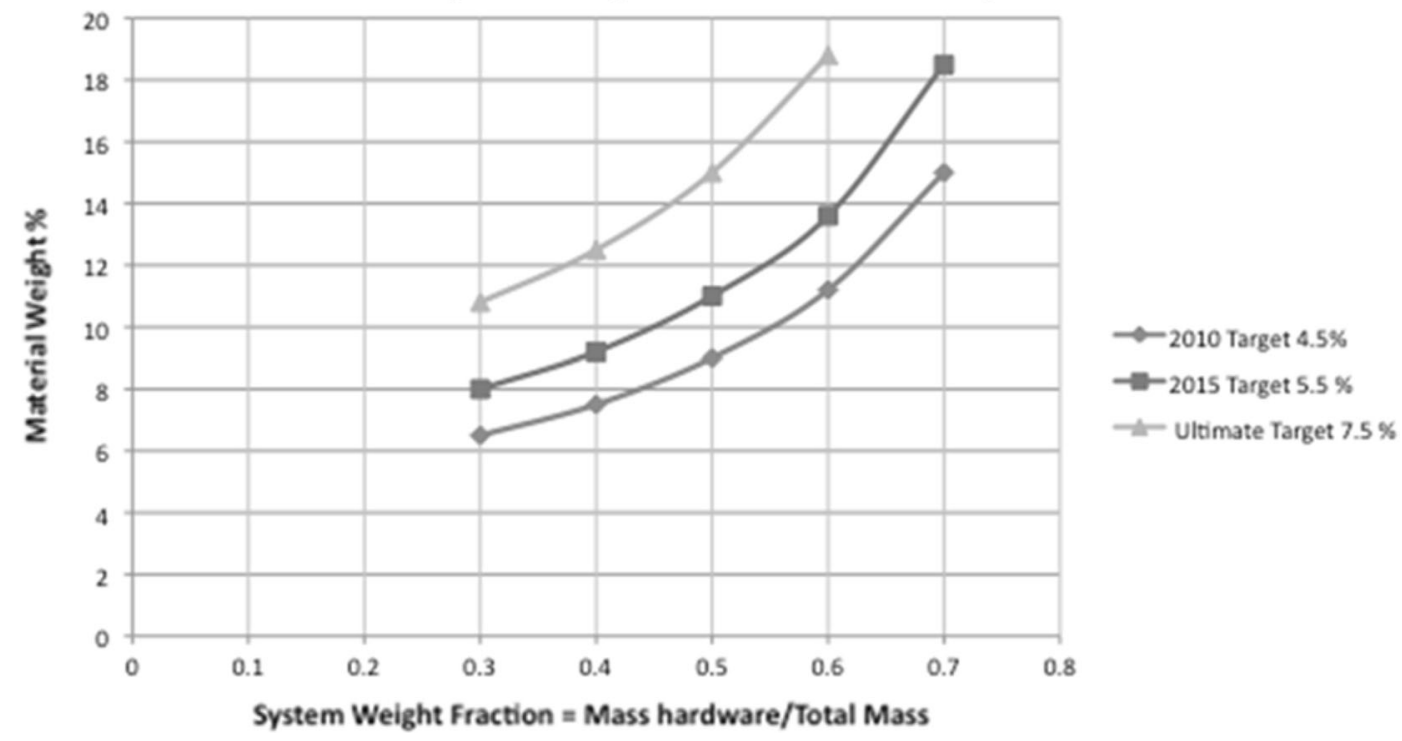

Fig. 21-The System Rules. Material wt pct vs system weight fraction derived from the DOE targets.

because of the simplicity of operation and the nearquantitative yields of ammonia borane from spent fuel. One major roadblock that remains is to reduce the cost of hydrazine which currently dominates the overall cost of this regeneration process, driving the overall cost of this regeneration to more than $\$ 45 / \mathrm{kg} \mathrm{H}_{2}$ equivalent! If $\mathrm{AB}$ is to be used on a large scale as a hydrogen storage material, then additional $R \& D$ would be required to improve the costs of the rather dated chemical processes by which hydrazine is currently produced.

While the CHSCoE successfully demonstrated a number of ammonia borane regeneration processes, still more $\mathrm{R} \& \mathrm{D}$ is required to demonstrate long-term cycling and maintenance of chemical efficiencies, reduce process material and energy inputs, and thus provide a better basis for cost estimation of chemical hydrogen storage materials that require offboard chemical regeneration of spent fuels.

\section{CONCLUSIONS}

The CHSCoE demonstrated many chemical hydrogen storage materials that liberate hydrogen from covalent compounds, and also demonstrated that the spent fuel may be efficiently recycled back to starting material using offboard chemical-reprocessing strategies. Together, these results provide substantial proofof-principle that chemical hydrogen storage is technically feasible as an onboard storage mechanism. More work is required to demonstrate an engineered system, and gain a better understanding of the total cost of hydrogen that these approaches represent.

The CHSCoE demonstrated potential solutions to a number of key barriers to implementation of chemical hydrogen storage for onboard vehicular application. CHSCoE researchers demonstrated the utility of borane amine compounds as storage materials that can release hydrogen at rates that can meet vehicular requirements owing to the exothermicity of release. The CHSCoE's research also demonstrated means to further increase the rate of evolution of hydrogen at moderate temperatures that are commensurate with vehicle operation. These means consisted of additives and catalysts, both homogeneous and heterogeneous. These approaches also uncovered strategies to reduce or eliminate the presence of volatile impurities that could negatively affect downstream fuel cell stack components either by changing the reaction pathway to avoid volatile intermediate formation (in the case of additives) or by the use of catalysis to more rapidly cross-link borazine before exiting the hydrogen generation reactor.

At the conclusion of the research program carried out by the CHSCoE, the materials that were demonstrated to have the most probability of success of achieving all of the DOE technical targets for vehicular storage were ammonia borane mixtures either in ionic liquid solution or as a pumpable slurry. Both materials could then readily address fueling/defueling requirements. Other areas of promising research are on the heterocyclic CBN compounds that are just now emerging, and the class of metal amidoboranes, where there is reason to think that materials may be found that release hydrogen less exothermically.

\section{RECOMMENDATIONS}

\section{A. Hydrogen Release}

A simple algebraic analysis of the DOE gravimetric system targets indicates that to achieve system capacity targets, any viable hydrogen storage material must be able to achieve $>9$ wt pct while also achieving all other targets simultaneously. Even with aggressive hardware 
budgets for an engineered on board system, a material $<9$ wt pct $\mathrm{H}_{2}$ will be challenged to fulfill the 2010 $4.5 \mathrm{wt}$ pet system target as is shown in Figure 21. To achieve the "ultimate" target, materials must contain $15 \mathrm{wt}$ pct hydrogen assuming a hardware budget of half of the total system mass.

Discovery of high-capacity materials that release hydrogen less exothermically (nearly thermoneutral) is required to simplify onboard heat rejection, and to enable the material to be potentially onboard rechargeable. High-capacity materials that produce negligible gas-phase impurities under hydrogen release conditions are still required.

\section{B. Regeneration}

The Center has demonstrated that given a spent fuel from a chemical hydrogen system, efficient process chemistries can be devised and implemented for offboard regeneration. The chemistries that should be considered must have the minimal number of separations steps, and any separations should be of low energy intensity (e.g., crystallization). The reagent that transfers the hydrogen to the spent fuel should be inexpensive to recycle. Ideally, the incorporation of hydrogen into the spent fuel cycle should involve an efficient catalytic approach that can be directly coupled into a spent fuel regeneration scheme. Raw materials costs must be minimal, or there must be processes to make currently expensive reagents less expensive when practiced on a world scale.

\section{First Fill of Storage Material}

For any storage material, the cost of the material is central to the overall cost of the fuel. Many storage materials, whether they are a chemical hydrogen storage material, a sorbent, or a complex metal hydride, are derived from currently expensive starting materials. The CHSCoE's work on sodium borohydride has shown that reducing raw materials' costs is required to reduce the overall fuel cost. The CHSCoE's work on first fill also has implications for the $\mathrm{MHCoE}$, as many of the storage materials they have examined are borohydride based, and the cost of these fuels will also rely upon cost-effective synthesis of borohydride intermediates.

More emphasis on process analysis and process research is needed to determine whether there is a path forward for a given material type to achieve cost targets. If so, more emphasis is required on research to develop energy and chemically efficient syntheses of first fill hydrogen storage materials of all types.

\section{Resource Availability}

When large-scale hydrogen storage materials needs are considered, resource availability studies should be performed at an early stage to ensure that there is enough U.S. and/or global resources available to accomplish the scale at which the implementation of the storage material is intended.

\section{HYDROGEN SORPTION CENTER OF EXCELLENCE (HSCoE)}

The primary focus of the $\mathrm{HSCoE}$ was to develop sorbent materials that could be used to meet DOE 2010 and 2015 onboard hydrogen storage system targets due to the relatively low volumetric energy density of hydrogen compared to typical liquid transportation fuels. The hydrogen sorbents investigated by the $\mathrm{HSCOE}$ typically rely on non-covalent interactions (for example, typically 5 to $\sim 30 \mathrm{~kJ} / \mathrm{mol}$ ). The optimal hydrogen interactions with sorbents could enable fast hydrogen on-vehicle fill and discharge rates, nominal thermal management requirements during fueling, lower pressure requirements for onboard storage and fueling, ease of engineering on the vehicle, and favorable "well-tofuel cell" energy efficiencies that decrease vehicle and station costs. In general, sorbents increase hydrogen storage capacities compared to high-pressure compressed gas systems at a given pressure and temperature, thus enabling lower pressure to be used to achieve a comparable or higher capacity. At sufficiently high pressures where compressed $\mathrm{H}_{2}$ becomes very dense (typically 250 to 300 bar at ambient temperature), sorbents no longer improve hydrogen storage capacities. When the HSCoE was established, the main challenge for sorbents revolved around the low binding energies of $\mathrm{H}_{2}$ with interfaces, and thus the need to use cryogenic temperatures to achieve high capacity. Thus, from the outset, the HSCoE focused on adjusting the binding energies to achieve higher capacity at temperatures closer to ambient. Overall, the main issues for hydrogen storage with sorbents involve achieving required volumetric and gravimetric capacities as well as system cost. These issues are related, because system costs are directly addressed by increased capacities and storage at temperatures closer to ambient and at lower pressures.

Since detailed system analysis, which was outside the scope of the $\mathrm{HSCoE}$, is needed to project actual $\mathrm{H}_{2}$ storage system capacities, the HSCoE typically reported what is termed "excess" $\mathrm{H}_{2}$ storage material values. Excess values represent the $\mathrm{H}_{2}$ actually stored on the sorbent surfaces and thus what the material is contributing to storage in the system/tank. Since sorbents tend to have additional pore and intraparticle volume where $\mathrm{H}_{2}$ gas also resides, a given material will typically "contain" more (i.e., material "total") $\mathrm{H}_{2}$ than the reported material excess value. However, DOE-directed detailed analyses performed by Ahluwalia and colleagues ${ }^{[106]}$ indicate that systems using sorbents will have usable system capacities close to the excess values, and thus these excess values can be used to gauge differences between materials and what an actual system may store. Specifically, while the exact details will vary based on the storage pressure, temperature, and storage mechanism, the HSCoE focused on developing sorbents with excess capacities greater than $\sim 6$ wt pct and $40 \mathrm{~g} / \mathrm{L}$, and in reducing system and station costs by limiting storage pressures to $<200$ bar and temperatures to higher than $\sim 77 \mathrm{~K}\left(-196^{\circ} \mathrm{C}\right)$, with the ultimate goal of higher than $200 \mathrm{~K}\left(-73^{\circ} \mathrm{C}\right)$. Note that material "total" capacities 
Table IV. Hydrogen Sorption Center of Excellence List of Partners

\begin{tabular}{lll}
\hline Industrial Partners & \multicolumn{1}{c}{ Academic Partners } & \multicolumn{1}{c}{ National Laboratories } \\
\hline Air Products \& Chemicals Inc. & California Institute of Technology & Argonne National Laboratory \\
& Duke University & Lawrence Livermore National Laboratory \\
& University of Michigan & National Institute of Standards and Technology \\
& University of Missouri-Columbia & National Renewable Energy Laboratory \\
& Pennsylvania State University & Oak Ridge National University \\
& Rice University & \\
Texas A\&M University & \\
& University of North Carolina, Chapel Hill & \\
& University of Pennsylvania & \\
& University of California, Los Angeles & \\
\hline
\end{tabular}

are only normalized to the sorbent weight and are often misleading because they typically translate to far lower system capacities when the weight of the entire system is used. ${ }^{[107]}$

When the HSCoE was established, the main challenge for sorbents revolved around the low binding energies of $\mathrm{H}_{2}$ with interfaces, and thus the need to use cryogenic temperatures to achieve high capacity. Previous to the start of the center, a substantial amount of work had been done developing "activated" and "superactivated" carbons, with materials such as $\mathrm{AX}-21$ representing the state-of-the-art in sorbents. These superactivated carbons are formed using pyrolysis and/or chemical-treatment techniques that create pores in bulk natural carbons. Kidnay and $\mathrm{Hiza}^{[108]}$ was one of the first to investigate the use of high-surface-area carbons for hydrogen sorption. In this early work, Kidnay and Hiza reported $\sim 2 \mathrm{wt}$ pet hydrogen storage at $76 \mathrm{~K}\left(-197{ }^{\circ} \mathrm{C}\right)$ and 25 atm using coconut-shell-derived charcoal. Since then, numerous investigations have demonstrated that activated carbon can store 4 to $6 \mathrm{wt}$ pet hydrogen at moderately low pressures ( $\sim 40$ bar) and cryogenic temperatures $\left(\sim 77 \mathrm{~K}\left[\sim-196^{\circ} \mathrm{C}\right]\right)$ (e.g., see the reviews by Dillon and Heben, ${ }^{[109]}$ Bénard and Chahine, ${ }^{[110]}$ Poirier et al., ${ }^{[111]}$ Carpetis and Peschka, ${ }^{[12]}$ Hynek et al., ${ }^{[113]}$ and the work by Schwarz et al. ${ }^{[114,115]}$ However, work by Ströbel and colleagues show that only $\sim 1.6 \mathrm{wt}$ pct hydrogen storage has been measured for activated/ porous carbons at ambient temperatures, even with pressures up to $125 \mathrm{~atm} .{ }^{[116]}$ It should be noted that typical hydrogen storage values at ambient temperatures of activated carbons are significantly lower. Carpetis, and Peschka and others have suggested that activated carbons may be used to inexpensively store hydrogen at cryogenic temperatures. As discussed by Chahine and Bénard, ${ }^{[117]}$ for activated carbons, typically the maximum hydrogen uptake at $77 \mathrm{~K}\left(-196^{\circ} \mathrm{C}\right)$ is $\sim 1$ wt pct for every $500 \mathrm{~m}^{2} / \mathrm{g}$ of specific surface area. However, the inclusion of the best available "conventional" activated carbons in a storage tank can only marginally enhance the overall energy storage density of a compressed hydrogen gas system under specific pressure and temperature conditions. Hynek et al. ${ }^{[113]}$ compared the hydrogen storage of several types of porous carbon materials to that of an empty compressed tank. The results indicated that of the ten materials they tested, only one showed marginal improvement over an empty tank at $190 \mathrm{~K}$ and $300 \mathrm{~K}\left(-83^{\circ} \mathrm{C}\right.$ and $\left.26^{\circ} \mathrm{C}\right)$. None of the materials were better than the empty tank at cryogenic temperatures (i.e., $80 \mathrm{~K}\left[-193^{\circ} \mathrm{C}\right]$ ). Chahine and Bénard ${ }^{[118]}$ formalized this concept by defining a "gain" parameter that provides a direct measure of the improvement a sorbent material provides in a compressed hydrogen system. Sorbents such as AX-21 have $\sim 5 \mathrm{wt}$ pct maximum excess hydrogen storage capacity at $\sim 80 \mathrm{~K}\left(-193^{\circ} \mathrm{C}\right)$ with $\sim 30$-bar pressures, but because of their relatively large pore sizes ( 1 to $4 \mathrm{~nm}$ ), their bulk densities are relatively low $(\sim 0.3 \mathrm{~g} / \mathrm{mL}$ as powders), and thus their volumetric hydrogen storage capacities are only $\sim 15 \mathrm{~g} / \mathrm{L}$. Thus, from the outset, the HSCoE focused on adjusting the binding energies to achieve higher capacity at temperatures closer to ambient. Overall, the main issues for hydrogen storage with sorbents involve achieving required volumetric and gravimetric capacities as well as system cost. System costs are directly addressed by increased capacities and storage at temperatures closer to ambient and at lower pressures.

HSCoE partners were chosen to provide the specific expertise and capabilities necessary to develop materials that could fulfill DOE requirements. The National Renewable Energy Laboratory (NREL) led the HSCoE, with other U.S. national laboratories, universities, and corporate partners. The HSCoE development activities were performed at more than 20 institutions throughout the United States with direct collaborations at institutions around the world. The HSCoE combined capabilities that enabled the design, synthesis, and characterization of the hydrogen storage performance of nearly all sorbents. The HSCoE partners are listed in Table IV.

A guiding principle the HSCoE used in developing the required materials is that a continuum of energies existed for hydrogen bound to substrates and molecules. On the weak side of the continuum is non-dissociative (hydrogen remains a molecule, $\mathrm{H}_{2}$ ) physisorption, which is due purely to van der Waals (vdW) forces $(\sim 5 \mathrm{~kJ} /$ $\mathrm{mol}$ ). On the opposite end is the full $\mathrm{C}-\mathrm{H}$ chemical bond in methane with an energy of $\sim 400 \mathrm{~kJ} / \mathrm{mol}$. The DOE targets can be met with sorbents if (1) the energy for hydrogen adsorption (i.e., the enthalpy) can be designed to be in a nominal optimal range of $\sim 10$ to $40 \mathrm{~kJ} / \mathrm{mol}$, depending on the entropy (i.e., effectively the state of the sorbed hydrogen compared to the relatively disordered state of the hydrogen gas), desired operating pressure, 
and temperature; and/or (2) efficient volumetric arrangement of a sufficient number of suitable binding sites can be achieved with a low-weight material. HSCoE principals identified four main mechanisms for hydrogen storage by sorbents and created specific development plans to ensure that the appropriate resources were applied to solving the very difficult technical issues with each one. To ensure efficiency and accelerate development, the HSCoE formed complementary research focus areas/groups loosely aligned with the four sorptionbased hydrogen storage mechanisms:

(1) Optimized Nanostructures primarily focused on increasing the specific surface area and optimizing the pore sizes to maximize physisorption of hydrogen.

(2) Substitution focused on increasing dihydrogen binding through boron substitution in high specific surface area carbons. Typically, the boron concentration and specific surface area are inversely related.

(3) Strong/Multiple $\mathrm{H}_{2}$ Binding by Metal Centers used partially coordinated metal atoms and other electronically unsatisfied structures to create sorbent sites with strong binding to dihydrogen and/or the ability to sorb multiple dihydrogen molecules.

(4) Weak Chemisorption/Spillover investigated materials with weaker than anticipated binding to atomic hydrogen such that storage could be accomplished via dihydrogen dissociation and spillover onto the receptor surfaces.

Specific partners with the right skill sets were assigned to each research group; these partners worked closely together on the most difficult issues for each focus area. Selection criteria were established for each focus area, and the HSCoE quickly selected specific sorbents/classes for focused development efforts based on their hydrogen storage potential and/or performance-along with material classes that should not be developed further.

\section{RESULTS AND ACCOMPLISHMENTS}

During its 5-year tenure, the HSCoE made substantial progress in developing sorbents that can be used for light-duty vehicle and other applications. The HSCoE's close interactions enabled substantially more development to occur more quickly than could have ever been done as independent projects. The HSCoE developed high specific surface area sorbents that could be used to construct systems that meet DOE's 2010 system targets (i.e., $4.5 \mathrm{wt}$ pct and $28 \mathrm{~g} / \mathrm{L}$ ). Furthermore, the HSCoE identified development paths for designing and synthesizing sorbents with the potential to meet DOE's 2015 and DOE's ultimate full-fleet system targets for lightduty vehicles. ${ }^{[3]}$ The HSCoE worked together to systematically develop or investigate hundreds of different materials and/or processes, resulting in hundreds of publications, with more than 25 pct of them involving multiple U.S. and international institutions as coauthors. Based on the huge number of framework [e.g., metal organic frameworks (MOF)] materials alone,

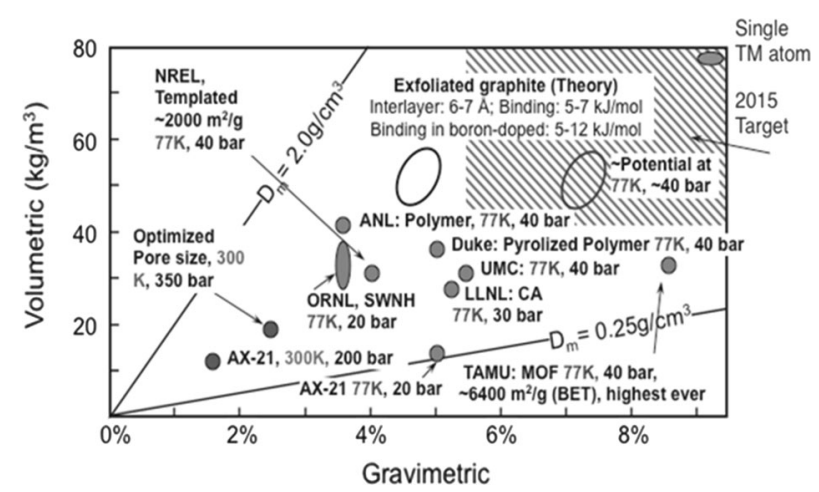

Fig. 22-Summary plot of excess volumetric and gravimetric capacities achieved for different sorbents. Note that the "AX-21" data are representative of sorbent materials before the HSCoE started.

as well as the large number of potential new materials identified, the exact number of materials developed/ studied is impossible to quantify.

The HSCoE also determined more than a hundred pathways (e.g., synthesis routes) and materials that were down-selected as not being applicable to meeting current light-duty vehicle targets. For example, elements with molecular weights over $\sim 16$ grams per $\mathrm{mol}(\mathrm{g} / \mathrm{mol})$ probably cannot be used to meet DOE 2015 storage targets at temperatures above $\sim 80 \mathrm{~K}\left(\sim-193{ }^{\circ} \mathrm{C}\right)$ with physisorption. Furthermore, if stronger $\mathrm{H}_{2}$ bonding is produced, then elements with molecular weights higher than $\sim 32 \mathrm{~g} / \mathrm{mol}$ will require multiple $\mathrm{H}_{2}$ adsorptions per sorbent atom to be able to meet DOE targets. In addition, nearly all the atoms must be accessible to the hydrogen to have sufficient capacities. These simple criteria virtually eliminate many typical sorbents such as zeolites.

HSCoE principals identified four main mechanisms for adsorbent hydrogen storage and created specific development plans to solve the associated technical issues. Specific results are provided below.

\section{CRYOGENIC STORAGE VIA PHYSISORPTION ON HIGH SPECIFIC SURFACE AREA (SSA) MATERIALS}

For most chemically stable materials or materials with electronic configurations that induce no significant adsorption, the primary adsorption mechanism is physisorption, with typical adsorption enthalpies (i.e., binding energies) of $\sim 5 \mathrm{~kJ} / \mathrm{mol}$ for $\mathrm{H}_{2} /$ material surface interactions. In most hydrogen sorption materials with the potential to meet DOE targets, almost every atom must be accessible and lightweight. Therefore, materials with high SSA are required. In addition, to meet volumetric targets, the sorption sites need to be arranged to minimize the amount of open space so that the bulk density can be as high as possible, approaching the skeletal density of the material. This suggests that porous structures should be optimized to allow hydrogen egress in and out to reduce diffusion resistances, but the hydrogen should be in contact with some kind of sorption site. Logically, the materials should have no mesoporosity or macroporosity (pores greater than $\sim 2 \mathrm{~nm}$ diameter) and should have 
nominal pore sizes between 0.7 and $\sim 1.5 \mathrm{~nm}$. Thus, regardless of the chemical composition, a physisorption material needs to have a SSA of more than $\sim 3000$ square meters per gram $\left(\mathrm{m}^{2} / \mathrm{g}\right)$ to meet DOE hydrogen storage targets ${ }^{[19]}$ at temperatures greater than $\sim 77 \mathrm{~K}$ $\left(-196{ }^{\circ} \mathrm{C}\right)$. This requirement alone eliminates hundreds of elements and materials that are too heavy. In general, storage capacities increase with higher SSAs and bulk densities. $^{[120]}$ Although these are necessary requirements for high capacity, other factors, including optimized pore sizes (i.e., 0.7 to $1.5 \mathrm{~nm}$ ) and enhanced binding energies (i.e., $>5 \mathrm{~kJ} / \mathrm{mol}$ ) for the entire capacity range, are also important. The $\mathrm{HSCoE}$ focused its efforts on improving all of these material properties independently and simultaneously (Figure 22). The work of Brunauer and Zhao and their colleagues successfully created materials with extremely high SSAs $\left(>6000 \mathrm{~m}^{2} / \mathrm{g}\right)^{[121]}$ and excess gravimetric capacities $(>8$ wt pct) at $77 \mathrm{~K}\left(-196{ }^{\circ} \mathrm{C}\right)$ and $\sim 50$ bar, ${ }^{[122]}$ high bulk densities in the range of 0.7 to 1.4 grams per milliliter $(\mathrm{g} / \mathrm{mL})$, and in a few cases materials with both high SSAs and bulk densities.

The HSCoE interactively used theory developed by Ding et al. ${ }^{[123]}$ and experiments to design and synthesize different high-SSA sorbents to tune pore size distributions and understand their relationship to $\mathrm{H}_{2}$ storage capacity. Syntheses developed included precursor pyrolysis, polymer chemistry, aerogel chemistry, templating, chemical vapor nanotube and nanohorn processing, and scaffolding. For example, McNicholas and colleagues at Duke made pyrolyzed polyether ether ketone (PEEK) materials and worked with NREL, Caltech, NIST, and UNC to optimize its pore structures to produce carbonbased sorbents with tunable pore sizes that provide excellent gravimetric and volumetric hydrogen storage capacities. ${ }^{[124]}$ This and other synthesis techniques were employed by the HSCoE to develop a number of different high-SSA materials. Typically, materials made by these processes followed the general empirical rule of $\sim 1$ percent by weight (wt pct) maximum excess $\mathrm{H}_{2}$ storage capacity for every 500 meter square area per gram $\left(\mathrm{m}^{2} / \mathrm{g}\right) \mathrm{SSA}$ at $77 \mathrm{~K}\left(-196^{\circ} \mathrm{C}\right)$ and $\sim 30$ to 60 bar. Several materials were made with SSAs $>2500 \mathrm{~m}^{2} / \mathrm{g}$ that had $\sim 5$ wt pct excess $\mathrm{H}_{2}$ storage capacities at $77 \mathrm{~K}$ $\left(-196{ }^{\circ} \mathrm{C}\right)$. However, unlike commercially available activated carbons that typically have bulk densities of 0.1 to $0.3 \mathrm{~g} / \mathrm{mL}$, several of these materials developed by McNicholas and Yuan et al.$^{[124,125]}$ have pore sizes in the range of 0.7 to $1.5 \mathrm{~nm}$, which enable bulk densities between 0.7 and $1.4 \mathrm{~g} / \mathrm{mL}$. With $\sim 5 \mathrm{wt}$ pct excess capacity, these materials have volumetric capacities over $35 \mathrm{~g} / \mathrm{L}$. In general, activated-carbon-based materials with SSAs substantially $>3000 \mathrm{~m}^{2} / \mathrm{g}$ were not achieved; therefore, while optimization of pore sizes may still improve the volumetric capacities slightly, no significant additional improvement is anticipated with these materials. However, material optimization may still be needed if high-SSA sorbents are used for applications where substantially cooler storage temperatures are used. $\mathrm{H}_{2}$ excess storage capacities vary substantially with temperature, and $\sim 14$ wt pct and $90 \mathrm{~g} / \mathrm{L}$ can be achieved at $\sim 30 \mathrm{~K}\left(-243^{\circ} \mathrm{C}\right)$.
To go beyond the SSA's achievable with activated carbons, TAMU, Michigan, Caltech, NREL, UNC, and NIST developed (via molecular modeling and design) crystalline nanoporous materials based on coordination of multifunctional and multiple binding ligands to welldefined metal centers. With a vast library of ligand "building blocks" and different coordination chemistries, the HSCoE literally made hundreds of frameworks that were characterized by XRD, SSA analysis, and $\mathrm{H}_{2}$ capacities. The HSCoE efforts by Wong-Foy and colleagues was at the forefront of formulating and synthesizing frameworks for hydrogen storage ${ }^{[126]}$ and the first to make materials with $>3800 \mathrm{~m}^{2} / \mathrm{g} \mathrm{SSA}$ and $7 \mathrm{wt}$ pct excess $\mathrm{H}_{2}$ storage capacities. Subsequently, frameworks with $\sim 6500 \mathrm{~m}^{2} / \mathrm{g}$ and $\sim 8.5 \mathrm{wt}$ pct excess $\mathrm{H}_{2}$ storage have been reported by Farha and colleagues. ${ }^{[127]}$ The main issues with these framework materials are the need for cryogenic storage temperature and the trade-off between very high SSAs that achieve good gravimetric capacities and lower bulk densities (i.e., 0.1 to $0.5 \mathrm{~g} / \mathrm{mL}$ ) that have relatively low volumetric storage capacities (at best, less than $\sim 30 \mathrm{~g} / \mathrm{L}$ ).

Molecularly designed adsorbents such as MOF enable crystalline materials to be formed with high SSA and controlled pore sizes by coordinating multifunctional (multiple binding) ligands to well-defined metal centers. As with all porous physisorption-based materials, the goal is to design pores with sizes between 0.7 and $\sim 1.5 \mathrm{~nm}$ $(\mathrm{nm})$, which are ideal for high volumetric molecular hydrogen storage. This has been a challenge for framework materials that tend to have a substantial amount of their pores larger than $2 \mathrm{~nm}$. Furthermore, the heavier molecular weight of the metal centers can be offset to some degree by the potential for high binding energies. Thus, the HSCoE focused on developing framework materials with optimal pores sizes and metal centers that were not sterically hindered for molecular hydrogen storage. In addition, due to the nature of the chemical interactions in the structure, framework materials can be sensitive to contaminants such as water and oxygen. The specific methods investigated to improve hydrogen storage capacities and binding energies included

- Reducing pore size with nanoscopic cages or catenation (interconnected frameworks).

- Synthesizing stable frameworks with mesocavities (>2 nm) but microwindows $(<2 \mathrm{~nm})$.

- Synthesizing anthracene-derivative frameworks to provide additional binding sites.

- Using different coordinated metal centers to improve their affinities to hydrogen.

- Constructing frameworks with "close-packing" alignment of open metal sites.

Early in the HSCoE, Yaghi and co-workers ${ }^{[126]}$ began the explosion in framework development for hydrogen storage materials with a paper on MOF-177. At the time, MOF-177 had the highest reported SSA (i.e., $\sim 3800 \mathrm{~m}^{2} / \mathrm{g}$ ) and excess hydrogen uptake (i.e., $\sim 7$ wt pet) of any material at $\sim 80 \mathrm{~K}\left(-193{ }^{\circ} \mathrm{C}\right)$. Subsequent work within the $\mathrm{HSCOE}$ by Zhou and coworkers $^{[128]}$ produced framework materials with $\sim 5100 \mathrm{~m}^{2} / \mathrm{g}$ and $\sim 7 \mathrm{wt}$ pet excess $\mathrm{H}_{2}$ storage at $\sim 80 \mathrm{~K}$ 


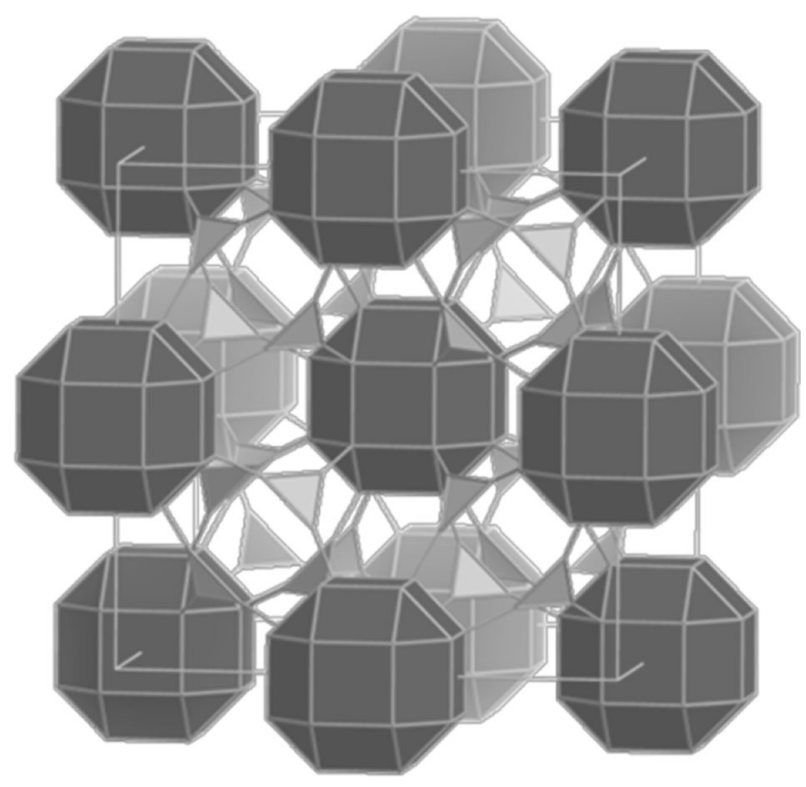

Fig. 23-Schematic of Porous Coordinated Network.

$\left(-193{ }^{\circ} \mathrm{C}\right)$. Zhou's materials (e.g., see Figure 23) have been the basis used recently to form MOFs with 8.5 to 9 wt pct excess $\mathrm{H}_{2}$ storage at $\sim 80 \mathrm{~K}\left(-193{ }^{\circ} \mathrm{C}\right)$. Also, within the HSCoE, NIST worked with many groups from around the world to determine the isosteric heat of adsorption at specific adsorption sites. Brown and colleagues at NIST found that isosteric heats of hydrogen adsorption to the metal sites were the highest in the frameworks (i.e., in a manganese framework, 10 kilojoules per mole $[\mathrm{kJ} / \mathrm{mol}]) .{ }^{[129]}$ NIST worked with theorists Zhang and co-workers ${ }^{[130]}$ at NREL to understand the four key factors that affect the orbital interactions between the metal centers and $\mathrm{H}_{2}$, finding that the binding could range between 10 and $50 \mathrm{~kJ} / \mathrm{mol}$ depending on the specific metal used. NIST subsequently worked with Long and co-workers at the University of California, Berkeley to experimentally demonstrate the relationship between the specific metal used and the binding of $\mathrm{H}_{2}$. Unlike previous predictions by Zhou and colleagues, ${ }^{[131]}$ these results demonstrated that the relationship was not specifically related to the metal ion size.

Frameworks offer a huge potential to continue increasing the SSA and gravimetric capacities of $\mathrm{H}_{2}$ storage materials past $9 \mathrm{wt}$ pct. Furthermore, their ability to have higher binding energies and sub-nanometer-sized pores offers additional opportunities. For example, catenation or developing frameworks with smaller pore sizes has tended to result in decreased SSA and thus lower $\mathrm{H}_{2}$ capacities. Furthermore, the relatively small number of metal atoms and their limited access by $\mathrm{H}_{2}$ means that only one to two $\mathrm{H}_{2}$ could interact and have enhanced binding. Since metals make up only a small percentage of the frameworks, and due to the relatively high molecular weight of many metals typically used (i.e., copper, iron, manganese, and zinc), $\mathrm{H}_{2}$ storage by the metal centers may decrease the overall $\mathrm{H}_{2}$ storage capacity of the material. Thus, the enhanced binding from the metal centers must be carefully integrated to enhance storage capacities. The main focus for future framework-development efforts needs to be on optimizing the pore sizes for $\mathrm{H}_{2}$ adsorption with air- and water-stable materials, while still retaining suitable SSAs. In addition, future framework development should also investigate methods for improving binding energies of the high-SSA ligand components.

At the outset of the HSCoE's activities, numerous publications including results from Zlotea et al. ${ }^{[132]}$ had reported extraordinary results for high-SSA materials in which the enhanced capacities were potentially a result of novel geometries or structures within the material. In general, Purewal and colleagues ${ }^{[133]}$ showed that heats of adsorption can be increased with multiple wall interactions, but this ultimately reduces capacities due to the decrease in space for the hydrogen molecules. The HSCoE did not validate any single-element material or any materials with unexceptional electronic states that have substantially higher capacities beyond that expected based on SSA and specific storage conditions. For example, at one time carbon nanotubes where thought to possibly have unique $\mathrm{H}_{2}$ storage properties; but after a dedicated focused effort, the HSCoE made a No-Go decision on using carbon nanotubes as an ambienttemperature hydrogen storage material. Ultimately, carbon nanotubes may still provide excellent hydrogen storage at cryogenic temperatures. Based on a vast amount of measured sorbent results and through thorough detailed investigations of numerous published results to the contrary, the $\mathrm{HSCoE}$ concluded that standard physisorption-based dihydrogen adsorption scales with specific surface area, and thus no substantial increase in capacity can be achieved with geometric structures alone. The main issue is that increases in $\mathrm{H}_{2}$ binding can be achieved with very small $(<0.4 \mathrm{~nm})$ pores due to multiple wall interactions, but less space is available for hydrogen and thus the capacities actually decrease.

\section{TOWARD AMBIENT-TEMPERATURE STORAGE WITH INCREASED AND MULTIPLE $\mathrm{H}_{2}$ BINDING}

To have higher capacities at temperatures closer to ambient compared to pure physisorption, enhanced electronic interactions between the sorption material surface and $\mathrm{H}_{2}$ are required. For materials to be stable, all bonds must be chemically satisfied. For pure elemental and/or stable high-SSA materials, $\mathrm{H}_{2}$ can adsorb on the surfaces; but with no chemical bonds significantly altered, only physisorption can occur. To increase the binding, materials must be formed in which components of the surfaces are chemically frustrated and able to induce enhanced interactions with $\mathrm{H}_{2}$. The $\mathrm{HSCoE}$ investigated several methods to do this, with perhaps the most conceptually simple approach being the substitution of specific elements in otherwise chemically homogeneous structures. For example, boron (B) substituted into carbon (C) graphene lattices (Figure 24) was predicted by Kim et al..$^{[134]}$ and then experimentally validated by Chung et al. ${ }^{[135]}$ to enhance $\mathrm{H}_{2}$ isosteric 


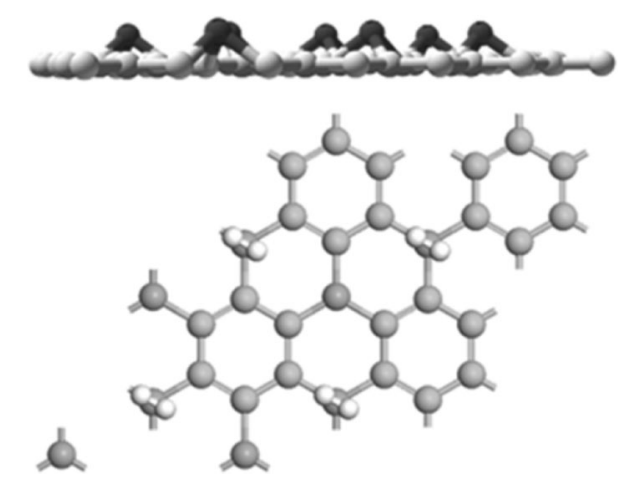

Fig. 24-Schematic of $\mathrm{BC}_{3}$.

heats of adsorption to $\sim 11 \mathrm{~kJ} / \mathrm{mol}$. Enhancement occurs because the empty p-orbitals on boron substituted for carbon induce electron donation from $\mathrm{H}_{2}$. Here, the empty p-orbitals created by substituting boron (B) for carbon (C) in a C-matrix induce electron donation from the hydrogen molecule to enhance binding energies by a factor of three (i.e., from $\sim 5$ to 10 to $15 \mathrm{~kJ} / \mathrm{mol}$ ) and thus increase capacities, especially at operating temperatures above $200 \mathrm{~K}\left(-73{ }^{\circ} \mathrm{C}\right) \cdot{ }^{[134]}$ Substitution of lithium, nitrogen $(\mathrm{N})$, oxygen, or other lightweight elements into graphene does not enhance $\mathrm{H}_{2}$ binding. ${ }^{[134]}$ Similarly, C-substituted B structures, BN, BCN, and other lightweight materials either do not enhance or have decreased $\mathrm{H}_{2}$ binding. Thus, after an initial short set of collaborative efforts to identify potential materials, the HSCoE focused its experimental development on forming high-SSA $\mathrm{BC}_{x}$ with several different scalable and inexpensive synthesis methods. $\mathrm{BC}_{3}$ represents the ultimate material composition goal. This level of $\mathrm{B}$ concentration allows the maximum concentration where the $\mathrm{H}_{2}$ binding energy will be increased throughout the lattice. Higher or lower B concentrations will have lower overall binding energy.

Boron substitution was achieved by either starting with chemical compounds with high concentrations of $\mathrm{B}^{[135]}$ and forming high-SSA materials, forming B-substituted activated and graphitic carbons (e.g., $\left.\mathrm{BC}_{3}\right),{ }^{[136]}$ or substituting boron for carbon atoms in preformed materials accomplished by Tour and Kittrell. ${ }^{[137]}$ These multiple institution efforts culminated with Brown and colleagues ${ }^{[138]}$ obtaining neutron spectroscopy data showing, for the first time, a large rotational splitting, indicative of enhanced $\mathrm{H}_{2}$ interactions in a B-substituted carbon. Similarly, for the first time, HSCoE measurements from diffuse reflectance infrared Fourier transform spectroscopy (DRIFTS) showed reversible hydrogen interaction with the B:C material. Although different approaches were used, the ultimate boron concentration and SSA achieved were approximately the same: SSAs of $\sim 800 \mathrm{~m}^{2} / \mathrm{g}$ with 10 to 15 pet B substitution. This is well short of the $\sim 3000$ square meters area per gram $\left(\mathrm{m}^{2} / \mathrm{g}\right)$ and $\sim 25$ pct B concentrations expected to be achievable. In addition, based on X-ray photoelectron spectroscopy (XPS), approximately 25 pct of the B in these materials is in the correct coordination for enhanced binding, indicat- ing that only small fractions of the B in the materials were providing enhanced hydrogen binding. However, the $\mathrm{BC}_{x}$ materials typically have approximately twice the hydrogen storage adsorption on a per SSA basis compared to activated carbon. In general, maximum excess gravimetric hydrogen adsorption capacities of $\sim 3 \mathrm{wt}$ pct are observed at $77 \mathrm{~K}\left(-196{ }^{\circ} \mathrm{C}\right)$ for materials with 600 to $800 \mathrm{~m}^{2} / \mathrm{g}$ SSAs. This compares to $\sim 1.5 \mathrm{wt}$ pct for activated carbons with similar surface areas at $77 \mathrm{~K}\left(-196{ }^{\circ} \mathrm{C}\right)$. In addition, $\sim 65 \mathrm{pct}$ of the $77 \mathrm{~K}\left(-196^{\circ} \mathrm{C}\right)$ capacity is retained with some porous $\mathrm{BC}_{x}$ materials at $\sim 200 \mathrm{~K}\left(-73^{\circ} \mathrm{C}\right)$. This compares to 25 to 30 pct with pure carbon materials at $200 \mathrm{~K}\left(-73^{\circ} \mathrm{C}\right)$.

Future efforts must focus on increasing simultaneously both the boron concentration (in $\mathrm{BC}_{3}$ coordination) and SSAs of these substituted materials. Paths forward to do both include solution-phase synthesis and lower-energy chemical vapor synthesis in which the $\mathrm{BC}_{x}$ surfaces with the stronger binding are not allowed to interact and collapse. If a $\mathrm{BC}_{3}$ material can be made, then more than half of the hydrogen storage capacity would be at the higher isosteric heats of adsorption needed to have substantially higher hydrogen storage at temperatures greater than $\sim 200 \mathrm{~K}\left(-73{ }^{\circ} \mathrm{C}\right)$.

Prior to the HSCoE, little systematic work had succeeded in identifying ways of increasing $\mathrm{H}_{2}$ binding to well-coordinated chemically stable sorbents, especially for the majority of the material capacity. The HSCoE focused efforts by Kim et al. ${ }^{[139,140]}$ on the use of unsaturated coordinated metal centers to increase $\mathrm{H}_{2}$ binding energies (predicted values of $>20 \mathrm{~kJ} / \mathrm{mol}$ ) and to enable the potential of multiple $\mathrm{H}_{2}$-molecule binding at a single adsorption metal site. In these materials, the metal atoms interact with a lattice but are sufficiently configured to have enhanced interactions with $\mathrm{H}_{2}$ via both forward and back donation of electrons. Zhao et al.' $\mathrm{s}^{[139,140]}$ seminal paper in this area was the first to predict unique structures that may have the potential to hold multiple (i.e., 2 or more) $\mathrm{H}_{2}$ molecules at a specific metal site. The results in this paper opened up new areas of investigation for hydrogen storage. The key findings on this topic since the inception of the HSCoE are that lightweight alkali, alkaline earth, and 3d-transition metals may be configured to enhance binding and have the potential to bind multiple $\mathrm{H}_{2}$ molecules to a single metal atom. More fundamental experimental work is needed to fully prove these concepts where configurations can be made to adsorb multiple dihydrogen molecules while appropriately controlling dissociation and provide experimental validation for the model predictions. However, the potential is promising: the $\mathrm{HSCoE}$ identified materials with improved synthesis pathways with the potential to store $10 \mathrm{wt}$ pct and $100 \mathrm{~g} / \mathrm{L}$ at ambient temperature. ${ }^{[140]}$

\section{AMBIENT-TEMPERATURE STORAGE VIA WEAK CHEMISORPTION/SPILLOVER}

The HSCoE actively investigated methods to efficiently store dissociated hydrogen molecules (e.g., hydrogen atoms). Dissociated or atomic hydrogen forms strong bonds with other materials (e.g., metal or 
chemical hydrides) that require high temperatures (e.g., $\left.>500 \mathrm{~K}\left[226^{\circ} \mathrm{C}\right]\right)$ to break the bonds. However, it is possible for hydrogen atoms to adsorb on surfaces in such a way that the bonding is weaker (i.e., 10 to $25 \mathrm{~kJ} /$ mol) and conducive to reversible storage capacities at near-ambient temperature and moderate pressure. From a practical standpoint, a metal catalyst is typically needed to dissociate the $\mathrm{H}_{2}$ gas. The concept of hydrogen spillover (Figure 25) has its genesis in heterogeneous metal catalysis, particularly with the type of systems used for chemical hydrogenation reactions. ${ }^{[141]}$ Since most common industrial catalysts (e.g., platinum, palladium, and nickel) are relatively heavy and expensive (e.g., platinum-group metals), reaching the DOE targets will require catalysts that are appropriately integrated with a lightweight and compact material such as carbon or boron so that the dissociated hydrogen can "spillover" and be stably and reversibly stored, primarily on the lightweight inexpensive receptor material. The HSCoE group at Michigan of Wang and Yang ${ }^{[142]}$ provides a good review of more than a hundred different spillover publications, including several result summary tables. These tables show claims that spillover can increase hydrogen storage capacities by more than nine times compared to $\mathrm{H}_{2}$ adsorption on the same base materials. The HSCoE also identified several other potential spillover materials including endohedral fullerenes, boron-substituted materials, and Met-Cars.

Computations by Rice, APCI, and NREL identified that it is thermodynamically possible for hydrogen atoms to be stably stored in groups or clusters. The main step that is not well understood is that of hydrogen atom diffusion on the receptor. The team of Lee and colleagues was the first to identify that barriers to migration are lowered sufficiently via structural (e.g., hopping between closely spaced surfaces) and electronic features. ${ }^{[143]}$ Collaborative work from Mitchell et al. ${ }^{[144]}$ using inelastic neutron scattering spectroscopy observed spillover hydrogen on carbon supports. Deuterium tracer investigations demonstrated that, effectively, the spillover process is sequential with the first hydrogen adsorbed being the last desorbed. The results are direct evidence that (1) atomic species are formed during the spillover processes, as shown by hydrogen-deuterium formation, and (2) the desorption follows a reverse spillover process in which atoms migrate back onto the

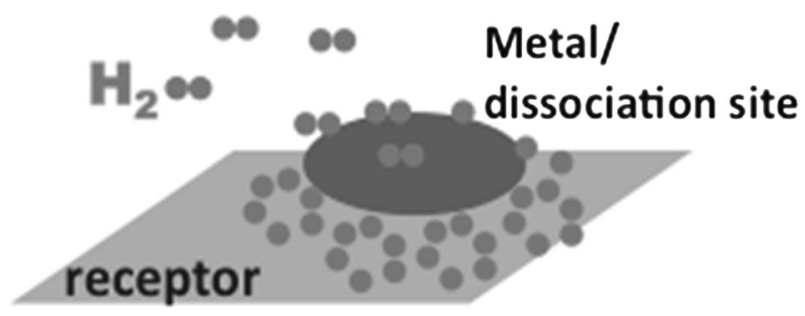

Fig. 25-Conceptual diagram of hydrogen spillover processes. Reversible room-temperature spillover hydrogen storage involves a series of steps: (a) molecular $\mathrm{H}_{2}$ dissociates on metal catalyst particles; $(b)$ atomic $\mathrm{H}$ migrates to the receptor; $(c)$ diffusion of atomic $\mathrm{H}$ across the receptor surfaces. metal particle to recombine and desorb as molecules. In general, the size, dispersion, and type of catalyst affect the efficiency and thus the capacity of spillover.

In general, the conclusion from the different computational and mechanistic work by Lin and co-workers $^{[145]}$ is that hydrogen atoms can interact with materials such as graphene in a way in which the graphene structures are not substantially (irreversibly) changed, and the hydrogen interaction is more like adsorption. The diffusion and storage of atomic hydrogen on the receptor surfaces must have substantially weaker bonding/barriers to migration than typically observed with chemical covalent bonding (i.e., weak chemisorption). Although the phenomenon of spillover has been known for decades for petrochemical and refining catalysis applications with $\sim 0.01 \mathrm{wt}$ pct hydrogen adsorption, ${ }^{[141}$ the HSCoE partners $\mathrm{Li}$ and Yang ${ }^{[146]}$ reported that this process could be used to reversibly store substantially more $(>30 \mathrm{~g} / \mathrm{L}$ and $>4$ wt pct) hydrogen at ambient temperatures and nominal pressures ( $<200$ bar). This is over 300 pct greater than $\mathrm{H}_{2}$ storage on a sorbent or as gas in a compressed tank at the same pressure and temperature. The HSCoE demonstrated spillover both experimentally and by confirming agreement with thermodynamic principles as a process that may be appropriate for ambient temperature, reversible hydrogen storage.

However, the materials tend to be very sensitive to processing conditions, the material synthesis procedures lack reproducibility, and the accuracy of the measurement techniques varied, all of which can lead to substantial variations in sorption capacities. ${ }^{[147]}$ Although theoretical predictions and non-reversible hydrogenation experiments demonstrate that capacities of close to one hydrogen atom per receptor atom (e.g., carbon) should be achievable via spillover. This translates to a potential for excess capacities $>7 \mathrm{wt}$ pet and $50 \mathrm{~g} / \mathrm{L}$ at ambient temperatures and $<200$ bar. At the end of the HSCoE, DOE formed an international team led by NREL to validate the measurement and synthesis methods of spillover materials to improve reproducibility. In addition, the team is determining the specific hydrogen-receptor interactions using spectroscopic techniques to fully understand the mechanisms involved. This is important to understanding the significant difference between fill and discharge rates, as well as issues that limit capacities. Ultimately, the issues with slow fill rates and lower than expected capacities may be related, and once the mechanisms are fully understood, these issues should be addressable.

Overall, the HSCoE demonstrated that substantial increases in hydrogen storage capacity are achieved at ambient temperatures with weak chemisorption processes such as spillover. Future work must improve adsorption rates (e.g., refill kinetics) via improved catalyst dispersion and integration, and improved receptor properties. Care must be taken to ensure that irreversible chemical reactions with the receptor materials do not occur and that the measured uptake is truly representative of the amount of hydrogen that can be delivered to the fuel cell. Although a significant amount of work is still required (including fundamental surface science studies) to develop highly reproducible and 
robust materials that have high adsorption rates, kinetics, and capacities, the clear indication is that weak chemisorption is a potential path for on-vehicle hydrogen storage.

\section{CONCLUSIONS}

The major conclusions of the HSCoE include results for materials, measurements, and theory.

For cryogenic storage, new materials were developed that increased gravimetric $(>60 \mathrm{pct}$, i.e., from $\sim 5$ to $>8.5 \mathrm{wt}$ pct at $\left.\sim 80 \mathrm{~K}\left[-193{ }^{\circ} \mathrm{C}\right]\right)$ and volumetric $(\sim 150$ pct, i.e., from $\sim 15$ to $>35 \mathrm{~g} / \mathrm{L}$ at $\sim 80 \mathrm{~K}$ $\left.\left[-193{ }^{\circ} \mathrm{C}\right]\right)$ hydrogen storage on high-SSA sorbents by optimizing pore size distributions $(0.7$ to $1.5 \mathrm{~nm})$ to increase SSA and packing density - standard physisorption-based $\mathrm{H}_{2}$ gravimetric capacity scales with SSA. Thus, no substantial increase in capacity can be achieved with geometric structures alone. Although binding energies can be effectively doubled with very small pores that enable multiple wall interactions with the $\mathrm{H}_{2}$ molecules, effectively, the space for adsorption is decreased, thus decreasing the overall capacity.

To move toward more ambient-temperature storage, the isosteric heat of adsorption must be increased. Substitutional materials such as boron in carbon or metal-organic frameworks (MOFs) were developed that exhibit enhanced dihydrogen binding energy (i.e., 8 to $12 \mathrm{~kJ} / \mathrm{mol}$ ) that may increase capacities in some materials (e.g., doubles or triples) on a per SSA basis at nearambient temperatures. Furthermore, reversible highcapacity sorbents that were designed and made via ambient-temperature hydrogenation techniques such as spillover store 1 to $4 \mathrm{wt}$ pct at ambient temperatures, with the potential of $7 \mathrm{wt}$ pct and $50 \mathrm{~g} / \mathrm{L}$ at ambient temperatures and less than 200 bar. In addition, coordinated unsaturated metal centers are a novel class of $\mathrm{H}_{2}$ storage materials with the potential to store at ambient temperature $>10 \mathrm{wt}$ pct and $>100 \mathrm{~g} / \mathrm{L}$. More fundamental experimental work is needed to fully prove these concepts and provide validation for the model predictions.

The HSCoE focused significant efforts on improving unique measurement capabilities to accurately and reproducibly characterize $\mathrm{H}_{2}$ storage properties of small laboratory-scale samples (1 to $200 \mathrm{mg}$ ). These measurement capabilities enhanced high-throughput, rapidscreening analyses. In addition to capacity measurements, a high-pressure nuclear magnetic resonance spectroscopy system was developed to help identify hydrogen interactions in micropores $v s$ those in macropores. The HSCoE also used several different techniques including neutron scattering, Raman and Fourier transform infrared spectroscopies, as well as differential volumetric measurements to provide unique hydrogen storage materials' characterization. In addition, the HSCoE helped with the publication of DOE's "Best Practices" guide for hydrogen storage measurements - a reference guide for kinetics, capacity, thermodynamics, and cycling measurements. ${ }^{[148]}$
Finally, research approaches used by the HSCoE, which combined iterative and coupled theory and experimental efforts, accelerated materials' design and development. First-principles theorists designed synthesis pathways and accompanying materials with optimal hydrogen storage properties. These predictive approaches sped identification of materials with the potential to meet DOE hydrogen storage targets, including novel heterogeneous materials, paths to creating high-capacity, fast-filling spillover materials, and novel classes of sorbents with the potential of $>100 \mathrm{~g} / \mathrm{L}$ and $10 \mathrm{wt}$ pet at ambient temperature. If these materials are reproducibly synthesized, they would have the potential of enabling systems that meet DOE's 2017 system targets.

\section{RECOMMENDATIONS}

The HSCoE demonstrated that the onboard fueling capability of sorbent materials offers advantages that should be exploited for light-duty vehicle applications. Thus, the HSCoE recommends that future development efforts be performed that focus on reducing material and associated balance-of-plant system costs by improving material storage capacities and transient performance at near-ambient temperatures (i.e., between $193 \mathrm{~K}$ and $353 \mathrm{~K}\left[-80{ }^{\circ} \mathrm{C}\right.$ and $\left.\left.80{ }^{\circ} \mathrm{C}\right]\right)$. Overall, the $\mathrm{HSCoE}$ recommends that development efforts for specific material classes be continued where viable reproducible routes exist for synthesizing sorbents that can be used to meet the appropriate set of application targets. In general, the closer to ambient conditions the system operates, the less expensive the system. This must be traded against overall system performance, which includes the potential need for added heat removal during fueling at the station. This need for balance led to four specific recommendations related to materials for associated hydrogen storage systems and classes. Ultimately, cryogenic storage of hydrogen gas may be able to meet DOE near term targets but will require materials with substantial specific surface areas. Thus, efforts should be limited to development of materials in which the storage mechanism is purely physisorption to only those with optimized pore structures and micropore volumes. However, the use of these materials for light-duty vehicles will have the highest hydrogen infrastructure costs and environmental impact, and these costs probably will not be reduced significantly even with anticipated material performance improvements. Thus, the HSCoE recommends that longer-term efforts need to be made to develop materials that store substantial amounts of hydrogen at or near ambient temperatures and relatively low pressures. This includes developing substituted/heterogeneous materials with demonstrated hydrogen binding energies of 10 to $25 \mathrm{~kJ} / \mathrm{mol}$ over most of the capacity range, multiple dihydrogen sorbents, and possibly weak chemisorption materials. While a substantial amount of fundamental development will be needed, the latter two classes of materials provide the potential to meet DOE hydrogen storage system targets at ambient temperatures. Specifically, the development 
of materials for hydrogen storage by weak chemisorption needs to emphasize reproducible syntheses and performance, with improved hydrogen fill kinetics and overall net available capacity. Similarly, substantial fundamental experimental work needs to be performed to fully prove concepts of multiple dihydrogen adsorption on designed metal complexes and to provide experimental validation for the model predictions.

The recommended sorbent classes as a whole have common issues remaining that must be adequately addressed. These include the need to use fundamental and applied research to develop robust, reproducible, scalable, and cost-effective syntheses that manufacture materials in which all adsorption sites are accessible to the hydrogen. Efforts should be made to improve fundamental computational methods to more accurately predict the ability to synthesize designed materials and hydrogen storage capacity as a function of temperature and pressure. This could help develop a better fundamental and applied understanding of atomic hydrogen transport energetics and kinetics on receptor materials, as well as a better fundamental understanding of metal center coordination and how the processes can be directly applied to create high-capacity, low-cost hydrogen sorbents.

Based on systematic development efforts, the $\mathrm{HSCoE}$ also recommended that no additional research and development be performed on numerous materials and processes. Only a select few elements and materials used in sorbents will be able to meet DOE light-duty vehicle system targets. The key is arranging those elements and materials optimally for hydrogen storage. For more details, please see the full Final Report for the HSCoE. ${ }^{[149]}$ The Final Report also provides a bibliography of the publications and patents from $\mathrm{HSCoE}$ partners.

Furthermore, highly accurate hydrogen storage materials' characterization capabilities, including sorbent material measurements' standards and certifications, must be emphasized to quickly identify material properties and validate results so that minimal efforts are wasted on poor materials or erroneous results. This is critical to eliminating the large expense and years of effort often associated with rooting out what ultimately turns out to be erroneous results. Finally, future efforts need to also adequately address additional material properties related to hydrogen storage systems including thermal conductivity, heat dissipation, refill and discharge rates, durability, and other engineering issues.

\section{SUMMARY COMMENTS}

Through the 5-year efforts of the three multi-partner collaborative Hydrogen Storage Materials Centers of Excellence, substantial progress was achieved in expanding the knowledge and understanding of the potential of materials for hydrogen storage applications. The progress was accelerated through inclusion of multiple institutional partners that brought theory and compu- tational capabilities, various materials synthesis and preparation methods, and a wide range of materials characterization techniques for use in the efforts. While a comprehensive review of all of the hundreds of materials investigated, the conclusions made and the recommendations developed through these efforts are beyond the scope of this paper, interested readers are directed to the complete final reports from each of the Centers of Excellence, available through the DOE's Fuel Cell Technologies Office's website. ${ }^{[150]}$ To further aid in advancing development of hydrogen storage materials, the DOE has launched a searchable hydrogen storage materials' properties database that includes data from the Centers of Excellence efforts, the DOE/IEA-HIA metal hydrides database, and individual research efforts. ${ }^{[151]}$

\section{ACKNOWLEDGMENTS}

This work was performed through the collaborations of the Metal Hydride, Chemical Hydrogen Storage and Hydrogen Sorption Centers of Excellence, funded through the Fuel Cell Technologies Office of the DOE's Office of Energy Efficiency and Renewable Energy. The authors acknowledge and thank all of the Centers of Excellence partners who contributed to the work described in this review. L. E. Klebanoff wishes to acknowledge the contributions of all Principal Investigators within the $\mathrm{MHCoE}$ to the work summarized herein. L. E. Klebanoff also acknowledges the many DOE and U.S. DRIVE Hydrogen Storage Tech Team members who have assisted the MHCoE in its work. Special thanks to Dr. Jay Keller who served as the Deputy Director of the MHCoE and to Marcina Moreno who was the MHCoE business manager. L. J. Simpson would like to specifically acknowledge all the people both within the $\mathrm{HSCoE}$ and especially those throughout the world who contributed and provided wonderful collaborations to help advance our efforts. Special thanks should also be given to Michael Heben for starting these efforts and for the support of the U.S. Department of Energy, Office of Energy Efficiency and Renewable Energy, under Contract No. DE-AC36-08-GO28308 with the National Renewable Energy Laboratory. L. J. Simpson would also like to pay a special tribute to Anne Dillon, Peter Eklund, Alan MacDiarmid, and Richard Smalley. Kevin Ott would like to thank all of the excellent and hardworking partners who were involved in the Chemical Hydrogen Storage Center of Excellence.

\section{REFERENCES}

1. T. Nguyen and J. Ward: Program Record 10001: Number of Cars Equivalent to 100 Metric Tons of Avoided Greenhouse Gases per Year, 510 2010. [Online]. Available http://hydrogen.energy.gov/ pdfs/10001_well_to_wheels_gge_petroleum_use.pdf. Accessed 26 February $\overline{2012}$. 
2. S. Satyapal, J. Petrovic, and G. Thomas: Sci. Am., 2007, vol. 296, pp. $80-87$.

3. Department of Energy: DOE Targets for Onboard Hydrogen Storage Systems for Light-Duty Vehicles, 2009. [Online]. Available: http://www1.eere.energy.gov/hydrogenandfuelcells/storage/ pdfs/targets_onboard_hydro_storage.pdf. Accessed 22 March 2012.

4. N.T. Stetson and L.S. Blair: Ceram. Trans., 2011, vol. 224, pp. 3-16.

5. M. Dresselhaus, G. Crabtree, and M. Buchanan: Basic Research Needs for the Hydrogen Economy, A Report of the Basic Energy Science Workshop on Hydrogen Production, Storage, and Use, 2003, pp. 31-51; [Online]. Available: http://science.energy.gov/ / media/bes/pdf/reports/files/nhe_rpt.pdf.

6. J. Milliken: Hydrogen Storage Subprogram Review, in Proceedings of the 2004 DOE Hydrogen Program Annual Merit Review and Peer Evaluation Meeting, Washington, 2004.

7. E. Huston and G. Sandrock: J. Less-Common Met., 1980, vol. 74 (2), pp. 435-43.

8. G. Sandrock: in Handbook of Fuel Cells-Fundamentals, Technology and Applications, Wiley, Chichester, 2010, pp. 101-12.

9. B. Chao and L. Klebanoff: in Hydrogen Storage Technology, Materials and Applications, Taylor and Francis, Boca Raton, 2012, p. 109.

10. B.B. Bogdanovic and M. Schwickardi: J. Alloy Compd., 1997, vols. 253-254, pp. 1-9.

11. Z. Xiong, J. Wu, and P. Chen: Adv. Mater., 2004, vol. 16 (17), pp. $1522-25$.

12. J. Vajo, S. Skeith, and P. Chen: J. Phys. Chem. B, 2005, vol. 109 (9), pp. 3719-22.

13. U. Bosenberg, S. Doppiu, L. Mosegaard, G. Barkhordarian, N. Eigen, A. Borgschulte, T. Jensen, Y. Cerenius, O. Gutfleisch, T. Klassen, M. Dornheim, and R. Bormann: Acta Mater., 2007, vol. 55 (11), pp. 3951-58.

14. G. Sandrock, J. Reilly, J. Graetz, W.-M. Zhou, J. Johnson, and J. Wegrzyn: Appl. Phys. A Mater. Sci. Process., 2005, vol. 80 (4), pp. $687-90$.

15. L. Schlapbach: MRS Bull., 2002, vol. 27, pp. 675-79.

16. L. Klebanoff and J. Keller: Final Report for the DOE Metal Hydride Center of Excellence, Sandia National Laboratories, Livermore, 2012. Available: https://wwwl.eere.energy.gov/ hydrogenadnfuelcells/pdfs/metal_hydride_coe_final_report.pdf.

17. L.E. Klebanoff and J.O. Keller: Int. J. Hydrogen Energy, 2013, vol. 38 , pp. $4533-76$.

18. S. Orimo, Y. Nakamori, J. Eliseio, A. Zuttel, and C. Jensen: Chem. Rev., 2007, vol. 107, pp. 4111-32.

19. J. Vajo, F. Mertens, C. Ahn, R. Bowman, and B. Fultz: J. Phys. Chem. B, 2004, vol. 108, pp. 13977-83.

20. V. Stavila, L. Klebanoff, J. Vajo and P. Chen: in Hydrogen Storage Technology, Materials and Applications, Taylor and Francis, Boca Raton, 2012, pp. 133-211.

21. J.J. Vajo and G. Olson: Scripta Mater., 2007, vol. 56 (10), pp. 829-34.

22. J. Vajo, W. Li, and P. Liu: Chem. Commun., 2010, vol. 46, pp. 6687-89.

23. P.E. de Jongh and P. Adelhelm: ChemSusChem, 2010, vol. 3 (12), pp. 1332-48.

24. J. Vajo: Curr. Opin. Solid State Mater. Sci., 2011, vol. 15 (2), pp. 52-61.

25. S. Zhang, A. Gross, S. Van Atta, M. Lopez, P. Liu, C. Ahn, J. Vajo, and C. Jensen: Nanotechnology, 2009, vol. 20 (20), art. id 204027 (6 pp)

26. E. Majzoub and E. Ronnebro: Mat. Sci. Eng. R, 2012, vol. 73, pp. $15-26$.

27. E. Ronnebro: Curr. Opin. Solid State Mater. Sci., 2011, vol. 15 (2), pp. 44-51.

28. E. Ronnebro and E. Majzoub: J. Phys. Chem. B, 2007, vol. 111 (42), pp. 12045-47.

29. E. Majzoub and E. Ronnebro: J. Phys. Chem. C, 2009, vol. 113 (8), pp. 3352-58.

30. E. Majzoub and V. Ozolins: Phys. Rev. B, 2008, vol. 77 (10), art. id 104115 (13 pp).

31. Y. Filinchuk, E. Ronnebro, and D. Chandra: Acta Mater., 2009, vol. 57 , pp. 732-38.
32. V. Konopolev: Russ. J. Inorg. Chem., 1980, vol. 25 (7), pp. 964 66.

33. G. Soloveichik, Y. Gao, J. Rijssenbeek, M. Andrus, R. Bowman, Jr, S.-J. Hwang, and J.-C. Zhao: Int. J. Hydrogen Energy, 2009, vol. 34 (5), pp. 2144-52.

34. G. Severa, E. Ronnebro, and C. Jensen: Chem. Commun., 2010, vol. 46 (3), pp. 421-23.

35. V. Stavila, J.-H. Her, W. Zhou, S.-J. Hwang, C. Kim, L.-A.M. Ottley, and T. Udovic: J. Solid State Chem., 2010, vol. 183 (5), pp. 1133-40.

36. V. Ozolins, E. Majzoub, and C. Wolverton: J. Am. Chem. Soc., 2009, vol. 131 (1), pp. 230-37.

37. P. Chen, Z. Xiong, J. Luo, J. Lin, and K. Tan: Nature, 2002, vol. 420 (6913), pp. 302-04.

38. W. Luo and S. Sickafoose: J. Alloys Compd., 2006, vol. 407 (1-2), pp. $274-81$.

39. S.V. Alapati, K. Johnson, and D.S. Sholl: Phys. Chem. Chem. Phys., 2007, vol. 9 (12), pp. 1438-52.

40. J. Lu, Z. Fang, Y. Choi, and H. Sohn: J. Phys. Chem., 2007, vol. 111, pp. 12129-34.

41. A. Akbarzadeh, V. Ozolins, and C. Wolverton: Adv. Mater., 2007, vol. 19 (20), pp. 3233-39.

42. J.J. Lamb, D. Chandra, W.-M. Chien, D. Phanon, N. Penin, R. Cerny, and K. Yvon: J. Phys. Chem. C, 2011, vol. 115 (29), pp. $14386-91$.

43. J. Graetz, D. Wolstenholme, G. Pez, L. Klebanoff, G. McGrady, and A. Cooper: in Hydrogen Storage Technology, Materials and Applications, Taylor and Francis, Boca Raton, 2012, p. 239.

44. G. Sandrock, J. Reilly, J. Graetz, W.-M. Zhou, J. Johnson, and J. Wegrzyn: J. Alloys Compd., 2006, vol. 421 (1-2), pp. 185-89.

45. J. Graetz, J. Reilly, V. Yartys, J. Machlen, B. Bulychev, V. Antonov, B. Tarasov, and I. Gabis: J. Alloys Compd., 2011, vol. 509 (2), pp. S517-28.

46. T. Hua and R. Ahluwalia: Int. J. Hydrogen Energy, 2011, vol. 36 (23), pp. 15259-65.

47. R. Zidan, B. Garcia-Diaz, C. Fewox, A. Stowe, J. Grey, and A. Harte: Chem. Commun., 2009, vol. 36 (25), pp. 3717-19.

48. X. Liu, G. McGrady, H. Langmi, and C. Jensen: J. Am. Chem. Soc., 2009, vol. 131 (14), pp. 5032-33.

49. S. McGrady: Personal Communication to L.E.K., University of New Brunswick, Fredericton, NB, February 2012.

50. C. Wolverton, V. Ozolins, and M. Asta: Phys. Rev. B, 2004, vol. 69 (14), pp. 1-16.

51. A.D. Kulkarni, L.-L. Wang, D.D. Johnson, D.S. Sholl, and K.J. Johnson: J. Phys. Chem. C, 2010, vol. 114 (34), pp. 14601-05.

52. S. Opalka, X. Tang, B. Laube, and T. Vanderspurt: Nanotechnology, 2009, vol. 20 (20), art. id 204024 (9 pp).

53. B. Chao: Personal Communication to L.E.K., BASF Battery Materials-Ovonic, Rochester Hill, MI, May 2011.

54. A. Cooper: Reversible Liquid Carriers for an Integrated Production, Storage, and Delivery of Hydrogen, in DOE Annual Merit Review Meeting, Washington, DC, 2010. Available: http:// www.hydrogen.energy.gov/pdfs/review10/pd046_cooper_2010_p_ web.pdf.

55. A. T-Raissi: Hydrogen Program Annual Review Meeting, Berkeley, CA, 2003. Available: http://wwwl.eere.energy.gov/ hydrogenandfuelcells/pdfs/merit03/58 fsec ali raissi.pdf.

56. Y. Wu, M.T. Kelly and J.V. Ortega: Review of Chemical Processes for the Synthesis of Sodium Borohydride, DOE, 2004. Available: http://www1.eere.energy.gov/hydrogenandfuelcells/ pdfs/review_chemical_processes.pdf.

57. B. Liu and Z. Li: Power Sources, 2009, vol. 187 (2), pp. 527-34.

58. D. Neiner, H.W. Chiu, and S.M. Kauzlarich: J. Am. Chem. Soc., 2006, vol. 128 (34), pp. 11016-17.

59. D. Neiner, N.L. Okamoto, P. Yu, S. Leonard, C.L. Condron, M.F. Toney, Q.M. Ramasse, N.D. Browning, and S.M. Kauzlarich: Inorg. Chem., 2010, vol. 49 (3), pp. 815-22.

60. D. Neiner and S.M. Kauzlarich: Chem. Mater., 2010, vol. 22 (2), pp. 487-93.

61. D. Neiner, N. Okamoto, C. Condron, Q. Ramasse, P. Yu, N. Browning, and S. Kauzlarich: J. Am. Chem. Soc., 2007, vol. 129 (45), pp. 13857-62.

62. D.E. Schwarz, T.M. Cameron, P.J. Hay, B.L. Scott, W. Tumas, and D.L. Thorn: Chem. Commun., 2005 (47), pp. 5919-21. 
63. S. Linehan, A. Chin, N. Allen, R. Butterick, N. Kendall, and I. Klawiter: Low-Cost Precursors to Novel Hydrogen Storage Materials, U.S. Department of Energy, 2010.

64. U.S. Department of Energy: Go/No-Go Recommendation for Sodium Borohydride for On-Board Vehicular Hydrogen Storage, National Renewable Energy Laboratory, Golden, 2007. Available: http://www.hydrogen.energy.gov/pdfs/42220.pdf.

65. A.V. Safronov, S.S. Jalisatgi, H.B. Lee, and M.F. Hawthorne: Int. J. Hydrogen Energy, 2011, vol. 36 (1), pp. 234-39.

66. C.W. Yoon and L.G. Sneddon: J. Am. Chem. Soc., 2006, vol. 128 (43), pp. 13992-93.

67. C. Yoon, P. Carroll, and L. Sneddon: J. Am. Chem. Soc., 2009, vol. 131 (2), pp. 855-64.

68. M. Bowden and T. Autrey: Curr. Opin. Solid State Mater. Sci., 2011, vol. 15 (2), pp. 73-79.

69. F.H. Stephens, V. Pons, and R.T. Baker: Dalton Trans., 2007 (25), pp. 2613-26.

70. A. Gutowska, L. Li, Y. Shin, C.M. Wang, X.S. Li, J.C. Linehan, R.S. Smith, B.D. Kay, B. Schmid, W. Shaw, M. Gutowski, and T. Autrey: Angew. Chem. Int. Ed., 2005, vol. 44 (23), pp. 3578-82.

71. A. Feaver, S. Sepehri, P. Shamberger, A. Stowe, T. Autrey, and G. Cao: J. Phys. Chem. B, 2007, vol. 111 (26), pp. 7469-72.

72. D. Neiner, A. Karkamkar, J.C. Linehan, B. Arey, T. Autrey, and S.M. Kauzlarich: J. Phys. Chem. C, 2009, vol. 113 (3), pp. 1098-1103.

73. D. Neiner, A. Luedtke, A. Karkamkar, W. Shaw, J. Wang, N.D. Browning, T. Autrey, and S.M. Kauzlarich: J. Phys. Chem. C, 2010, vol. 114 (32), pp. 13935-41.

74. F. Stephens, R. Baker, M. Matus, D. Grant, and D. Dixon: Angew. Chem. Int. Ed., 2007, vol. 46 (5), pp. 746-49.

75. J.L. Fulton, J.C. Linehan, T. Autrey, M. Balasubramanian, Y. Chen, and N.K. Szymczak: J. Am. Chem. Soc., 2007, vol. 129 (39), pp. 11936-49.

76. R.J. Keaton, J.M. Blacquiere, and R.T. Baker: J. Am. Chem. Soc., 2007, vol. 129 (7), pp. 1844-45.

77. N. Blaquiere, S. Diallo-Garcia, S.I. Gorelsky, D.A. Black, and K. Fagnou: J. Am. Chem. Soc., 2008, vol. 130 (43), pp. 14034-35.

78. T.J. Clark, K. Lee, and I. Manners: Chemistry, 2006, vol. 12 (34), pp. $8634-48$.

79. T.J. Clark, C.A. Russell, and I. Manners: J. Am. Chem. Soc., 2006, vol. 128 (30), pp. 9582-83.

80. M.C. Denney, V. Pons, T.J. Hebden, D.M. Heinekey, and K.I. Goldberg: J. Am. Chem. Soc., 2006, vol. 128 (37), pp. 12048-49.

81. T.M. Douglas, A.B. Chaplin, and A.S. Weller: J. Am. Chem. Soc., 2008, vol. 130 (44), pp. 14432-33.

82. T.D. Forster, H.M. Tuononen, M. Parvez, and R. Roesler: $J$. Am. Chem. Soc., 2009, vol. 131 (19), pp. 6689-91.

83. C.A. Jaska and I. Manners: J. Am. Chem. Soc., 2004, vol. 126 (9), pp. 2698-99.

84. C.A. Jaska, K. Temple, A.J. Lough and I. Manners: Chem. Commun., 2001 (11), pp. 962-63.

85. C.A. Jaska, K. Temple, A.J. Lough, and I. Manners: J. Am. Chem. Soc., 2003, vol. 125 (31), pp. 9424-34.

86. Y. Jiang and H. Berke: Chem. Commun., 2007 (34), pp. 3571-73.

87. A. Paul and C. Musgrave: Angew. Chem. Int. Ed., 2007, vol. 46 (43), pp. 8153-56.

88. M.E. Bluhm, M.G. Bradley, R. Butterick, III, U. Kusari, and L.G. Sneddon: J. Am. Chem. Soc., 2006, vol. 128 (24), pp. 7748-49.

89. M.E. Bluhm, M.G. Bradley, and L.G. Sneddon: Prepr. Symp. Am. Chem. Soc. Div. Fuel Chem., 2006, vol. 51, pp. 571-72.

90. D.W. Himmelberger, L.R. Alden, M.E. Bluhm, and L.G. Sneddon: Inorg. Chem., 2009, vol. 48 (20), pp. 9883-89.

91. D.W. Himmelberger, C.W. Yoon, M.E. Bluhm, P.J. Carroll, and L.G. Sneddon: J. Am. Chem. Soc., 2009, vol. 131 (39), pp. 14101-10.

92. D.W. Himmelberger, M.E. Bluhm, and L.G. Sneddon: Prepr. Symp. Am. Chem. Soc. Div. Fuel Chem., 2008, vol. 53, pp. 666-67.

93. V. Pons, R.T. Baker, N. Szymczak, D. Heldebrant, and J. Linehan: Chem. Commun., 2008 (48), pp. 6597-99.

94. P.G. Campbell, A.J.V. Marwitz, and S.-Y. Liu: Angew. Chem. Int. Ed., 2012, (51), pp.6074-92.

95. S. Xu, L.N. Zakharov, and S.-Y. Liu: J. Am. Chem. Soc., 2011, vol. $133(50)$, pp. 20152-55.

96. Z. Xiong, C.K. Yong, G. Wu, P. Chen, W. Shaw, A. Karkamkar, T. Autrey, M.O. Jones, S.R. Johnson, P.P. Edwards, and W.I.F. David: Nat. Mater., 2007, vol. 7, pp. 138-41.
97. K. Shimoda, K. Doi, T. Nakagawa, and Y. Zhang: J. Phys. Chem. C, 2012, vol. 116 (9), pp. 5957-64.

98. H. Diyabalanage, R. Shrestha, T. Semelsberger, and B. Scott: Angew. Chem. Int. Ed., 2007, vol. 46 (47), pp. 8995-97.

99. H. Diyabalanage, T. Nakagawa, R. Shrestha, and T.A. Semelsberger: J. Am. Chem. Soc., 2010, vol. 132 (34), pp. 11836-37.

100. Y.J. Choi, Y. Xu, W.J. Shaw, and E.C.E. Rönnebro: J. Phys. Chem. C, 2012, vol. 116 (15), pp. 8349-58.

101. M.T. Mock, R.G. Potter, D.M. Camaioni, and J. Li: J. Am. Chem. Soc., 2009, vol. 131 (40), pp. 14454-65.

102. B.L. Davis, A.D. Sutton, J.C. Gordon, D.E. Schwarz, B.L. Scott, and D.L. Thorn: Main Group Chem., 2010, vol. 9 (1-2), pp. 13539.

103. B. Davis, D. Dixon, E. Garner, J. Gordon, M. Matus, B. Scott, and F. Stephens: Angew. Chem. Int. Ed., 2009, vol. 48 (37), pp. $6812-16$.

104. A.D. Sutton, B.L. Davis, K.X. Bhattacharyya, B.D. Ellis, J.C. Gordon, and P.P. Power: Chem. Commun., 2010, vol. 46 (1), pp. $148-49$.

105. A.D. Sutton, A.K. Burrell, D.A. Dixon, E.B. Garner, III, J.C. Gordon, T. Nakagawa, K.C. Ott, J.P. Robinson, and M. Vasiliu: Science, 2011, vol. 331 (6023), pp. 1426-29.

106. R.K. Ahluwalia, T. Hua, J.-K. Peng and R. Kumar: On-Board and Off-Board Analyses of Hydrogen Storage Options, U.S. Department of Energy, Washington, 2010. Available: https:// www.hydrogen.energy.gov/pdfs/progress10/iv_e_1_ahluwalia. pdf.

107. More details on excess versus total capacities are available in a white paper by request (lin.simpson@nrel.gov).

108. A. Kidnay and M. Hiza: Adv. Cryog. Eng., 1967, vol. 12, pp. $730-$ 40 .

109. A. Dillon and M. Heben: Appl. Phys. A Mater. Sci. Process., 2001, vol. 72 (2), pp. 133-42.

110. P. Bénard and R. Chahine: Langmuir, 2001, vol. 17 (6), pp. 195055.

111. E. Poirier, R. Chahine, P. Benard, D. Cossement, L. Lafi, E. Melancon, T. Bose, and S. Desilets: Appl. Phys. A Mater. Sci. Process., 2004, vol. 78 (7), pp. 961-67.

112. C. Carpetis and W. Peschka: Intl. J. Hydrogen Energy, 1980, vol. 5 (5), pp. 539-54.

113. S. Hynek, W. Fuller, and J. Bentley: Intl. J. Hydrogen Energy, 1997, vol. 22 (6), pp. 601-10.

114. R. Agarwal, J. Noh, J. Schwarz, and P. Davini: Carbon, 1987, vol. 25 (2), pp. 219-26.

115. J. Schwarz: Final Report for the Tasks XC-1-1108-1 and XAE-313346-01, National Renewable Energy Laboratory, Golden, 1994.

116. R. Ströbel, L. Jörissen, T. Schliermann, and V. Trapp: Power Sources, 1999, vol. 84 (2), pp. 221-24.

117. R. Chahine and P. Benard:, in Advances in Cryogenic Engineering, P. Kittel, ed., Plenum Press, New York, 1998, vol. 43, p. 1257.

118. R. Chahine and P. Benard: in Hydrogen Energy Progress XII, J. Bolcich and T. Verziroglu, eds., International Association of Hydrogen Energy, Coral Gables, 1998.

119. U U.S. Department of Energy: Hydrogen, Fuel Cells \& Infrastructure Technology Program Multi-Year Research, Development and Demonstration Plan, U.S. Department of Energy, Washington, 2009. Available: http://wwww1.eere.energy.gov/ hydrogenandfuelcells/mypp/index.html.

120. The bulk density is calculated based on the actual volume of the lightweight highly porous sorbent powder or pellets.

121. S. Brunauer, P.H. Emmett, and E. Teller: J. Am. Chem. Soc., 1938, vol. 60 (2), pp. 309-19.

122. D. Zhao, D. Timmons, D. Yuan, and H. Zhou: Acc. Chem. Res., 2011, vol. 44 (2), pp. 123-33.

123. F. Ding, Y. Lin, P.O. Krasnov, and B.I. Yakobson: J. Chem. Phy., 2007, vol. 127 (16), pp. 164703-06.

124. T.P. McNicholas, A. Wang, K. O'Neill, R.J. Anderson, N.P. Stadie, A. Kleinhammes, P. Parilla, L. Simpson, C.C. Ahn, Y. Wang, Y. Wu, and J. Liu: J. Phys. Chem. C, 2010, vol. 113 (32), pp. 13902-08.

125. S. Yuan, S. Kirklin, B. Dorney, D.-J. Liu, and L. Yu: Macromolecules, 2009, vol. 42 (5), pp. 1554-59. 
126. A.G. Wong-Foy, A.J. Matzger, and O.M. Yaghi: J. Am. Chem. Soc., 2006, vol. 128 (11), pp. 3494-95.

127. O.K. Farha, A.Ö. Yazaydın, I. Eryazici, C.D. Malliakas, B.G. Hauser, M.G. Kanatzidis, S.T. Nguyen, R.Q. Snurr, and J.T. Hupp: Nat. Chem., 2010, vol. 2, pp. 944-48.

128. D. Yuan, D. Zhao, D. Sun, and H.-C. Zhou: Angew. Chem. Int. Ed., 2010, vol. 49 (31), pp. 5357-61.

129. M. Dincă, A. Dailly, Y. Liu, C.M. Brown, D.A. Neumann, and J.R. Long: J. Am. Chem. Soc., 2006, vol. 128 (51), pp. 16876-83.

130. Y.Y. Sun, Y.-H. Kim, and S.B. Zhang: J. Am. Chem. Soc., 2007, vol. 129 (42), pp. 12606-07.

131. W. Zhou, H. Wu, and T. Yildirim: J. Am. Chem. Soc., 2008, vol. 130 (46), pp. 15268-69.

132. C. Zlotea, P. Moretto, and T. Steriotis: Intl. J. Hydrogen Energy, 2009, vol. 34 (7), pp. 3044-57

133. J.J. Purewal, J.B. Keith, C.C. Ahn, B. Fultz, C.M. Brown, and M. Tyagi: Phys. Rev. B, 2009, vol. 79 (5), art. id 054305 (7 pp).

134. Y.-H. Kim, Y. Zhao, A. Williamson, M.J. Heben, and S.B. Zhang: Phys. Rev. Lett., 2006, vol. 96 (1), art. id 016102 (4 pp).

135. T.C.M. Chung, Y. Jeong, Q. Chen, A. Kleinhammes, and Y. Wu: J. Am. Chem. Soc., 2008, vol. 130 (21), pp. 6668-69.

136. J. Bult: Unpublished research.

137. J.M. Tour and C. Kittrell: Nanoengineered Graphene Scaffolds with Atom Substitution for $\mathrm{H}_{2}$ Adsorption, in Fuel Cell Technologies Annual Merit Review Meeting, Washington, 2010. Available: http://www.hydrogen.energy.gov/pdfs/review10/st076_ tour_2010_o_web.pdf.

138. D. Neumann, C.M. Brown, Y. Liu, and J.-H. Her: NIST Center for Neutron Research in Support of the Hydrogen Sorption Center of Excellence, U.S. Department of Energy, Washington, 2008. Available: http://www.hydrogen.energy.gov/pdfs/progress08/iv_c_ 1c_neumann.pdf.

139. Y. Zhao, Y.-H. Kim, A.C. Dillon, M.J. Heben, and S.B. Zhang: Phys. Rev. Lett., 2005, vol. 94 (15), art id. 155504 (4 pp).
140. Y.-H. Kim, Y.Y. Sun, and S.B. Zhang: Phys. Rev. B, 2009, vol. 79 (11), art. id 115424 (5 pp).

141. W.C. Conner and J.L. Falconer: Chem. Rev., 1995, vol. 95 (3), pp. $759-88$.

142. L. Wang and R.T. Yang: Catal. Rev. Sci. Eng., 2010, vol. 52 (4), pp. 411-61.

143. K. Lee, Y.-H. Kim, Y.Y. Sun, D. West, Y. Zhao, Z. Chen, and S.B. Zhang: Phys. Rev. Lett., 2010, vol. 104 (23), p. 236101.

144. P.C.H. Mitchell, A.J. Ramirez-Cuesta, S.F. Parker, J. Tomkinson, and D. Thompsett: J. Phys. Chem. B, 2003, vol. 107 (28), pp. 6838-45.

145. Y. Lin, F. Ding, and B.I. Yakobson: Phys. Rev. B, 2008, vol. 78 (4), art. id 041402 (5 pp).

146. Y. Li and R.T. Yang: J. Am. Chem. Soc., 2006, vol. 128 (25), pp. 8136-37.

147. R. Campesi, F. Cuevas, M. Latroche, and M. Hirscher: Phys. Chem. Chem. Phys., 2010, vol. 12, pp. 10457-59.

148. K.J. Gross, K.R. Carrington, S. Barcelo, A. Karkamkar, and J. Purewal: Recommended Best Practices for the Characterization of Storage Properties of Hydrogen Storage Materials, H2 Technology Consulting, Newark, 2010. Available: http://www1.eere. energy.gov/hydrogenandfuelcells/pdfs/best_practices_hydrogen_ storage.pdf.

149. L. Simpson: Hydrogen Sorption Center of Excellence Final Report, National Renewable Energy Laboratory, 2010. Available at:http://wwwl.eere.energy.gov/hydrogenandfuelcells/pdfs/hydrogen sorption_coe_final_report.pdf.

150. U.S. Department of Energy, Hydrogen Technical Publications-Storage, April 2012. [Online]. Available: http://www1. eere.energy.gov/hydrogenandfuelcells/hydrogen_publications.html\# h2 storage.

151. U.S. Department of Energy: Hydrogen Storage Materials Database, December 2011. [Online]. Available: http:// hydrogenmaterialssearch.govtools.us/. 